\title{
Surface Modification of Stainless Steel by Electro-Spark Deposition
}

\author{
by \\ Zhen Jiao
A thesis
presented to the University of Waterloo
in fulfilment of the
thesis requirement for the degree of
Master of Applied Science
in \\ Mechanical and Mechatronics Engineering
}

Waterloo, Ontario, Canada, 2016

(C) Zhen Jiao 2016 


\section{Author's Declaration}

I hereby declare that I am the sole author of this thesis. This is a true copy of the thesis, including any required final revisions, as accepted by my examiners.

I understand that my thesis may be made electronically available to the public. 


\begin{abstract}
Electrospark Deposition (ESD) is a pulsed micro-welding process that is used to apply surface coatings for repair of damaged high value precision products or modify their surfaces for specific properties. The low heat input, small heat affected zone and the ability to form metallurgical bonding of coating to substrate are some of the major advantages of ESD process. Many applications require the components to have excellent surface performance, such as wear resistance and corrosion resistance. To meet these requirements, some components are built with specific materials, compromising other properties and cost. ESD technique provides an approach to modify the component surface without compromising the bulk properties. Stainless steel is an ideal material for many applications such as industrial equipment, surgical instruments, household hardware etc., due to its resistance to corrosion. Surface modification of stainless steel may improve its performance and may open new applications.
\end{abstract}

In this study, surface modification of 304 stainless steel by ESD was investigated. TiC, WC and Molybdenum (Mo) were employed as coating materials. The ESD processing windows for these coatings were investigated. Scanning electron microscope (SEM) and energy-dispersive X-ray spectroscopy (EDX) analysis was conducted to characterize the microstructure and composition of coated stainless steel. Micro-hardness and wear resistance tests were carried out to evaluate the mechanical properties of coated stainless steel. TiC and WC coatings dramatically increase the micro-hardness of 304 stainless steel. WC coating improves the abrasion wear resistance of stainless steel by more than 5 times, while TiC and Mo coatings also improve it by 2.5 times.

Electrochemical tests were conducted to investigate the corrosion resistance of coated stainless steel. Mo coating exhibits significant improvement on corrosion resistance in $5 \% \mathrm{NaCl}$ solutions, 
which corrodes 350 times slower than stainless steel. TiC coating also increases the corrosion resistance with 10 times slower corrosion rate. WC coating does not show improvement on the corrosion resistance. Electrochemical impedance spectroscopy (EIS) was employed to further investigate the electrochemical behavior of coated stainless steel. The results showed the polarization resistance of Mo coated sample is much larger than that of base metal stainless steel. XRD analysis indicate the phase transformation from austenite to ferrite after ESD of Mo.

Comprehensive metallurgical analysis of Mo coated 304 stainless steel is performed after heat treatment at $400^{\circ} \mathrm{C}, 650^{\circ} \mathrm{C}$ and $900^{\circ} \mathrm{C}$. The effects of heat treatment atmosphere are investigated by comparing the sample treated in air and Ar gas. SEM and EDX results show the coating thickness decreases with the increase of heat treatment temperature. Localized Mo rich area is found in heat-treated samples. More cracks, porosities and rougher surface conditions are observed in heat-treated samples. XRD analysis display phase transformation from austenite to ferrite at $400^{\circ} \mathrm{C}$. Mo rich intermetallic is detected at $650^{\circ} \mathrm{C}$ under $\mathrm{Ar}$ gas. Mo and $\mathrm{Cr}$ oxides are found in heat-treated samples above $650^{\circ} \mathrm{C}$ in air. XPS results show metallic state Mo disappears after heat treatment in air, while metallic state Mo only disappears at $650^{\circ} \mathrm{C}$ in $\mathrm{Ar}$ gas. It is suggested that Mo rich intermetallic is formed at specific temperature range around $650^{\circ} \mathrm{C}$.

Electrochemical test indicated heat-treated samples, either in Ar or in air atmosphere, have lower corrosion resistance than as-deposited sample. Metallic state Mo and a certain ratio of austenite and ferrite can contribute to better corrosion resistance. EIS analysis with modified equivalent circuit is conducted to further investigate the electrochemical behavior. The results indicate that heat-treated samples introduce more nonuniform coating layers because of oxidation and diffusion of alloy elements. Mo rich intermetallic phase decreases the corrosion potential of the heat-treated sample at $650^{\circ} \mathrm{C}$ in $\mathrm{Ar}$, and also decreases the corrosion rate of the sample. 


\section{Acknowledgements}

This research project would not exist without the dedicated support of my supervisors, Prof. Norman Zhou and Prof. Ehsan Toyserkani. I express my sincere thanks to my academic supervisors for their continued guidance and support.

I would like to thank Mr. Nigel Scotchmer, Kevin Chan and Dominic Leung at Huys Industries Ltd. for their assistance and technical support.

I would like to thank Huys industries Ltd, Ontario Centres of Excellence (OCE) and National Sciences and Engineering Research Council (NSERC) for providing financial support for this work. I also thank TechnoCoat Co.,Ltd, for materials support.

The advice, encouragement and counsel of Dr. Joyce Koo during times of need are the reasons I am capable of finishing this project. I'd like to express my gratitude for her help of getting materials, sharing references and invaluable discussions.

Mr. Stephen Peterkin is sincerely thanked for his assistance of this project. His readiness to share in mechanical design, software programing and genuine interest in the research has benefitted me a lot.

I would like to thank Dongwoon Huh, Mehrdad Iravani, Robert Liang and Lorenzo Felix for their assistance in RSW, wear test, ESD and electro-chemical experiments. I want to thank Dr. Yuquan Ding for SEM and EDX assistance. I would also like to thank colleagues from both CAMJ and MME department for their support.

Last but not least, I would like to thank my parents, my wife and my parents-in-law for their encouragement and endless supports during my study. 


\section{Table of Contents}

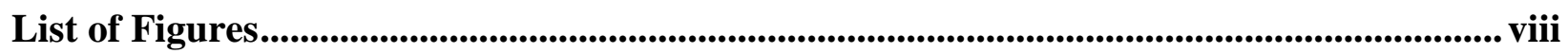

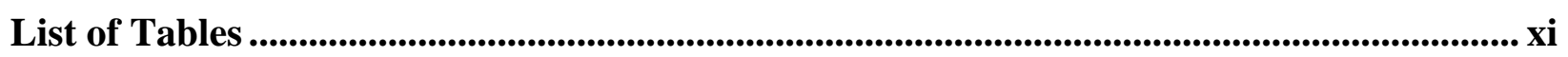

Chapter 1: Introduction ...................................................................................................................... 1

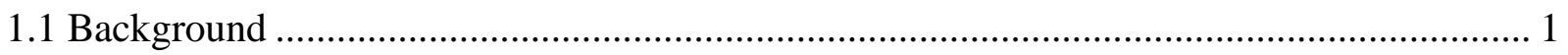

1.2 Justification and Problem ............................................................................................ 2

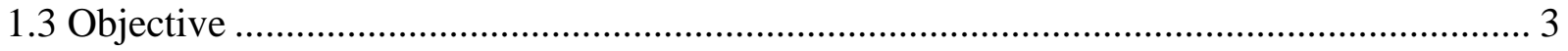

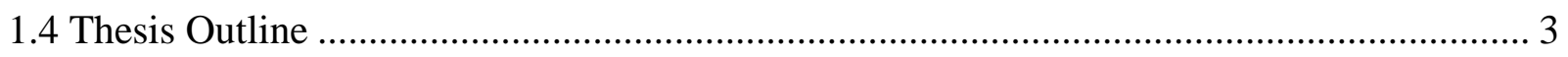

Chapter 2: Literature Review...................................................................................................... 5

2.1 Electrospark Deposition (ESD) Process........................................................................... 5

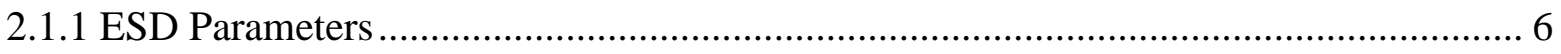

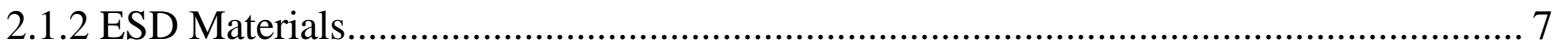

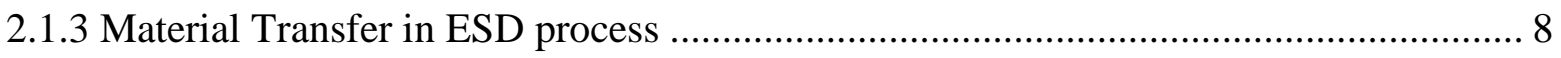

2.2 ESD Applications ..................................................................................................... 9

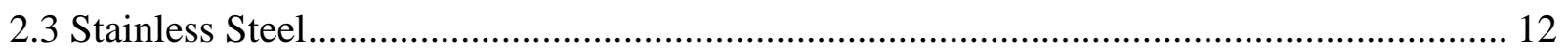

2.4 Heat Treatment of Stainless Steel .................................................................................... 14

2.5 Electrochemical Corrosion Analysis ................................................................................ 17

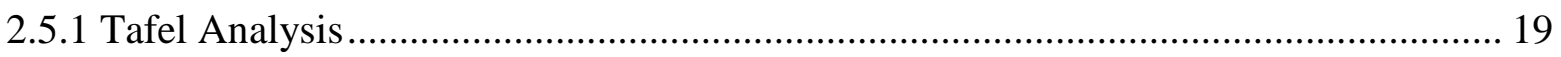

2.5.2 Electrochemical Impedance Spectroscopy (EIS) ……................................................. 20

Chapter 3: Experimental Methods..................................................................................................... 23

3.1 Electro-Spark Deposition Setup ................................................................................... 23

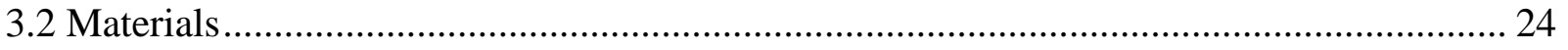

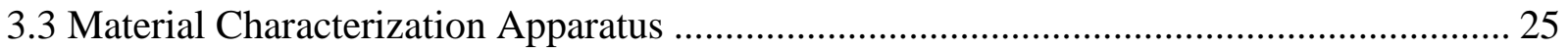

3.2.1 Microscopy and EDS Analysis.................................................................................... 25

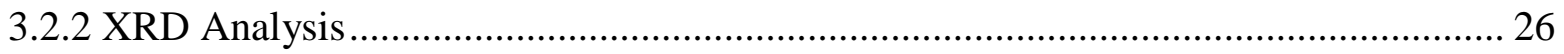

3.2.3 XPS Analysis .............................................................................................. 26

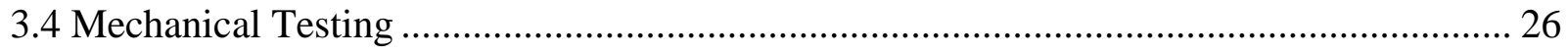

3.4.1 Micro-hardness Test .................................................................................................. 26

3.4.2 Wear Resistance Test................................................................................................... 27

3.5 Corrosion Resistance Testing......................................................................................... 29

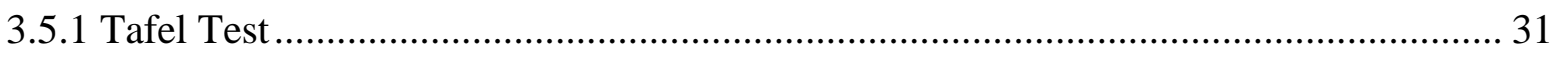




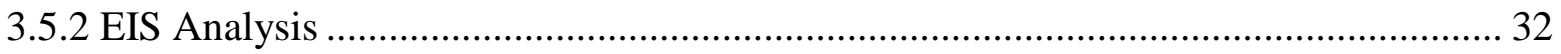

Chapter 4: Characterization of ESD Coated Stainless Steel ...................................................... 33

4.1 Electro-Spark Deposition on 304 Stainless Steel............................................................... 33

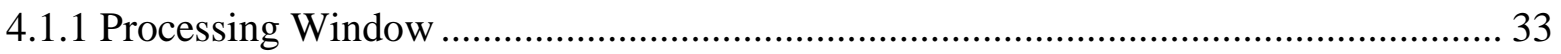

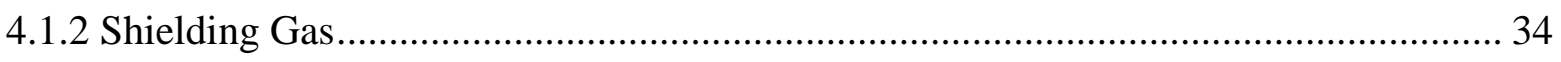

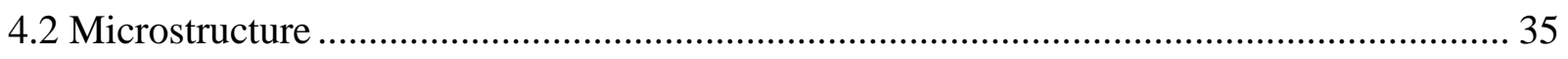

4.3 Mechanical Properties of Surface Modified 304 Stainless Steel ........................................ 38

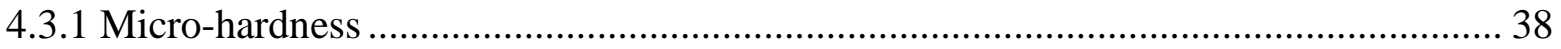

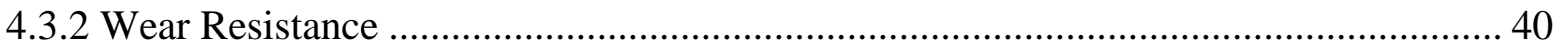

4.4 Corrosion Resistance of Surface Modified 304 Stainless Steel .......................................... 41

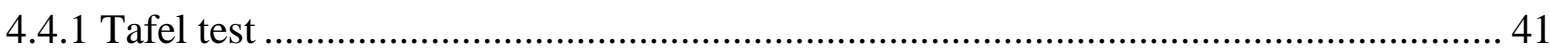

4.4.2 EIS analysis ....................................................................................................... 43

4.4.3 Detail tests for Molybdenum coated stainless steel..................................................... 44

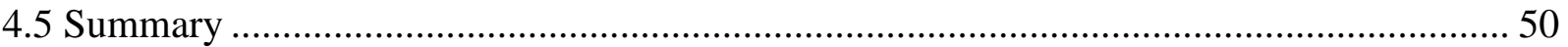

Chapter 5: Effects of Heat Treatment on Microstructure and Corrosion Resistance .......... 52

5.1 Microstructure of Heat Treated Samples ........................................................................... 52

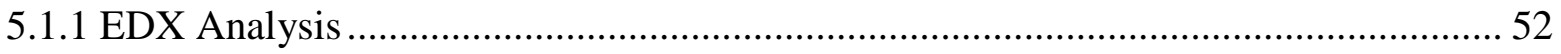

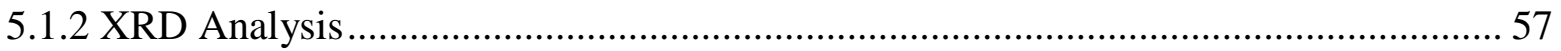

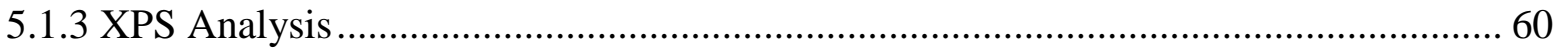

5.2 Corrosion Resistance of Heat Treated Samples ....................................................................... 63

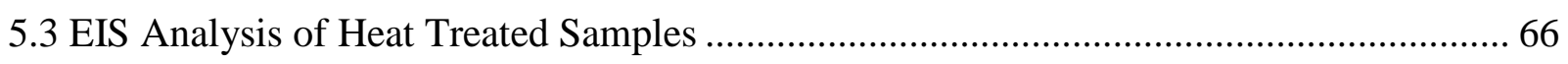

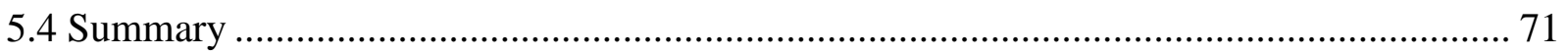

Chapter 6: Conclusions and Recommendations ............................................................................ 73

6.1 Conclusions ................................................................................................................... 73

6.1.1 Characterization of Surface Modified Stainless Steel by Electro-Spark Deposition ... 73

6.1.2 Effects of Heat Treatment on Microstructure and Corrosion Resistance ...................... 74

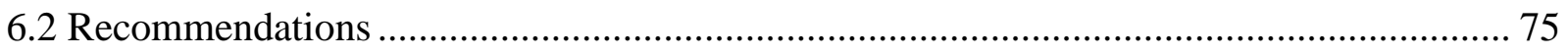

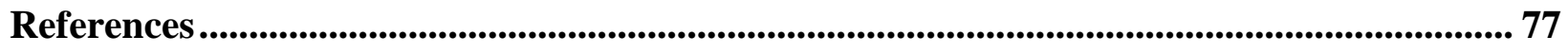

Appendix: EIS analysis data ......................................................................................................... 82 


\section{List of Figures}

Figure 2-1 Schematic images of electrospark deposition [8]............................................... 5

Figure 2-2 The physical model of the formation of a single-pulse deposition ............................ 8

Figure 2-3 Microstructure of WC-8Co coating applied by ESD [12] ..................................... 9

Figure 2-4 Spot-welding lives for electrodes with different coatings.................................... 10

Figure 2-5 SEM cross-section image of 9310 steel after ESD repair [17] ............................... 11

Figure 2-6 Microstructure and composition analysis of TiC layer by ESD [18]....................... 11

Figure 2-7 Ferrite content change after solution heat treatment [31] ................................... 14

Figure 2-8 Chi phase precipitation in duplex stainless steel [42] ....................................... 16

Figure 2-9 Intermetallic phase precipitations for duplex stainless steel [49] .......................... 17

Figure 2-10 Corrosion process showing anodic and cathodic components of current [50]......... 18

Figure 2-11 Simple Equivalent Circuit with One Time Constant [51] .................................... 21

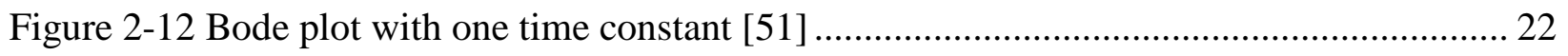

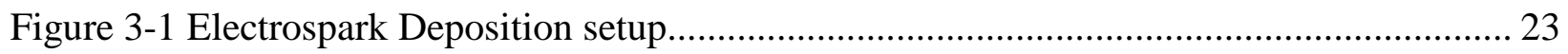

Figure 3-2 Wilson Vickers 402MVD micro-hardness tester ............................................... 27

Figure 3-3 (a) Schematic diagram of wear test apparatus (b) Wear test set up .......................... 28

Figure 3-4 Sample dimension for wear resistance test ................................................ 29

Figure 3-5 Schematic diagram of corrosion resistance test set up......................................... 30

Figure 3-6 Electrochemical experiment component and set up.......................................... 31

Figure 4-1 Macroscopic images of ESD coated steel ....................................................... 33

Figure 4-2 Microscope images of ESD TiC in different atmosphere (a) Ar (b) Air ................... 35

Figure 4-3 SEM image of ESD coated stainless steel (a) TiC (b) WC (c) Mo.......................... 36

Figure 4-4 EDX results of TiC coated stainless steel ...................................................... 37 
Figure 4-5 EDX results of WC coated stainless steel 37

Figure 4-6 EDX results of Mo coated stainless steel ....................................................... 38

Figure 4-7 Micro-hardness results of coated stainless steel................................................. 39

Figure 4-8 Wear resistance results of ESD coated stainless steel......................................... 40

Figure 4-9 Tafel analysis of stainless steel in 5\% $\mathrm{NaCl}$ solution ....................................... 41

Figure 4-10 Tafel test results of ESD coated stainless steel in 5\% $\mathrm{NaCl}$ solution ..................... 42

Figure 4-11 Schematic image of CPE equivalent circuit ................................................ 43

Figure 4-12 Bode plot of EIS spectra of 304 stainless steel ................................................ 43

Figure 4-13 Bode plot of EIS spectra of Mo coated stainless steel ...................................... 44

Figure 4-14 XRD pattern of 304 stainless steel ............................................................. 45

Figure 4-15 XRD pattern of Mo coated 304 stainless steel ................................................ 45

Figure 4-16 Effect of surface roughness on corrosion resistance of Mo coated stainless steel.... 46

Figure 4-17 Tafel test of 2205 duplex stainless steel....................................................... 47

Figure 4-18 Tafel test of Molybdenum coated DP980 steel ................................................ 48

Figure 4-19 Tafel test of Molybdenum coated 2205 duplex stainless steel............................. 49

Figure 5-1 EDX results of Mo coated stainless steel after heat treatment in air at $400^{\circ} \mathrm{C} \mathrm{\ldots ........} 53$

Figure 5-2 EDX results of Mo coated stainless steel after heat treatment in Ar at $400^{\circ} \mathrm{C} \ldots . . . . . . .54$

Figure 5-3 EDX results of Mo coated stainless steel after heat treatment in air at $650^{\circ} \mathrm{C} \ldots \ldots \ldots . . .54$

Figure 5-4 EDX results of Mo coated stainless steel after heat treatment in $\mathrm{Ar}$ at $650^{\circ} \mathrm{C} \ldots . . . . . . .55$

Figure 5-5 EDX results of Mo coated stainless steel after heat treatment in air at $900^{\circ} \mathrm{C} \ldots \ldots \ldots . . .56$

Figure 5-6 EDX results of Mo coated stainless steel after heat treatment in $\mathrm{Ar}$ at $900^{\circ} \mathrm{C} \ldots \ldots \ldots . . . .56$

Figure 5-7 XRD patterns of heat treated samples after $400^{\circ} \mathrm{C}$ (a) air (b) Ar............................ 57

Figure 5-8 XRD patterns of heat treated samples after $650^{\circ} \mathrm{C}$ (a) air (b) Ar............................ 58 
Figure 5-9 XRD patterns of heat treated samples after $900^{\circ} \mathrm{C}$ (a) air (b) Ar............................ 59

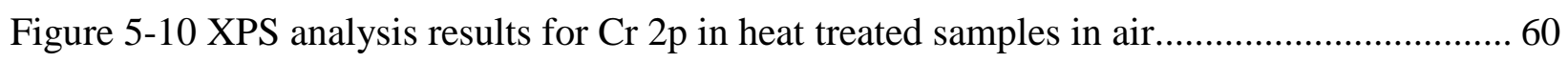

Figure 5-11 XPS analysis results for Mo 3d in heat treated samples in air ............................. 61

Figure 5-12 XPS analysis results for Cr 2p in heat treated samples in Ar................................. 62

Figure 5-13 XPS analysis results for Mo 3d in heat treated samples in Ar ............................. 63

Figure 5-14 Tafel test results of Mo coated stainless steel after heat treatment in air................ 64

Figure 5-15 Tafel test results of Mo coated stainless steel after heat treatment in Ar................ 65

Figure 5-16 Schematic image of modified equivalent circuit............................................ 66

Figure 5-17 Bode plot of EIS spectra with modified equivalent circuit ................................. 67 


\section{List of Tables}

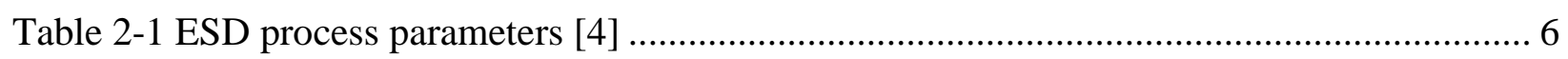

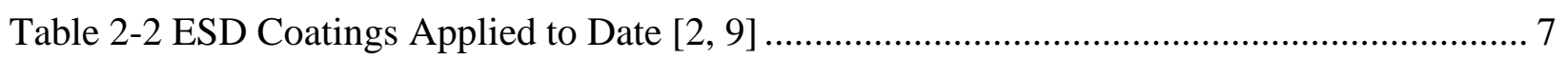

Table 2-3 Substrate alloys coated by ESD to date $[2,9]$.................................................. 7

Table 2-4 Intermetallic phases, chemical formulae and their temperature range [33] ............... 15

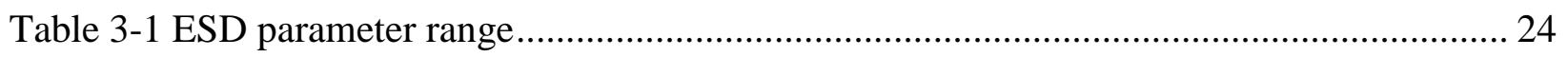

Table 3-2 Chemical composition of 304 stainless steel..................................................... 24

Table 3-3 Chemical composition of DP980 steel ............................................................... 25

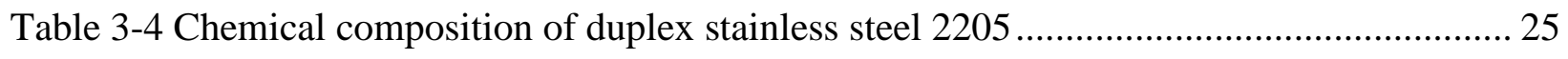

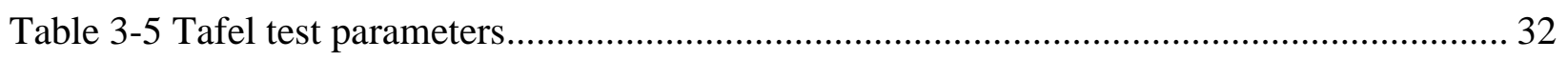

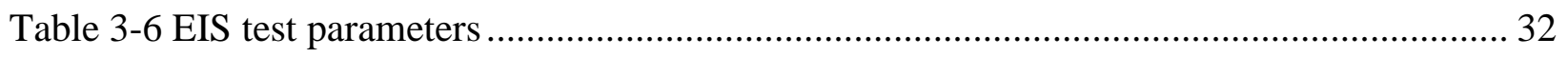

Table 4-1 Operation window of TiC, WC and Mo coating on stainless steel by ESD............... 34

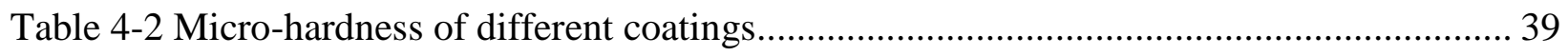

Table 4-3 Mass loss of different ESD coated stainless steel .............................................. 40

Table 4-4 Tafel analysis of stainless steel in 5\% $\mathrm{NaCl}$ solution............................................ 41

Table 4-5 Tafel analysis of ESD coated stainless steel in $5 \% \mathrm{NaCl}$ solution........................... 42

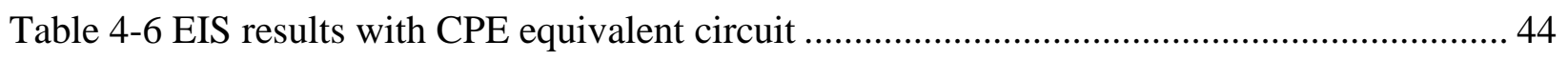

Table 4-7 Effect of surface roughness on Tafel results of Mo coated stainless steel .................. 47

Table 4-8 Tafel test results of 2205 duplex stainless steel.................................................. 48

Table 4-9 Tafel test results of Molybdenum coated DP980 steel.......................................... 49

Table 4-10 Tafel test results of Molybdenum coated 2205 duplex stainless steel...................... 50

Table 5-1 Tafel test results of heat treated samples in air................................................... 64

Table 5-2 Tafel test results of heat treated samples in Ar.................................................. 65 
Table 5-3 EIS test results of Mo coated stainless steel after heat treatment in air

Table 5-4 Fitting goodness for electrochemical analysis................................................ 69

Table 5-5 EIS test results of Mo coated stainless steel after heat treatment in Ar ..................... 70 


\section{Chapter 1: Introduction}

\subsection{Background}

Electrospark deposition is a micro welding process that uses short duration electrical pulses to deposit electrode materials onto conductive substrates. ESD is increasingly used to repair damaged high value precision products or modify their surfaces for specific properties [1]. ESD has a broad range of applications in aerospace, defense, automotive, and medical industries [2]. ESD is also considered as an environmentally friendly technique in replacing some of the other techniques such as hard chromium plating that uses hazardous chemicals [3]. ESD is able to apply coatings with metallurgical bond to the substrates, which ensures excellent adhesion with high spalling resistance [4]. In addition, ESD has low heat input that reduces the heat affected zone, thermal damage and impacts on substrate material [5]. The bulk substrate remains close to ambient temperature due to the very short deposition time.

Stainless steel is an ideal material where properties of steel and corrosion resistance are required. Stainless steels contain sufficient chromium to form a passive layer of chromium oxide, which prevents further surface corrosion into the metal's internal structure. There are different types of stainless steel which can be classified by their crystalline structure [6]. Various alloy elements are added into stainless steel to tune the microstructure and properties. Stainless steel has wide applications in household hardware, surgical instruments, major appliances, industrial equipment, automotive and aerospace structural alloy. However, some localized areas of the stainless steel components require specific properties, like better corrosion resistance, hardness, wear resistance. 
ESD technique provides a feasible approach to apply coating materials onto localized surface. Investigation on surface modification of stainless steel may introduce better surface performance without compromising the bulk material properties and thus it may open new applications for stainless steel.

\subsection{Justification and Problem}

304 stainless steel is the most widely used austenite steel due to its decent properties and low cost. The microstructure and composition of stainless steel are tuned to meet specific application requirements. For example, martensitic stainless steels are extremely strong and tough, as well as highly machinable [6]. However, martensitic stainless steels are not as corrosion-resistant as the other stainless steels. Duplex steel stainless steels have a mixed microstructure of $50 \%$ austenite and 50\% ferrite. Duplex stainless steels have better strength and higher corrosion resistance compared to normal austenitic stainless steels [7]. They contain high chromium (19-32\%) and molybdenum (up to 7\%) and lower nickel contents than austenitic stainless steels. However, some duplex is much more expensive than regular stainless steels. So the cost of duplex stainless steel component could be high if the whole part is made from it. In many applications, high corrosion resistance is only required on some localized areas. Applying a high corrosion resistance coating on localized area could be effective and economical.

Apply coatings on 304 stainless steel by ESD could be feasible way to improve localized surface performance. However, the coatability studies must be conducted to figure out which materials can be applied to 304 stainless steel surface under the current machine conditions. Although ESD may seem to be a relatively simple process, there are a lot of process parameters that must be 
optimized and controlled to achieve consistent, high quality coatings. Detailed performance evaluation is required to figure out the specific properties of coated 304 stainless steel.

\subsection{Objective}

The objective of this thesis is to investigate approaches to surface modifying 304 stainless steel by electrospark deposition technique. Microstructure and performance of promising coatings are characterized. The specific objectives include:

1) Process window investigation for depositing different coatings on 304 stainless steel by electrospark deposition

2) Microstructure and composition characterization for TiC, WC and Mo coatings on 304 stainless steel

3) Coating performance evaluation of coated 304 stainless steel, including micro-hardness test and wear resistance test and corrosion resistance test

4) Detailed metallurgical analysis on Mo coated 304 stainless steel to investigate effects of heat treatment on the microstructure change

5) Electrochemical analysis of heat-treated samples to correlate corrosion performance with microstructure change.

\subsection{Thesis Outline}

In this thesis Chapter 2 outlines the features of ESD process and presents a literature review on topics relevant to ESD applications and stainless steel surface modification. Chapter 3 describes the laboratory set up, experimental procedures as well as material characterization methods. 
Chapter 4 reports on characterization of surface modified stainless steel by electro-spark deposition. Microstructure and performance of coated stainless steel are investigated. In Chapter 5, microstructure changes of Mo coated stainless steel after heat treatment are characterized. The effects of heat treatment on electrochemical performance are correlated to microstructure changes. Finally, the main conclusions drawn from the results of this study as well as recommendations for future work are concluded in Chapter 6. 


\section{Chapter 2: Literature Review}

\subsection{Electrospark Deposition (ESD) Process}

Electrospark deposition (ESD) is a pulsed-arc micro welding process that uses short duration pulses of current to deposit electrode material onto a conductive substrate to improve wear, corrosion resistance or build up restoration [4]. A typical schematic image of ESD equipment is shown in Figure 2-1 [8].
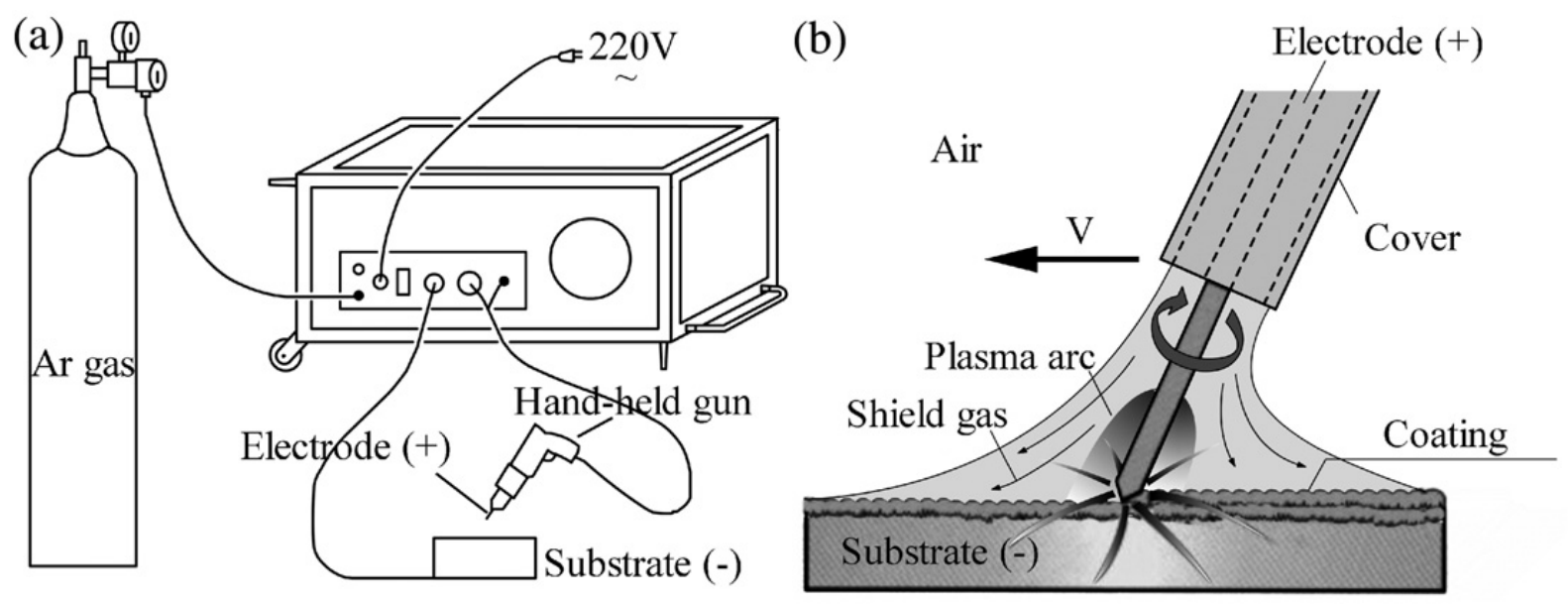

Figure 2-1 Schematic images of electrospark deposition [8]

ESD equipment contains a capacitor-based power supply which produces short duration high current pulses through a rotating consumable electrode. The electrode material is deposited onto the conductive substrate by means of electric sparks. In the ESD process, the electrode is the anode and the substrate is the cathode. The typical hand held applicator for the ESD includes a nonconductive case and an electric motor. The non-conductive case can provide electrical and thermal insulation between the electrode and the operator. The applicator can also contain a shielding gas system to deliver shielding gas to the deposition area. The electric motor can generate electrode 
movement, preventing the constant contact between the electrode and substrate. Vibration, rotation, and oscillation are the main types of the electrode movement.

During ESD process, the release of capacitor energy will generate a high temperature plasma arc between the electrode tip and the substrate. The electrode material is ionized by the plasma arc and the molten electrode material is transferred onto the substrate. The material transfer is very fast, followed by a rapid self-quenching process. ESD process has very low heat input to the substrate material so that there is very little impact on the substrate microstructure. Besides, ESD process is able to generate a good metallurgical bond between the coating and the substrate.

\subsubsection{ESD Parameters}

ESD is a micro-arc welding process and some traditional arc welding parameters may also apply to ESD. However, the ESD process is also different from arc welding that some important parameters are unique to the ESD process. Table 2-1 shows a summary of ESD parameters that are known to affect coating properties and structure [4].

Table 2-1 ESD process parameters [4]

\begin{tabular}{|c|c|c|c|c|}
\hline Electrode & Substrate & Environment & Electrical & Others \\
\hline $\begin{array}{c}\text { Material } \\
\text { Geometry } \\
\text { Motion } \\
\text { Speed } \\
\text { Contact Pressure } \\
\text { Orientation }\end{array}$ & $\begin{array}{c}\text { Material } \\
\text { Surface finish } \\
\text { Cleanliness } \\
\text { Temperature } \\
\text { Geometry }\end{array}$ & $\begin{array}{c}\text { Gas composition } \\
\text { Flow rate } \\
\text { Temperature } \\
\text { Flow geometry }\end{array}$ & $\begin{array}{l}\text { Power input } \\
\text { Voltage } \\
\text { Capacitance } \\
\text { Frequency } \\
\text { Spark rate }\end{array}$ & $\begin{array}{c}\text { System efficiency } \\
\text { Overlap of passes } \\
\text { Spark duration }\end{array}$ \\
\hline
\end{tabular}


The ESD process appears very simple, but it involves a lot of process parameters that must be controlled to obtain consistent coating quality and performance. A change in any of these parameters can lead to a change in deposition properties.

\subsubsection{ESD Materials}

Theoretically, all electrically conductive materials that can be melted in an arc can be deposited on conductive substrates. A broad variety of electrode and substrate materials combinations have been investigated in previous studies [2]. Table 2-2 lists some example electrode materials for improving wear resistance, corrosion resistance and build-up [2, 9]. Table 2-3 presents the related substrate materials for these applications [2, 9].

Table 2-2 ESD Coatings Applied to Date [2, 9]

\begin{tabular}{|c|c|c|}
\hline Wear Resistance Coating & $\begin{array}{c}\text { Corrosion Resistance } \\
\text { Coating }\end{array}$ & $\begin{array}{c}\text { Build-up or Special Surface } \\
\text { Modification }\end{array}$ \\
\hline $\begin{array}{c}\text { Hard carbides }^{(\mathrm{a})} \text { of: } \mathrm{W}, \mathrm{Cr}, \mathrm{Ti} \\
\text { Ta, Hf, Mo, Zr, V, Nb }\end{array}$ & $\begin{array}{l}\text { Stainless steels, Hastelloys } \\
\text { Inconels }^{(\mathrm{b})}, \text { Monels }^{(\mathrm{b})}\end{array}$ & $\begin{array}{l}\text { Ni-base and Co-base super } \\
\text { alloys }\end{array}$ \\
\hline $\begin{array}{c}\text { Hardfacing alloys: Stellites }^{\left({ }^{(b)}\right.} \text {, } \\
\text { Tribaloys }^{(\mathrm{b})} \text {, Colmonoys }^{(\mathrm{b})} \text {, } \\
\text { etc. }\end{array}$ & Aluminides of: $\mathrm{Fe}, \mathrm{Ni}$, and $\mathrm{Ti}$ & $\begin{array}{l}\text { Refractory Alloys (W, Ta, } \\
\text { Mo, Nb, Re, Hf) }\end{array}$ \\
\hline Borides of: $\mathrm{Cr}, \mathrm{Ti}, \mathrm{Zr}$, and $\mathrm{Ta}$ & FeCrAlY, NiCrAlY, CoCrAlY & $\begin{array}{c}\text { Noble metals (Au, Pt, Ag, Pd, } \\
\text { Ir) }\end{array}$ \\
\hline Intermetallics and Cermets & $\mathrm{Al}$ and $\mathrm{Al}$ Bronze Alloys & $\begin{array}{l}\text { Other Alloys (Fe, Ni, Cr, Co, } \\
\mathrm{Al}, \mathrm{Cu}, \mathrm{Ti}, \mathrm{V}, \mathrm{Sn}, \mathrm{Er}, \mathrm{Zr}, \mathrm{Zn})\end{array}$ \\
\hline 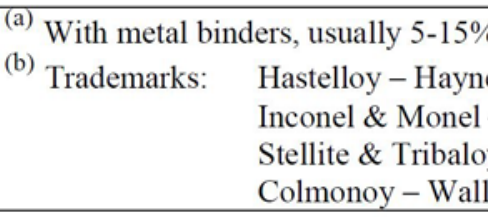 & $\begin{array}{l}\text { Ni or Co } \\
\text { International, Kokomo, IN } \\
\text { International Nickel Co, Huntington, W } \\
\text { - Deloro-Stellite Co., Goshen, IN } \\
\text { Colmonoy Corp., Detroit, MI }\end{array}$ & \\
\hline
\end{tabular}

Table 2-3 Substrate alloys coated by ESD to date [2, 9]

\begin{tabular}{ccc}
\hline High and Low Alloy Steels & Nickel and Cobalt Alloys & Refractory Metals $(\mathrm{W}, \mathrm{Re}, \mathrm{Ta}$, \\
& Titanium Alloys & $\mathrm{Mb})$ \\
Stainless Steels & Aluminum Alloys & Chromium \\
Tool Steels & Copper Alloys & Erbium \\
Zirconium Alloys & & Erbium \\
\hline
\end{tabular}




\subsubsection{Material Transfer in ESD process}

ESD process involves electrode materials transferring onto the substrate. Mass transfer mechanism were investigated to study how the materials deposited on the substrate. Galinov [10] studied the effect of pulse energy and pulse power on the material transfer during ESD process. Cathode mass gain, anode erosion and mass transfer coefficient were investigated. The results showed the solid state particles could erode the substrate, while the gaseous state material were mostly vaporized into the environment. The liquid state material could be deposited on the substrate and solidified to form the coating.

Liu et al. [11] presented a physical model of the formation of the single-pulse deposition spot, as shown in Figure 2-2. The first step is contact between moving electrode and the substrate. The second step is the pulsed electrospark discharges, which forms the deposition spot. Then the vibrating or rotating electrode will contact the substrate again and start a new pulsed discharging cycle.

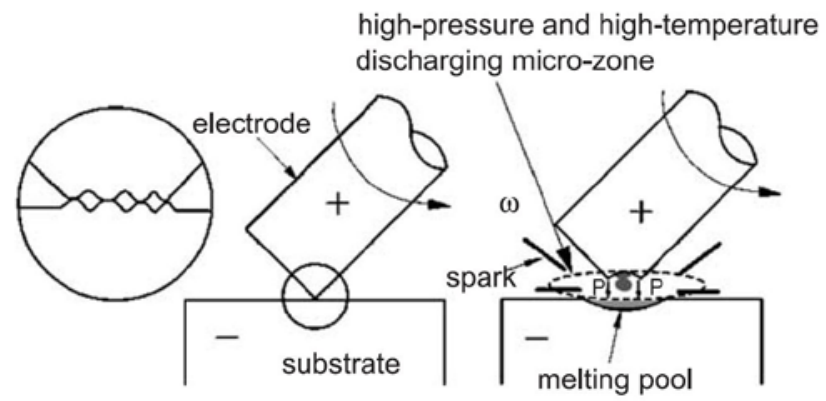

(a)

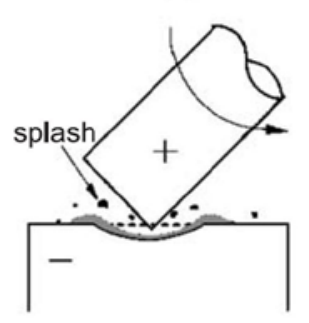

(c) (b)

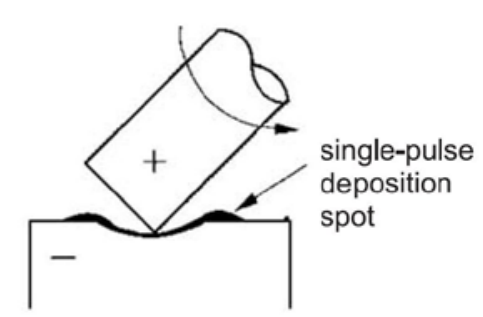

(d)

Figure 2-2 The physical model of the formation of a single-pulse deposition 


\subsection{ESD Applications}

There are mainly two types of ESD applications: surface modification and built-up repair. Surface modification is to apply a coating on the substrate surface to obtain specific properties, such as wear resistance, corrosion resistance, hardness. Raju et al. [12] applied WC-8Co coating on twist drills by ESD technique to increase the tool life. Figure 2-3 shows the microstructure and morphology of the ESD coating. The results showed the performance enhancement can be as high as 5-fold compared to the uncoated drills.
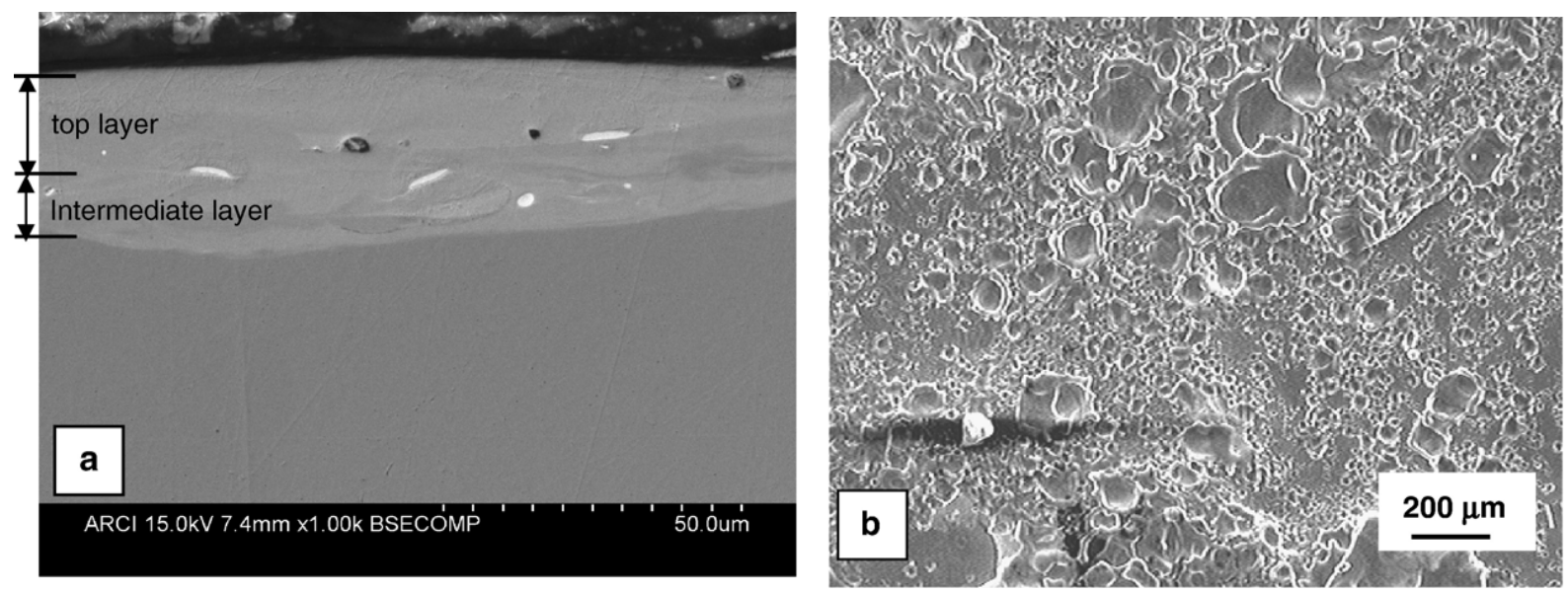

Figure 2-3 Microstructure of WC-8Co coating applied by ESD [12]

Kolomeichenko and Kuznetsov [13] studied wear properties of electrospark coatings of amorphous and nanocrystalline iron alloys. The results indicate the wear performance is dependent on the chemical composition and microstructure of the hardened layer of the studied coatings. Cheng et al. [14] applied $\mathrm{TiB}_{2} / \mathrm{Ni}$ coatings on copper electrode with electrospark deposition to improve the tip life of resistance spot welding electrodes. Figure 2-4 [14] shows the tip life test results with different coatings and $\mathrm{TiB}_{2}$ displayed the best performance. 


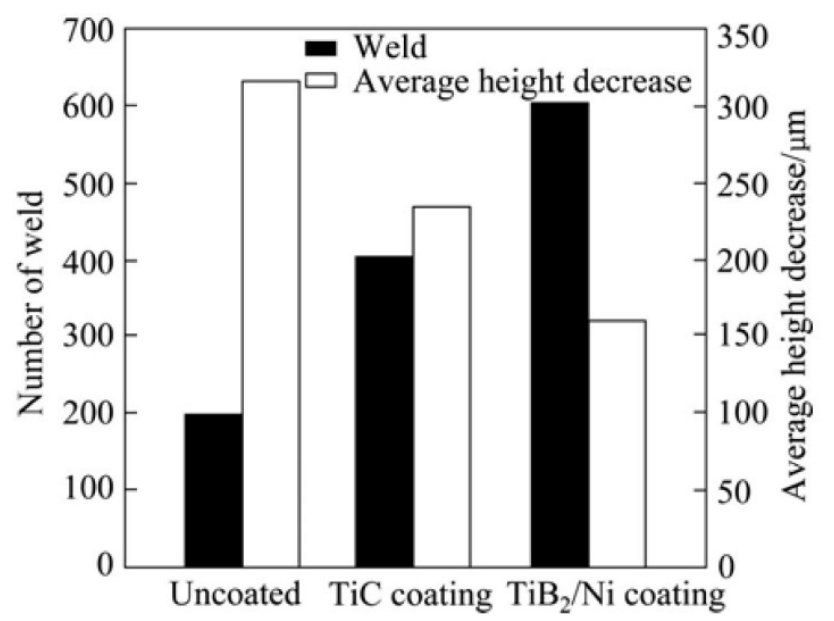

Figure 2-4 Spot-welding lives for electrodes with different coatings

Frangini et al. [15] deposited Cr7C3-based cermet coating on stainless steel surface by electrospark process to improve the corrosion resistance. The results showed the coating was fully dense and strongly adherent to the substrate steel. The corrosion resistance in $\mathrm{HCl}$ solutions was significantly increased. Brown et al. [16] applied coatings on high speed steels by ESD process to improve tool life. The results showed the best ESD coated tool had a life better than the uncoated tool by roughly $2000 \%$.

The second type of ESD application is built-up repairs, which is very useful to restore high value components. Champagne et al. [17] investigated repairing of corrosion pits and wear on helical gear shaft by ESD build-up. Figure 2-5 shows a cross-section image of the repaired sample. The results showed the thickness of the build-up layer was up to $1 \mathrm{~mm}$ and no major cracks were found in the build-up layer. 


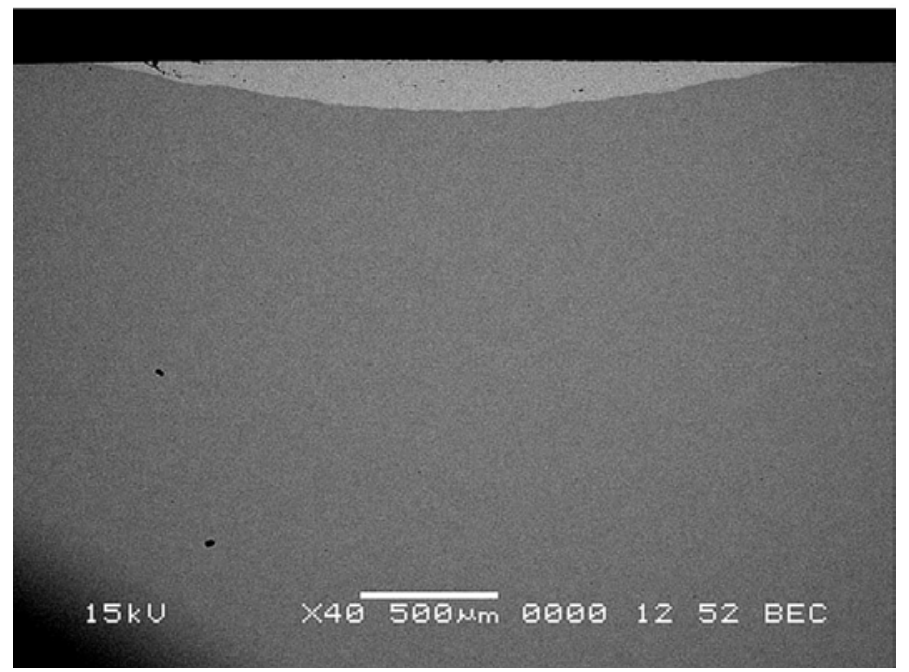

Figure 2-5 SEM cross-section image of 9310 steel after ESD repair [17]

Tusek et al. [18] investigated electrospark deposition for die repair. Figure 2-6 shows the microstructure and elemental analysis of ESD coated TiC layer.

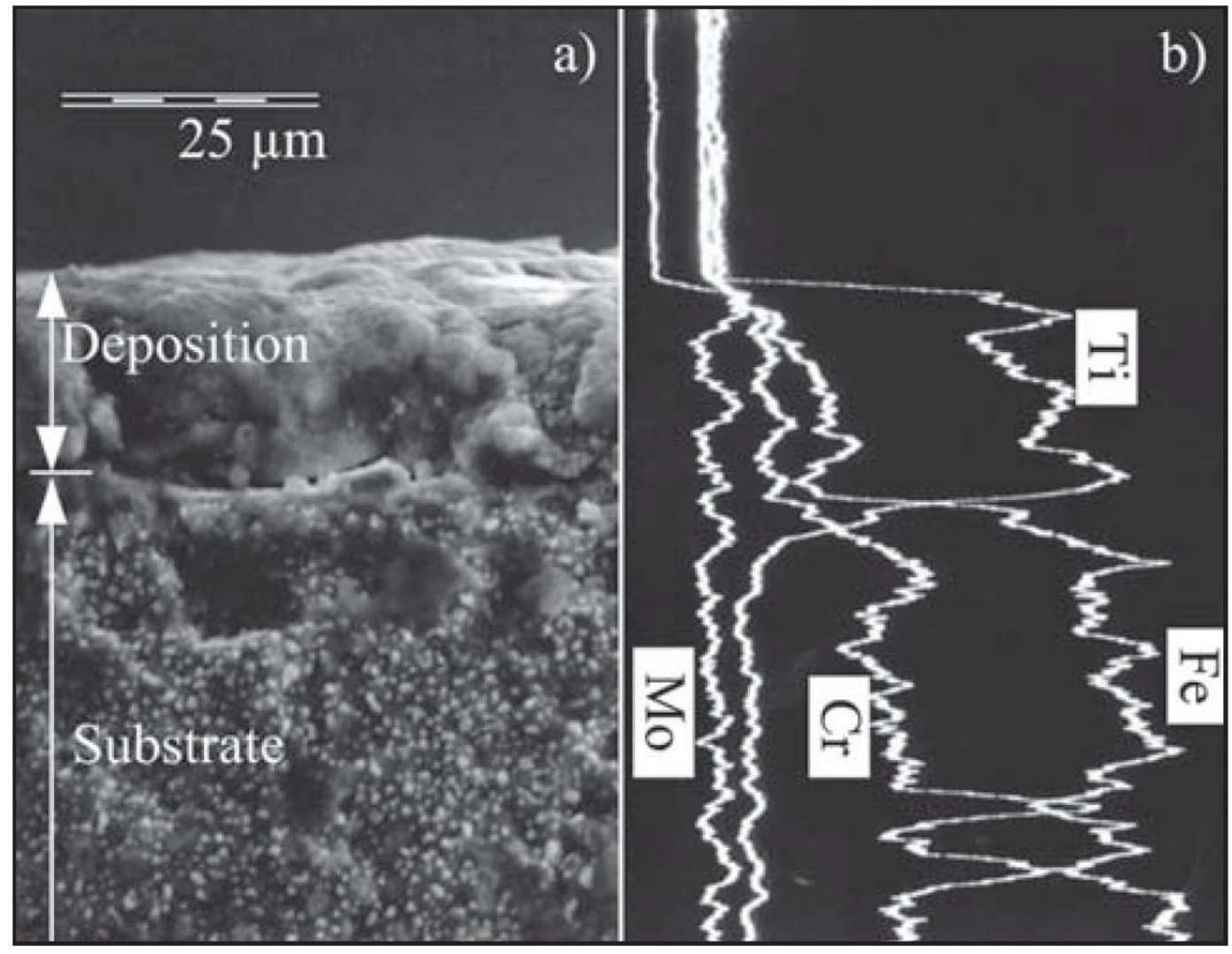

Figure 2-6 Microstructure and composition analysis of TiC layer by ESD [18] 


\subsection{Stainless Steel}

Stainless steels are commonly divided into five groups, based on the composition and microstructure [6]. Austenitic stainless steels have the best weldability and can be further divided into three groups: common chromium-nickel (300 series), manganese-chromium-nickel-nitrogen (200 series) and specialty alloys. The microstructure of austenitic stainless steels is face-centered cubic structure. Some grades can be susceptible to sensitization in the weld heat-affected zone. Austenitic stainless steel is the most common stainless steel and is widely used for various industrial and consumer applications, such as in chemical plants, food processing and household hardware.

Ferritic stainless steels are iron-chromium alloys and the microstructure is body-centered cubic. Ferritic stainless steels normally have good ductility and formability, while high-temperature strengths are not as good as austenitic stainless steels. Ferritic stainless steels can be used, in mufflers, exhaust systems and sinks. Some highly alloyed steels ferritic stainless steels have extremely high corrosion resistance to chloride solutions.

Martensitic stainless steels have a body-centered cubic crystal structure and the composition is similar to ferritic stainless steel. Martensitic stainless steels contain a certain amount of alloy elements, result in phase transformation from high temperature austenite to low temperature martensite.

Precipitation-hardening stainless steels are chromium-nickel stainless steels. The alloy elements such as aluminum, copper or titanium enables them to be hardened by a solution and aging heat treatment. Precipitation-hardening stainless steels can be either austenitic or martensitic in the aged condition. 
Duplex stainless steels are characterized by its microstructure that contains $50 \%$ of austenite and $50 \%$ ferrite. The composition of duplex stainless steels typically contains approximately 22-25\% chromium, 5\% nickel and up to 7\% of molybdenum. Due to the high corrosion resistance, duplex stainless steel is mainly used in chemical plants, marine and piping applications.

The alloy elements have significant effects on stainless steel properties and performance. Chromium is considered as a ferrite stabilizer [19]. One benefit of alloying Cr is forming a protective film to increase localized corrosion resistance. However, if $\mathrm{Cr}$ content is too high, $\mathrm{Cr}$ will facilitates formation of detrimental intermetallic phases in duplex stainless steels [20]. The Cr equivalent in duplex stainless steel is shown in Equation 2-1 [21].

$$
\mathrm{Cr}_{\mathrm{eq}}=\% \mathrm{Cr}+\% \mathrm{Mo}+0.7 \% \mathrm{Nb}
$$

Molybdenum is also a ferrite former [19]. Mo is able to increase the corrosion resistance of duplex stainless steel by forming oxy-hydroxide layer. From Pitting Resistance Equivalent Number (PREN) equation, it should be noted that Mo has a factor of 3.3 contributing to corrosion resistance [22]. However, high Mo contents might facilitate the formation of detrimental Cr-Mo rich chi and sigma phase at high temperatures [23]. Nickel is an austenite stabilizer which is also able to control phase balance and element partitioning. In stainless steel, the ferrite formers and austenite formers need to be added in appropriate amount to obtain the balance between ferrite and austenite. High Ni content is desired for improving corrosion resistance. However, the high Ni content facilitate formation of prime- $\alpha$ phase in ferrite which may cause embrittlement of the material [20]. Nitrogen is also an austenite stabilizer, which is able to increase pitting resistance and strength of stainless steel [24]. In addition, nitrogen increases corrosion resistance in acid solutions, while not as effective in other solutions [25]. On one hand, $\mathrm{N}$ is beneficial to increase corrosion resistance of duplex stainless steel since it can delay the precipitation of intermetallic [26]. On the other hand, 
high $\mathrm{N}$ content may introduce nitrides precipitation. Adding Mn to stainless steels can increase the wear, abrasion resistance, and tensile strength [27]. However, high Mn content may facilitate the formation of intermetallic phases as well as MnS, which could decrease the corrosion rensistance [28]. Copper additions contributes to the improvement of corrosion resistance in nonoxidizing environments like sulphuric acid. Also, high Cu content may form epsilon phase which decrease pitting resistance [29].

\subsection{Heat Treatment of Stainless Steel}

Stainless steels have considerable amount of alloy elements, which makes their microstructure and properties complicated after heat treatment. Hwang and Park [30] instigated the heat treatment effects on the phase ratio and corrosion resistance of duplex stainless steel. The results found that the ferrite content ratio changed during heat treatment process, as shown in Figure 2-7. Following electrochemical tests also revealed that heat treatment could affect the corrosion resistance of the duplex stainless steel.

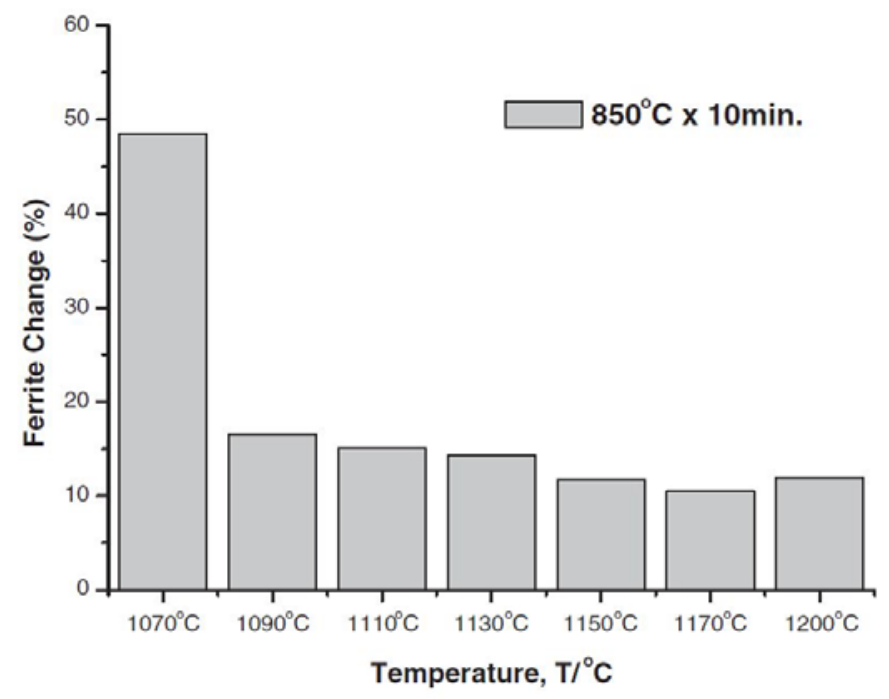

Figure 2-7 Ferrite content change after solution heat treatment [30] 
Jithin et al. [31] carried out detailed studies to investigate the effects of heat treatment on the properties of duplex stainless steel. The results indicated that different heat treatment method could affect the wear resistance, impact strength and hardness of duplex stainless steel.

Paulraj, et al. [32] studied the formation of intermetallic phase in duplex stainless steel and its effects on corrosion behavior and mechanical properties. Karlsson [33] summarized the possible intermetallic phase formed in duplex stainless steel at certain temperature range, as shown in Table $2-4$.

Table 2-4 Intermetallic phases, chemical formulae and their temperature range [33]

\begin{tabular}{|c|c|c|}
\hline $\begin{array}{c}\text { Intermetallic } \\
\text { phases }\end{array}$ & Chemical formula & $\begin{array}{c}\text { Temperature range } \\
\left({ }^{\circ} \mathrm{C}\right)\end{array}$ \\
\hline Sigma & $\mathrm{Fe}-\mathrm{Cr}-\mathrm{Mo}$ & $600-1000$ \\
\hline $\mathrm{Chi}$ & $\mathrm{Fe}_{36} \mathrm{Cr}_{12} \mathrm{Mo}_{10}$ & $700-900$ \\
\hline Nitrides & $\mathrm{CrN}_{1} \mathrm{Cr}_{2} \mathrm{~N}$ & $700-900$ \\
\hline Carbides & $\mathrm{M}_{7} \mathrm{C}_{3} / \mathrm{M}_{23} \mathrm{C}_{6}$ & $550-650$ \\
\hline $\mathrm{R}$ & $\mathrm{Fe}-\mathrm{Cr}-\mathrm{Mo}$ & $550-800$ \\
\hline$\Pi$ & $\mathrm{Fe}_{7} \mathrm{Mo}_{13} \mathrm{~N}_{4}$ & $550-600$ \\
\hline $\begin{array}{c}\text { Prime alpha }\left(\alpha^{\prime}\right) \\
\text { phase }\end{array}$ & $\mathrm{Fe}-\mathrm{Cr}$ & 475 \\
\hline
\end{tabular}

Sigma phase is a Fe-Cr-Mo rich hard precipitate which are formed at temperatures range from $600-1000^{\circ} \mathrm{C}[34,35]$. The alloy elements $\mathrm{Cr}, \mathrm{Mo}, \mathrm{Ni}, \mathrm{Si}$ and Mn can facilitate the formation of sigma phase. The formation of sigma phase is mainly caused by diffusion of chromium in ferrite [36]. Sigma is non-magnetic phase with tetragonal-crystalline structure [37]. This phase occurs due to ferrite phase is transformed into sigma and secondary austenitic phase $\left(\gamma_{2}\right)$ by eutectoid reaction [38]. Sigma phase precipitation starts at ferrite-ferrite boundaries and ferrite-austenite boundaries these areas has higher energy for nuclear [39]. For bulk material, sigma phase precipitation is difficult to avoid [40]. Increasing cooling rate or tuning chemical composition could minimizes the chances of sigma phase formation [41]. 
Chi phase $(\chi)$ is Mo rich phase but thermodynamically unstable. The forming temperature is between $750-850^{\circ} \mathrm{C}$, which is prior to sigma phase. Chi phase is formed on the ferrite-ferrite interface and grows into the ferrite [42]. The sigma phase is then formed by consuming Chi phase, as shown in Figure 2-8 [42].

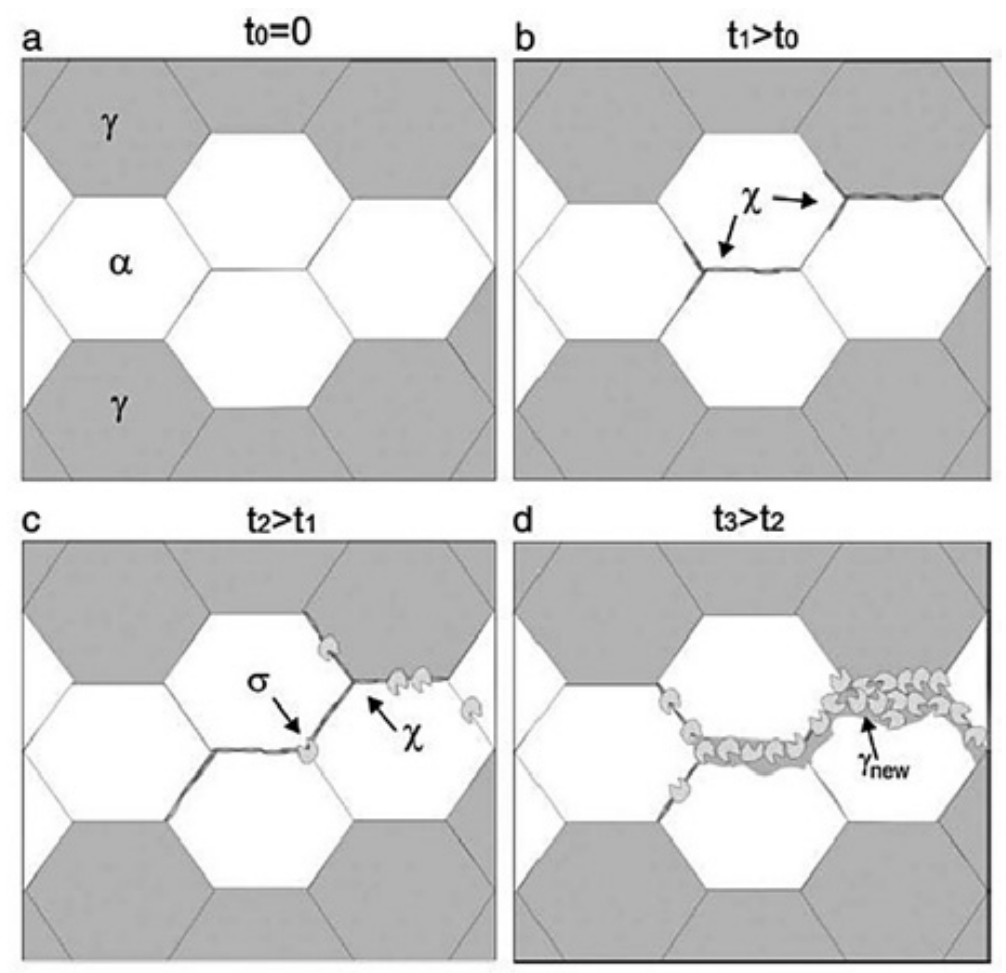

Figure 2-8 Chi phase precipitation in duplex stainless steel [42]

Secondary austenite $\left(\gamma_{2}\right)$ phase could be formed with different mechanisms at different temperatures. It can be formed below $650^{\circ} \mathrm{C}$ or between 650 to $800^{\circ} \mathrm{C}$. Secondary austenite is $\mathrm{Ni}$ rich phase as compared to ferrite. When comparing to normal austenite, secondary austenite is depleted in $\mathrm{Cr}$ and $\mathrm{N}$. If temperature is between 800 to $900^{\circ} \mathrm{C}, \gamma_{2}$ absorbs $\mathrm{Ni}$, which is austenite former and rejects $\mathrm{Cr}$ and Mo. This results in formation of $\mathrm{Cr}$, Mo rich precipitates such as sigma phase [38]. As $\gamma_{2}$ is depleted in $\mathrm{Cr}$ and Mo, they are the susceptible locations for pitting corrosion [43]. 
There are also some other intermetallic that could be formed in stainless steels under different temperatures such as chromium nitrides [44], R-phase [45, 46], П-phase [20], $\tau$-phase [47] and Alpha Prime phase [48]. Generally, these intermetallic is vulnerable to corrosion attack and thus will decrease the corrosion resistance of stainless steels. Figure 2-9 shows the intermetallic phase precipitations for duplex stainless steel [49].

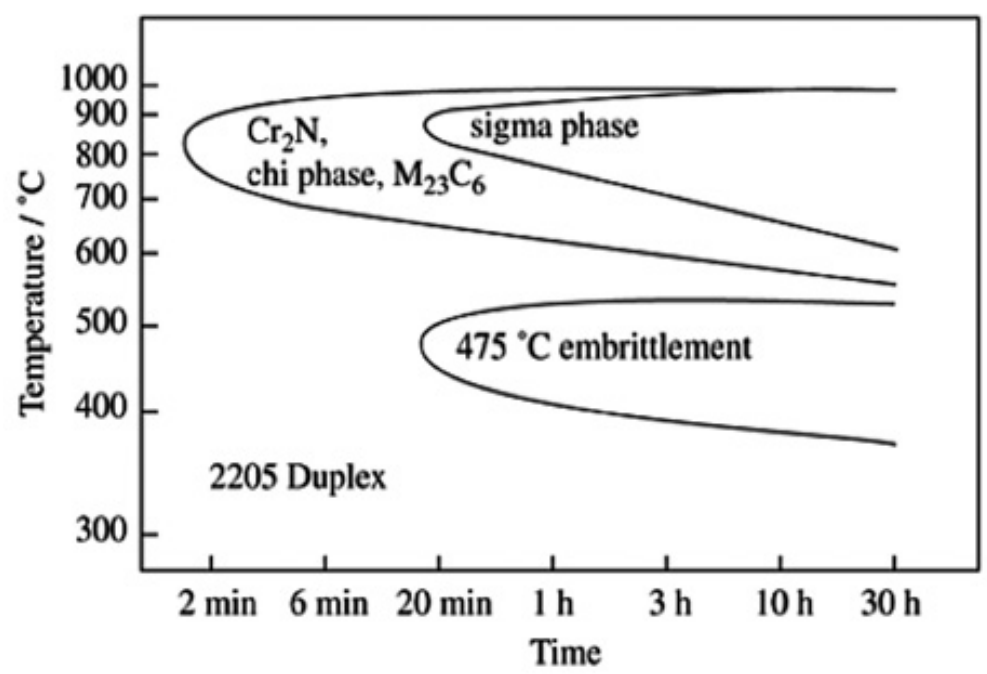

Figure 2-9 Intermetallic phase precipitations for duplex stainless steel [49]

\subsection{Electrochemical Corrosion Analysis}

Normally metals corrode via electrochemical reactions at the interface between the metal and an electrolyte solution. The rate of corrosion is usually determined by an equilibrium between opposing electrochemical reactions: anodic reaction and cathodic reaction. In anodic reaction, a metal is oxidized, releasing electrons into the metal. In cathodic reaction, a solution species is reduced, removing electrons from the metal. When these two reactions are in equilibrium state, the flow of electrons from each reaction is balanced so that no net electron flow (electrical current) is generated. The two reactions can occur on one metal or on dissimilar metals which are electrically connected [50]. 
Figure 2-10 shows the corrosion process involving anodic and cathodic current. The vertical axis is electrical potential and the horizontal axis is the logarithm of absolute current. The theoretical current for the anodic and cathodic reactions is measured as tangent of the curves. The curved line is the sum of the anodic and cathodic currents, which is the current that will be measured by sweeping the potential of the metal in electrochemical test. The sharp point in the curve indicates the point where anodic to cathodic reaction reverses. The sharp point is a result of plotting along a logarithmic axis. Since the current values varies significantly during a corrosion experiment, the use of a logarithmic axis is necessary [50].

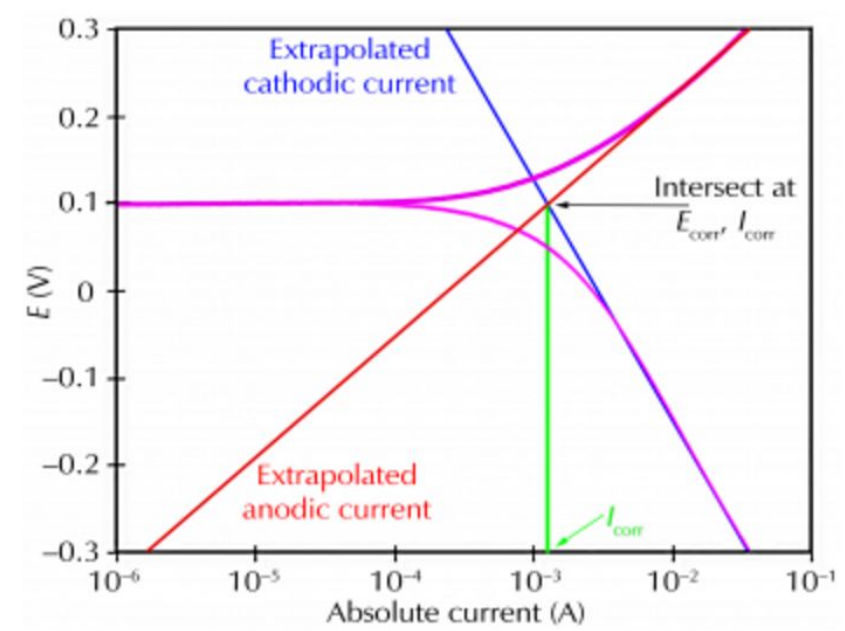

Figure 2-10 Corrosion process showing anodic and cathodic components of current [50]

The potential of a metal is determined when the anodic and cathodic reactions are kept in balance. The current from each half reaction is based on the electrochemical potential of the metal. If the anodic reaction releases too many electrons into the metal, extra electrons will shift the potential of the metal more negative, which slows the anodic reaction and speeds up the cathodic reaction. When there is no electrical connection to the metal, the equilibrium potential is called the opencircuit potential, $\mathrm{E}_{\text {oc. }}$ The value of either the anodic or cathodic current at $\mathrm{E}_{\mathrm{oc}}$ is called the corrosion current, $\mathrm{I}_{\text {corr. }} \mathrm{I}_{\text {corr }}$ could be used to calculate the corrosion rate of the metal. However, $\mathrm{I}_{\text {corr }}$ cannot 
be measured directly, while it can be estimated using electrochemical tests. Icorr and corrosion rate is determined by various parameters, such as type of metal, composition of the solution, temperature, metal history [50].

In electrochemical studies, a metal sample with a surface area of a few square centimeters is used to model the metal in a corrosive system. The metal sample is immersed in a specific solution, connected with additional electrodes. All the electrodes are connected to a device called a potentiostat, which allows you to change the potential of the metal sample in a controlled manner and measure the current corresponding to the applied potential. When the potential of a metal sample in solution is forced away from $E_{o c}$, the sample is polarizing. The current response of the metal sample is measured during the polarization process. The corrosion behavior can be modelled by analyzing the response [50].

\subsubsection{Tafel Analysis}

The corrosion current can be estimated current-voltage data. The measured data can fit to a theoretical model of the corrosion process. The model assumes that the rates of both the anodic and cathodic processes are controlled by the kinetics of the electron-transfer reaction at the metal surface. An electrochemical reaction under kinetic control follow the Tafel equation, as shown in Equation 2-2 [50].

$$
I=I_{0} e^{\frac{2.303\left(E-E_{0}\right)}{\beta}}
$$

In this equation, $\mathrm{I}$ is the current resulting from the reaction, $\mathrm{I}_{0}$ is a reaction-dependent constant called the exchange current, $E$ is the electrode potential, $E_{0}$ is the equilibrium potential, $\beta$ is the reaction's Tafel constant, which is constant for a given reaction with units of volts/decade. The Tafel equation describes the behavior of one isolated reaction, while there are two opposing 
reactions: anodic and cathodic reaction in a corrosion system. Thus, the Tafel equations for the anodic and cathodic reactions in a corrosion system can be combined to derive the Butler-Volmer equation, as shown in Equation 2-3 [50].

$$
I=I_{c o r r} e^{\frac{2.303\left(E-E_{c o r r}\right)}{\beta \alpha}}-e^{\frac{2.303\left(E-E_{c o r r}\right)}{\beta_{c}}}
$$

In this equation, I is the measured current from the cell, $\mathrm{I}_{\text {corr }}$ is the corrosion current, $\mathrm{E}$ is the electrode potential, $E_{\text {corr }}$ is the corrosion potential in volts, $\beta \alpha$ is the anodic $\beta$ Tafel constant in volts/decade, $\beta \mathrm{c}$ is the cathodic $\beta$ Tafel constant in volts/decade. A plot of log I versus $\mathrm{E}$ is called a Tafel plot. The Tafel plot in Figure 2-10 was generated from the Butler-Volmer equation [50].

Classic Tafel analysis is conducted by extrapolating the linear portions of a logarithmic current versus potential plot back to their intersection. An example of corrosion resistance test result is shown in Figure 2-10. The vertical axis is electrical potential and the horizontal axis is the logarithm of absolute current. The use of a logarithmic axis is necessary due to the wide range of current values that must be recorded during a corrosion test.

Corrosion rate (CR) can be calculated by measuring corrosion current, as shown in equation 2-3.

$$
C R=\frac{I_{c o r r} K \cdot E W}{d A}
$$

Where, $\mathrm{K}$ is a constant that defines the units for the corrosion rate, $\mathrm{EW}$ is the equivalent weight, $\mathrm{d}$ is density, A is sample area [50].

\subsubsection{Electrochemical Impedance Spectroscopy (EIS)}

Electrical resistance represents the ability of a circuit element to resist the flow of electrical current. But the resistance is limited to ideal resistor, which follows Ohm's Law at all current and voltage levels. The resistance value is independent of frequency. AC current and voltage signals though a 
resistor are in phase with each other. However, there are circuit elements that exhibit much more complicated behaviors. Impedance are introduced as a more general circuit parameter. Impedance is a measure of the ability of a circuit to resist the flow of electrical current, while it is not limited by the properties mentioned above. Electrochemical impedance is normally determined by applying an AC potential to an electrochemical cell and then measuring the current through the cell [51]. For example, if we apply a sinusoidal potential excitation, the response to this potential is an AC current signal. This current signal can be analyzed as a sum of sinusoidal functions.

EIS data are commonly analyzed by fitting to an equivalent electrical circuit model. The elements in the model includes resistors, capacitors and inductors. A schematic diagram of example equivalent circuit is shown in Figure 2-11.

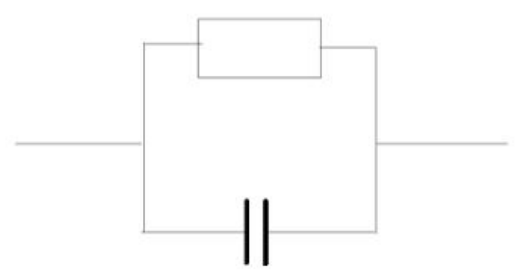

Figure 2-11 Simple Equivalent Circuit with One Time Constant [51]

Bode Plot is commonly used in EIS analysis. The impedance is plotted with log frequency on the $\mathrm{X}$-axis and both the absolute values of the impedance and the phase-shift on the Y-axis. An example bode plot is shown in Figure 2-12. 

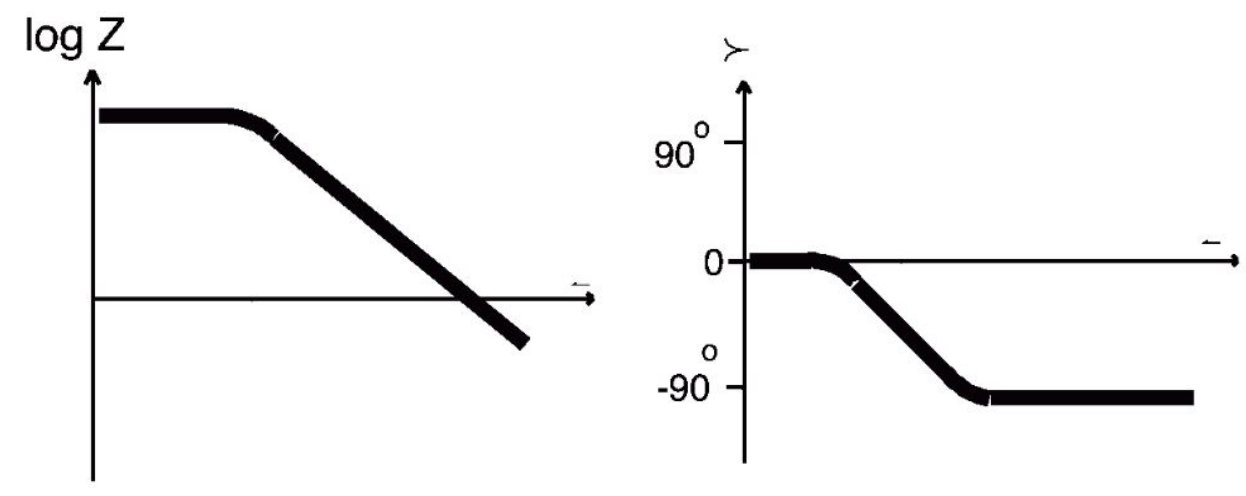

Figure 2-12 Bode plot with one time constant [51]

By fitting the bode plot, impedance of each element in equivalent circuit can be calculated. How individual factor that contributes or influence the corrosion behaviors can be discussed. 


\section{Chapter 3: Experimental Methods}

In this chapter, the experimental equipment, materials, characterization methods and performance test methods are presented. First, the set up and component functions of electrospark deposition are explained. Second, the materials information used in this study are presented. Third, the sample characterization methods, such as microstructure and composition analysis, are illustrated. Last, performance test methods, including mechanical test and corrosion resistance test are present in this chapter.

\subsection{Electro-Spark Deposition Setup}

The ESD machine was provided by Huys Industries Ltd. and modified in Center of Advance Materials Joining (CAMJ) at the University of Waterloo. The ESD machine components and setup are shown in Figure 3- 1.

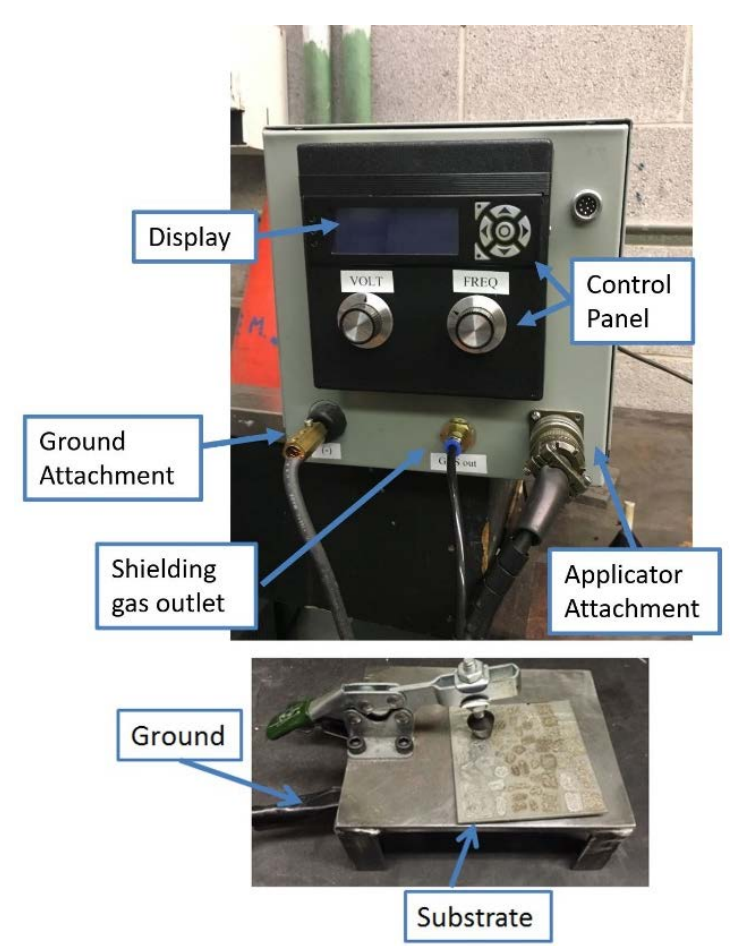

Figure 3-1 Electrospark Deposition setup 
The ESD machine has a control panel to change the electrical parameters including ESD voltage, capacitance and frequency. The electric parameters control range is shown in Table 3-1. These parameters can be displayed and monitored in real-time on the front screen. The ground attachment will connect with substrate by clamping to the substrate fixture. The ESD applicator connects to the shielding gas outlet and applicator attachment on the ESD machine. The rotation speed and direction can be controlled on the applicator. The shielding gas will come out from the shielding gas nozzle. In this study, shielding gas is ultra-pure Argon gas.

Table 3-1 ESD parameter range

\begin{tabular}{|c|c|c|c|}
\hline Parameter & Voltage & Capacitance & Frequency \\
\hline Range & $20 \mathrm{~V}-150 \mathrm{~V}$ & $10-310 \mu \mathrm{F}$ & $64 \mathrm{~Hz}-500 \mathrm{~Hz}$ \\
\hline
\end{tabular}

\subsection{Materials}

In this study, the substrate material is mainly 304 stainless steel with $1.2 \mathrm{~mm}$ thickness, supplied by McMaster Carr. The composition of the 304 stainless steel is shown in Table 3-2. DP980 steel and duplex stainless steel 2205 are also used for comparison experiments. The chemical composition of DP980 and 2205 is listed in and, respectively.

Table 3-2 Chemical composition of 304 stainless steel

\begin{tabular}{|c|c|c|c|c|c|c|}
\hline Element & $\mathrm{Cr}$ & $\mathrm{Ni}$ & $\mathrm{Fe}$ & $\mathrm{Mn}$ & $\mathrm{Si}$ & $\mathrm{C}$ \\
\hline Composition & $17.5-24 \%$ & $8-15 \%$ & $53.5-74.5 \%$ & $0-2 \%$ & $0-1 \%$ & $0-0.08 \%$ \\
\hline
\end{tabular}


Table 3-3 Chemical composition of DP980 steel

\begin{tabular}{|c|c|c|c|c|c|c|}
\hline Element & $\mathrm{Cr}$ & $\mathrm{Al}$ & $\mathrm{Mn}$ & $\mathrm{Si}$ & $\mathrm{C}$ & $\mathrm{Mo}$ \\
\hline Composition & $0.15 \%$ & $0.45 \%$ & $2.1 \%$ & $0.05 \%$ & $0.135 \%$ & 0.35 \\
\hline
\end{tabular}

Table 3-4 Chemical composition of duplex stainless steel 2205

\begin{tabular}{|c|c|c|c|c|c|c|}
\hline Element & $\mathrm{Cr}$ & $\mathrm{Ni}$ & $\mathrm{Fe}$ & $\mathrm{Mn}$ & $\mathrm{Mo}$ & $\mathrm{C}$ \\
\hline Composition & $22-23 \%$ & $4.5-6.5 \%$ & $63.7-70.4 \%$ & $0-2 \%$ & $3-3.5 \%$ & $0-0.03 \%$ \\
\hline
\end{tabular}

TiC, WC and Mo electrodes are used in this study, supplied by TechnoCoat Co., Ltd., Japan. The diameters of these electrodes are all 3mm. Cermet electrodes need some binding materials to be able to deposit onto conductive substrate. TiC electrode contains approximately $5 \%$ of $\mathrm{Ni}$ and WC electrode contains around 5\% Co as binding materials.

\subsection{Material Characterization Apparatus}

\subsubsection{Microscopy and EDS Analysis}

SEM analysis was carried out using a Jeol JSM 6460. Energy dispersive spectroscopy (EDS) analysis was performed with Oxford Instruments INCA-350 for elemental characterization. The coated samples were cross-sectioned with precision abrasive sawing and hot mounted in conductive mounting powder, supplied by TED PELLA, INC. The mounted samples were mechanically ground and polished with diamond suspended lubricant from $6 \mu \mathrm{m}$ to 1 um particle size. The EDS data are all shown in wt $\%$ in this study. 


\subsubsection{XRD Analysis}

XRD analysis was conducted with a PANalytical X'Pert PRO MPD equipment. Cu k-alpha X-ray source is generated with 1.54 angstrom wavelength. The samples were cut into $8 \mathrm{~mm}$ by $8 \mathrm{~mm}$ and ultrasonic cleaned in ethanol and deionized water. XRD data analysis was performed using JADE software which accompanies with the XRD equipment.

\subsubsection{XPS Analysis}

XPS analysis was performed with a Thermo-VG Scientific ESCALab-250 equipment. The sample preparation was the same with XRD analysis samples. The XPS data was analyzed using CasaXPS software which comes with the XPS equipment.

\subsection{Mechanical Testing}

\subsubsection{Micro-hardness Test}

Vickers micro-hardness profiles were obtained using a Wilson Vickers 402MVD automated hardness tester with 100-gram load and 15s dwell time. The test was performed by following ASTM E384-16 standard. Figure 3-2 shows a photo of the micro-hardness tester. The hardness indentations were spaced at least three diameters from one another to avoid interference from the strain fields of the previous indents. The sample preparation was the same as SEM samples. 


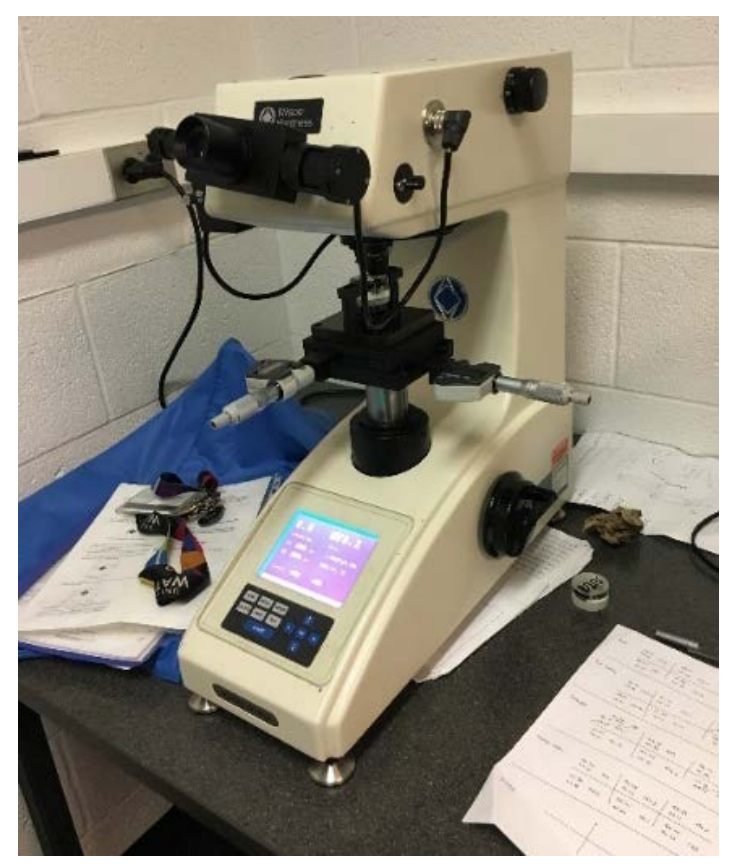

Figure 3-2 Wilson Vickers 402MVD micro-hardness tester

\subsubsection{Wear Resistance Test}

Wear Resistance test was conducted as per the ASTM-G65-04 standard (Measuring Abrasion Using the Dry Sand/Rubber Wheel) using Procedure C. Figure 3-3 (a) shows the schematic image of wear resistance test. The test is to evaluate resistance to scratching abrasion under a specified set of conditions. In this study, the wear resistance was evaluated by mass loss of the tested specimen. Figure 3-3 (b) shows the real experiment set up for wear test. 

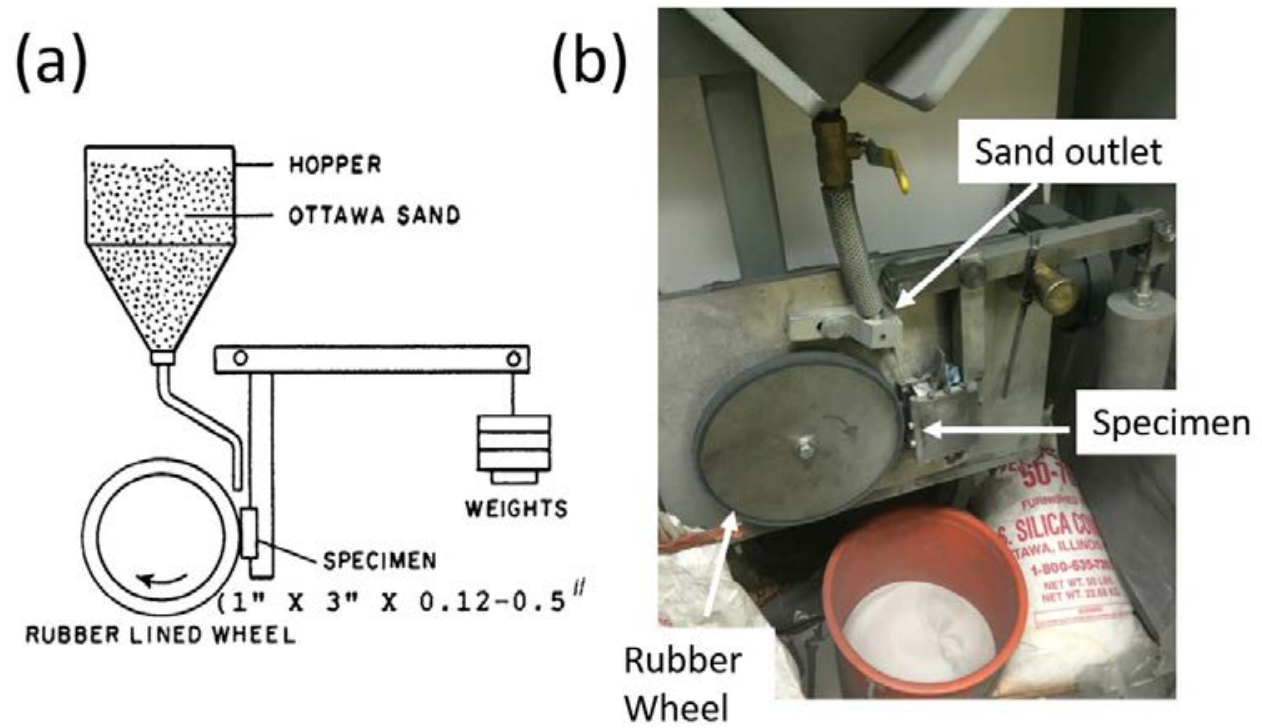

Figure 3-3 (a) Schematic diagram of wear test apparatus (b) Wear test set up

The abrasive used was Ottawa silica sand in a 50/70 mesh size (particle size is $212-300 \mu m$ in diameter) with an angular morphology. The sample size and wear test locations are displayed in Figure $3-4$. The whole sample is $25 \mathrm{~mm}$ by $103 \mathrm{~mm}$ and the wear tested area is $14 \mathrm{~mm}$ by $22 \mathrm{~mm}$. 304 stainless steel substrates were cut into the exact size to fit into the wear resistance test machine. ESD coatings were applied to the test location. To eliminate the effects of coating edges, the coated area is $2 \mathrm{~mm}$ larger than the tested area. The samples were ultrasonic cleaned in ethanol and deionized water before wear resistance test. Procedure $C$ applies 100 revolutions of the abrasive wheel with $130 \mathrm{~N}$ load on the wheel. 

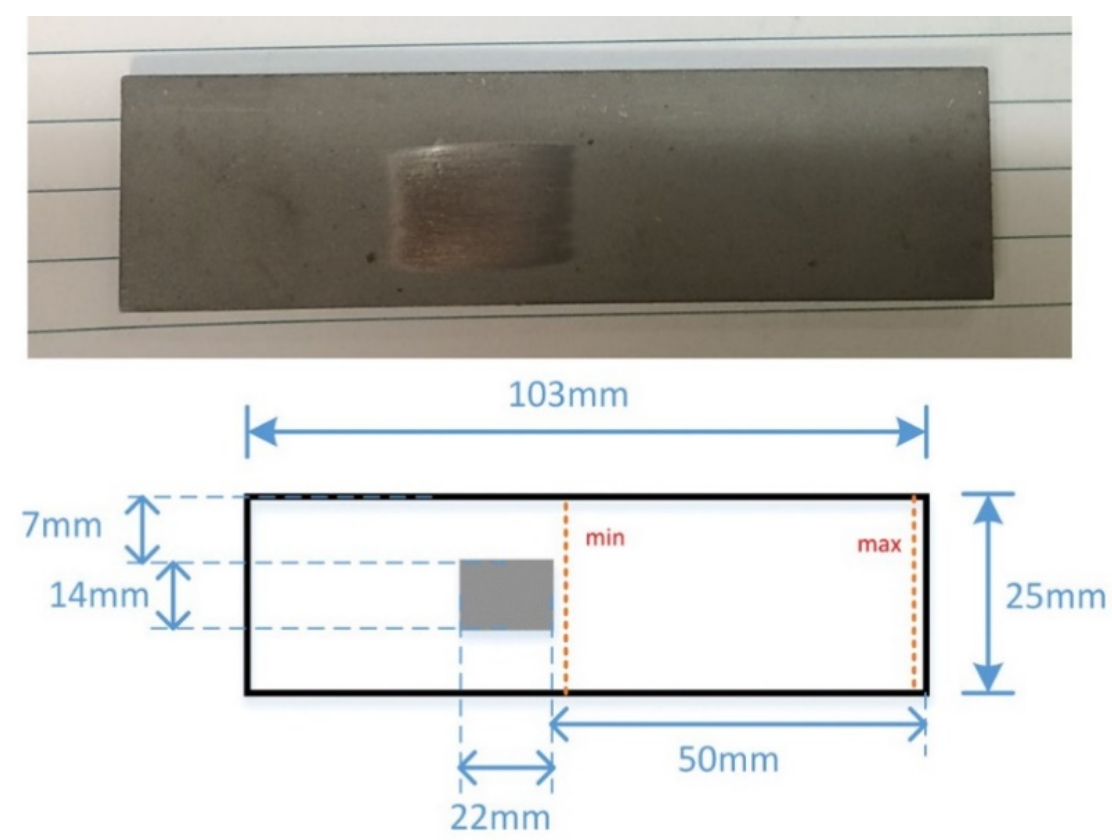

Figure 3-4 Sample dimension for wear resistance test

The wear resistance was evaluated by mass loss of the tested samples. The weight of sample was tested before and after wear test. The sample was ultrasonic cleaned before weighing on the balance. According the standard, procedure $\mathrm{C}$ requires a sensitivity of $0.0001 \mathrm{~g}$. So in these tests, the weight values were rounded to 4 decimal places.

\subsection{Corrosion Resistance Testing}

Electrochemical tests were performed using a Gamry Series G300 Potentiostat to evaluate the samples corrosion resistance. The schematic diagram of the electrochemical tests set up is shown in Figure 3-5. 


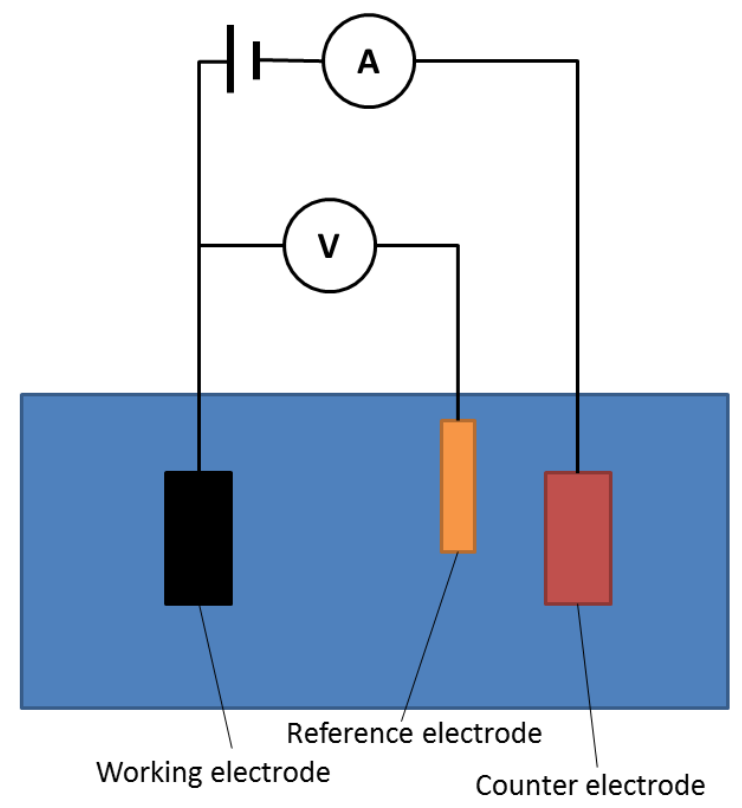

Figure 3-5 Schematic diagram of corrosion resistance test set up

In this study, $\mathrm{Ag} / \mathrm{AgCl}$ electrode was employed as the reference electrode due to its stable, welldefined electrochemical potential. Pure platinum wire was used as the counter electrode and the sample was set up as the working electrode. Oxygen is an electrochemically active gas. The reduction of oxygen can act as the cathodic half reaction in a corrosion reaction. Bubbling nitrogen was introduced to the electrochemical cell to remove oxygen from the test solution. The components and experiment set up are shown in Figure 3-6. The first image shows the real experiment set up for electrochemical test. Working electrode, reference electrode, counter electrode as well as the nitrogen outlet were fit into an electrochemical cell. The cell was then filled up with testing solution. The following images show the individual component used in the experiment. The testing sample was fixed inside the working electrode. 


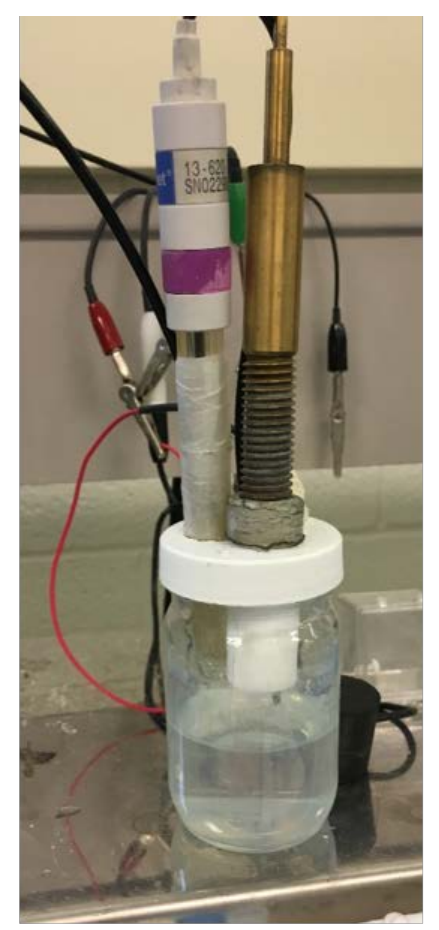

Electrochemical cell

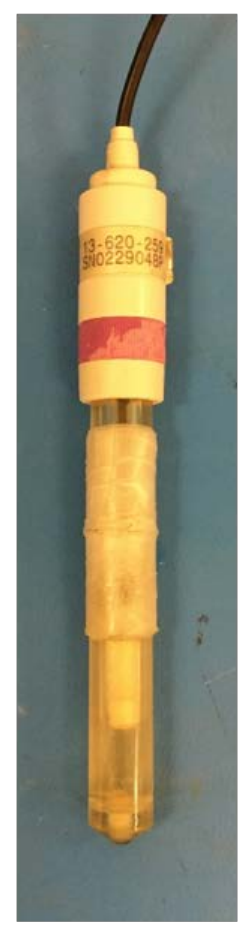

Reference Working Electrode

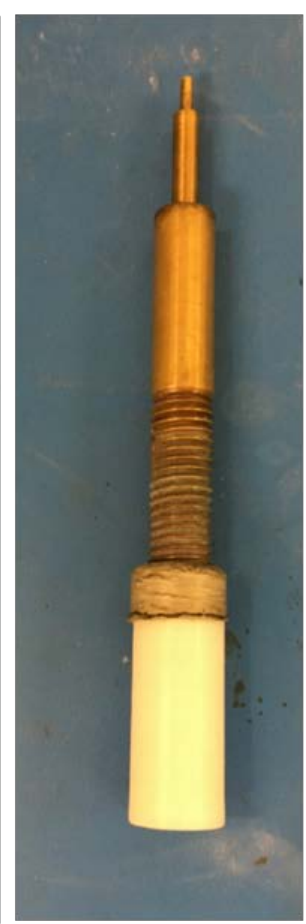

Electrode

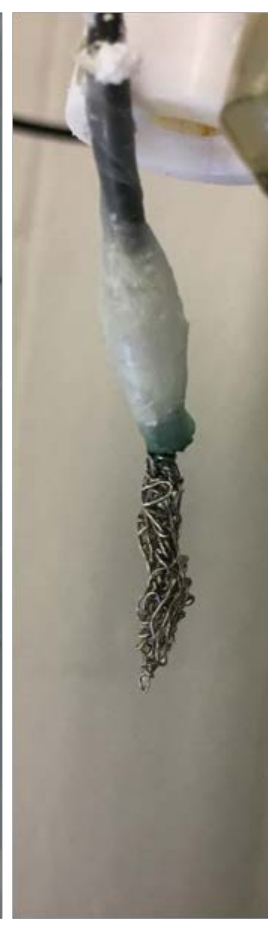

Counter Electrode

Figure 3-6 Electrochemical experiment component and set up

The solution was $5 \% \mathrm{NaCl}$ for all the electrochemical tests in this study. The size of testing sample was $9 \mathrm{~mm}$ by $9 \mathrm{~mm}$. The samples were ultrasonic cleaned in ethanol and deionized water before electrochemical test. The equipment was connected to a computer and the experiment was controlled by Gamry Instruments Software. The electrochemical data was analyzed by Echem Analyst software.

\subsubsection{Tafel Test}

Corrosion normally occurs at a rate determined by an equilibrium between anodic reaction and cathodic reaction. An example of corrosion resistance test result is shown in Figure 2-11. The vertical axis is electrical potential and the horizontal axis is the logarithm of absolute current. The 
use of a logarithmic axis is necessary due to the wide range of current values that must be recorded during a corrosion test.

Classic Tafel analysis is performed by extrapolating the linear portions of a logarithmic current versus potential plot back to their intersection. The value of anodic and cathodic current at the intersection is corrosion current $\mathrm{I}_{\text {corr. }}$. The corrosion rate can then be calculated with $\mathrm{I}_{\text {corr. }}$. The Tafel test parameters are listed in Table 3-5.

Table 3-5 Tafel test parameters

\begin{tabular}{|c|c|c|c|c|c|}
\hline Parameter & Scan Rate & Test Area & $\begin{array}{c}\text { Stabilisation } \\
\text { Time }\end{array}$ & $\begin{array}{c}\text { Initial } \\
\text { Potential }\end{array}$ & $\begin{array}{c}\text { Final } \\
\text { Potential }\end{array}$ \\
\hline Setting & $0.5 \mathrm{mV} / \mathrm{s}$ & $0.25 \mathrm{~cm}^{2}$ & $60 \mathrm{~min}$ & $-0.3 \mathrm{~V}$ & $0.3 \mathrm{~V}$ \\
\hline
\end{tabular}

\subsubsection{EIS Analysis}

Electrochemical impedance is measured by applying an AC potential to an electrochemical cell and then measuring the current through the cell. The EIS test parameters are listed in Table 3-6.

Table 3-6 EIS test parameters

\begin{tabular}{|c|c|c|c|c|c|}
\hline Parameter & AC Voltage & Test Area & $\begin{array}{c}\text { Stabilisation } \\
\text { Time }\end{array}$ & $\begin{array}{c}\text { Initial } \\
\text { Frequency }\end{array}$ & $\begin{array}{c}\text { Final } \\
\text { Frequency }\end{array}$ \\
\hline Setting & $10 \mathrm{mV} \mathrm{rms}$ & $0.25 \mathrm{~cm}^{2}$ & $60 \mathrm{~min}$ & $10000 \mathrm{~Hz}$ & $0.01 \mathrm{~Hz}$ \\
\hline
\end{tabular}




\section{Chapter 4: Characterization of ESD Coated Stainless Steel}

The approach to modify 304 stainless steel surface by ESD is discussed in this chapter. Three different coating materials, TiC, WC and Mo were employed in this study. The processing window, effects of shielding gas are presented. SEM, EDX and XRD analysis are carried out to characterize the microstructure of the coated sample. Mechanical properties such as wear resistance, microhardness are investigated. Electro-chemical performance such as corrosion resistance is also discussed in this chapter.

\subsection{Electro-Spark Deposition on 304 Stainless Steel}

\subsubsection{Processing Window}

Electrical parameters, such as ESD voltage, capacitance and frequency are critical for ESD coatings. When the power is low, no coating was found on the substrate surface. The rough surface was caused by etching effect of ESD process, while the power is not enough to melt electrode material. On the other hand, if the power input is too high, the electrode will get over heat which may form burnt deposition or big chunk of molten metal. Figure 4-1 shows an example of ESD coating morphology under proper power input.

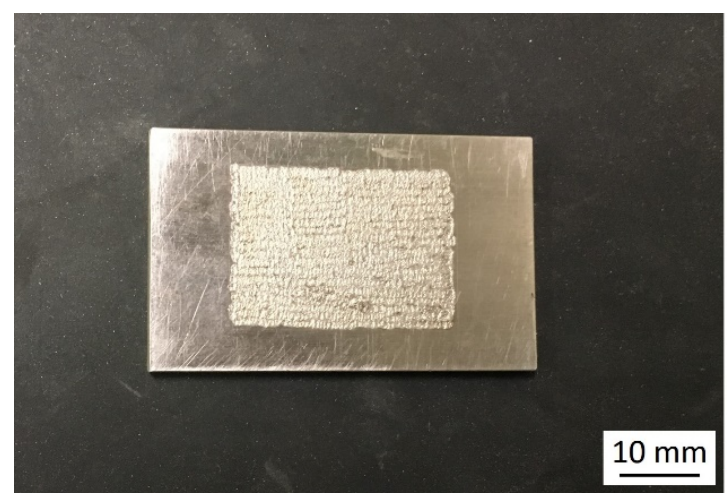

Figure 4-1 Macroscopic images of ESD coated steel 
The optimized parameters may vary significantly on different material combinations. A serial of experiments was carried out to find the processing window for depositing TiC, WC and Mo on 304 stainless steel by ESD. The tested operation window for these three coatings is listed in Table $4-1$.

Table 4-1 Operation window of TiC, WC and Mo coating on stainless steel by ESD

\begin{tabular}{|c|c|c|c|}
\hline Coating & TiC & WC & Mo \\
\hline Operation & $35 \mathrm{~V}, 280-300 \mu \mathrm{F}, 75-150 \mathrm{~Hz}$ & $35 \mathrm{~V}, 100-300 \mu \mathrm{F}, 150-850 \mathrm{~Hz}$ & $35 \mathrm{~V}, 150-300 \mu \mathrm{F}, 120-260 \mathrm{~Hz}$ \\
Window & $85 \mathrm{~V}, 100-150 \mu \mathrm{F}, 120-360 \mathrm{~Hz}$ & $85 \mathrm{~V}, 40-150 \mu \mathrm{F}, 150-1100 \mathrm{~Hz}$ & $85 \mathrm{~V}, 40-300 \mu \mathrm{F}, 120-360 \mathrm{~Hz}$ \\
& $135 \mathrm{~V}, 10-30 \mu \mathrm{F}, 120-260 \mathrm{~Hz}$ & $135 \mathrm{~V}, 10-40 \mu \mathrm{F}, 120-1100 \mathrm{~Hz}$ & $135 \mathrm{~V}, 10-120 \mu \mathrm{F}, 120-360 \mathrm{~Hz}$ \\
\hline Optimized & $85 \mathrm{~V}, 120 \mu \mathrm{F}, 260 \mathrm{~Hz}$ & $85 \mathrm{~V}, 100 \mu \mathrm{F}, 260 \mathrm{~Hz}$ & $85 \mathrm{~V}, 150 \mu \mathrm{F}, 260 \mathrm{~Hz}$ \\
Parameters & & & \\
\hline
\end{tabular}

\subsubsection{Shielding Gas}

The gas atmosphere of ESD process has significant effects on the coating qualities. Firstly, the interaction between the spark and gas is quite different, which could change the mass transfer process. Figure 4-2 displays the surface morphology of TiC coating deposited in Ar and air. It's obvious that the coating in Ar shielding gas was more likely formed from fine spray, while the coating in air was likely formed from molten droplet. With same parameters, the roughness of the coating in Ar is much less than that in air. 

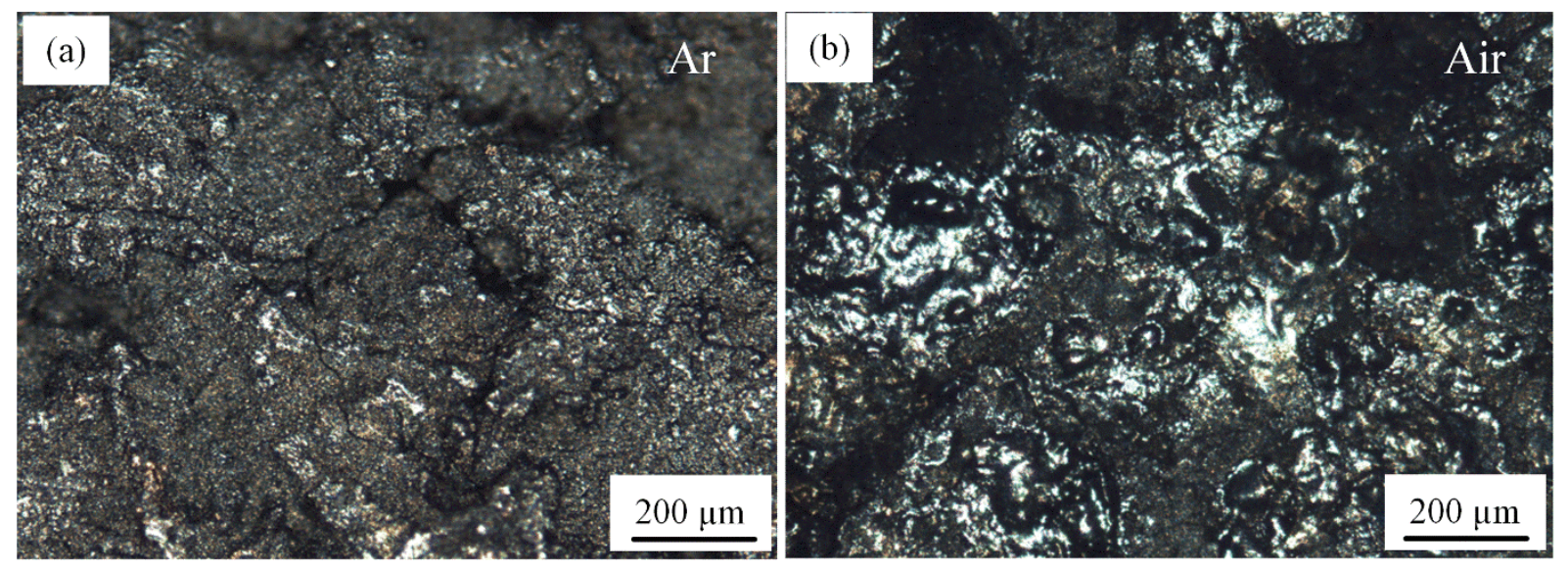

Figure 4-2 Optical microscope images of ESD TiC in different atmosphere (a) Ar (b) Air

Secondly, the shielding gas has different cooling effect on the electrode and substrate. Overheat phenomenon is much easier to occur for ESD in air, with the same electrical parameters. Heat generated during ESD process could further affect mass transfer rate and coating quality. Thirdly, oxidation of the coating material could significantly affect the coating composition, and introduce defects such as cracks and porosities.

Overall, in ESD process, proper shielding gas could contribute to better coating quality with finer coating roughness, much less oxidization and defects. In this study, all the ESD experiments were carried out under Ar shielding gas.

\subsection{Microstructure}

Figure 4-3 shows the SEM images of TiC, WC and Mo coatings on 304 stainless steel substrate by ESD. The deposition time are all 2 mins with the optimized parameters shown in Table 4-1. 

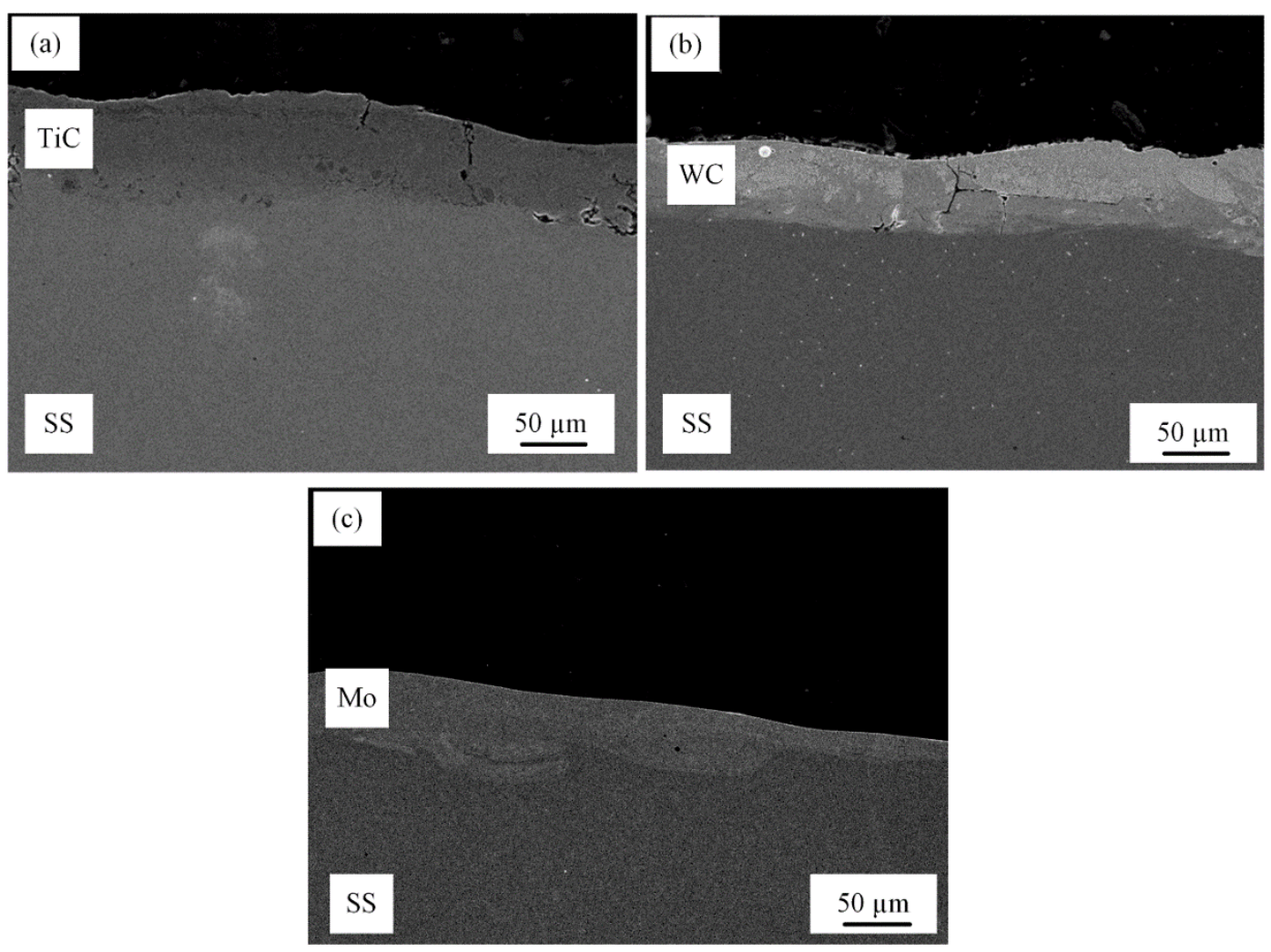

Figure 4-3 SEM image of ESD coated stainless steel (a) TiC (b) WC (c) Mo

Figure 4-3 (a) and (b) show very few transverse cracks and porosities in the TiC and WC coatings. No major cracks are found at the interface between coating and stainless steel substrate. The contrast variations in WC coating indicate the coating composition is not uniform. It should be noted that there are no major defects in Mo coating, as shown in Figure 4- 2 (c). The Mo coating is more uniform and the surface roughness is relatively low compared with other two coatings.

EDX test was conducted to analyse the coating composition. Figure 4-4 shows EDX results of TiC coated 304 stainless steel. The points in Figure 4-4 (a) indicates the testing location and Figure 44 (b) shows the corresponding composition data. It can be seen that Ti content is decreasing from the coating surface into the substrate while the elements in base metal is increasing in to the substrate. There is very little Fe content on the coating surface, which means TiC coating has good barrier effect to stop stainless steel diffusing to the coating surface. 


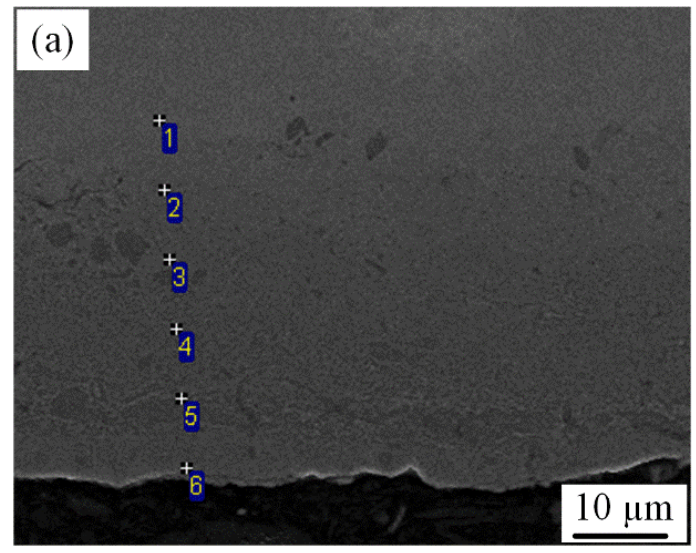

(b)

Figure 4-4 EDX results of TiC coated stainless steel

(a) The points indicate testing location (b) Corresponding composition data

Figure 4-5 shows EDX results of WC coated stainless steel. The content of all the elements are relatively constant compared to TiC coating. There are some bright areas in the WC coating and spectrum 6 indicates that the bright area is pure WC. It can be concluded from the EDX results that the electrode material and substrate material are randomly mixed together. The heat generated in the ESD process can only melt the binding material, but cannot melt WC. This explains why there are many WC blocks in the coating area. In addition, there are considerable amounts of Fe detected on the coating surface, so WC cannot provide a barrier layer for stainless steel.

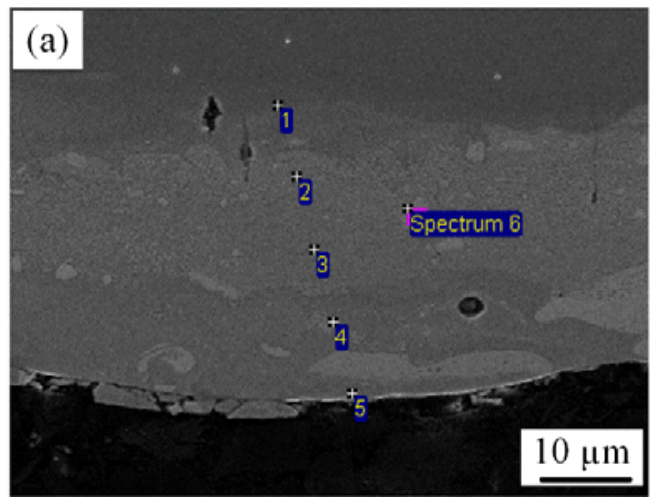

\begin{tabular}{|c|c|c|c|c|}
\hline Spectrum & $\mathrm{Cr}$ & $\mathrm{Fe}$ & $\mathrm{Ni}$ & W \\
\hline 1 & 19.43 & 62.36 & 5.20 & 13.01 \\
\hline 2 & 8.65 & 32.21 & 5.22 & 53.92 \\
\hline 3 & 10.33 & 41.34 & 3.38 & 44.95 \\
\hline 4 & 9.06 & 35.26 & 5.49 & 50.19 \\
\hline 5 & 10.14 & 36.88 & 7.40 & 45.57 \\
\hline 6 & & & & 100.00 \\
\hline
\end{tabular}

Figure 4-5 EDX results of WC coated stainless steel

(a) The points indicate testing location (b) Corresponding composition data 
Figure 4-6 shows EDX results of Mo coated stainless steel. It can be found that the Mo content is relatively constant from the coating surface into the substrate. The coating is quite uniform and no major cracks and porosities are found. From phase diagram, Mo can easily react with Fe and Cr to form various alloys. As a result, ESD of Mo on stainless steel can be considered as a surface alloying process.

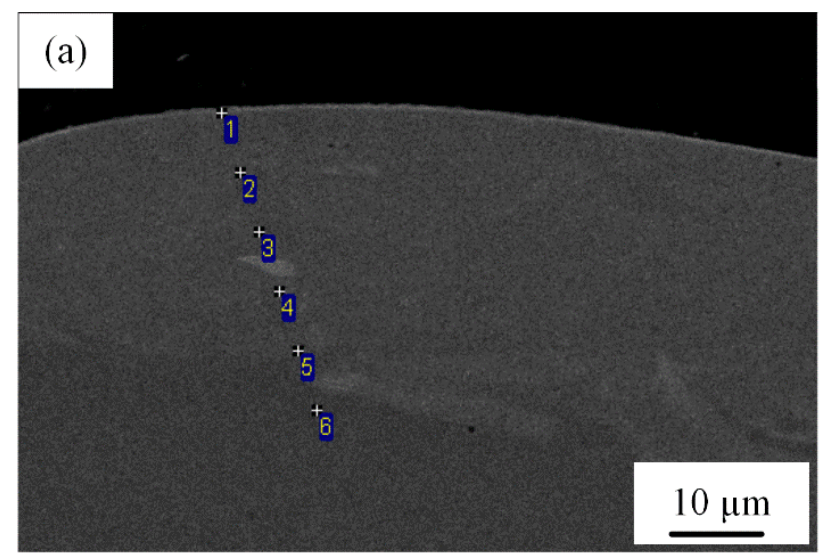

(b)

\begin{tabular}{|c|c|c|c|}
\hline Spectrum & $\mathbf{C r}$ & Fe & Mo \\
\hline $\mathbf{1}$ & 13.31 & 53.14 & $\mathbf{3 3 . 5 5}$ \\
\hline $\mathbf{2}$ & 11.54 & 52.17 & $\mathbf{3 6 . 2 9}$ \\
\hline $\mathbf{3}$ & 11.43 & 51.54 & $\mathbf{3 7 . 0 3}$ \\
\hline $\mathbf{4}$ & 12.86 & 49.30 & $\mathbf{3 7 . 8 4}$ \\
\hline $\mathbf{5}$ & 13.19 & 65.52 & 21.29 \\
\hline $\mathbf{6}$ & 19.19 & 80.81 & \\
\hline
\end{tabular}

Figure 4-6 EDX results of Mo coated stainless steel

(a) The points indicate testing location (b) Corresponding composition data

\subsection{Mechanical Properties of Surface Modified 304 Stainless Steel}

\subsubsection{Micro-hardness}

Micro-Hardness test results are shown in Figure 4-7. The plots display the micro-hardness change with the distance to coating surface. The average coating hardness and improvement over base metal are shown in Table 4-2. The micro-hardness of cermet coatings TiC and WC are more than five times harder than base metal 304 stainless steel. While the Mo coating doubled the hardness of base metal. 

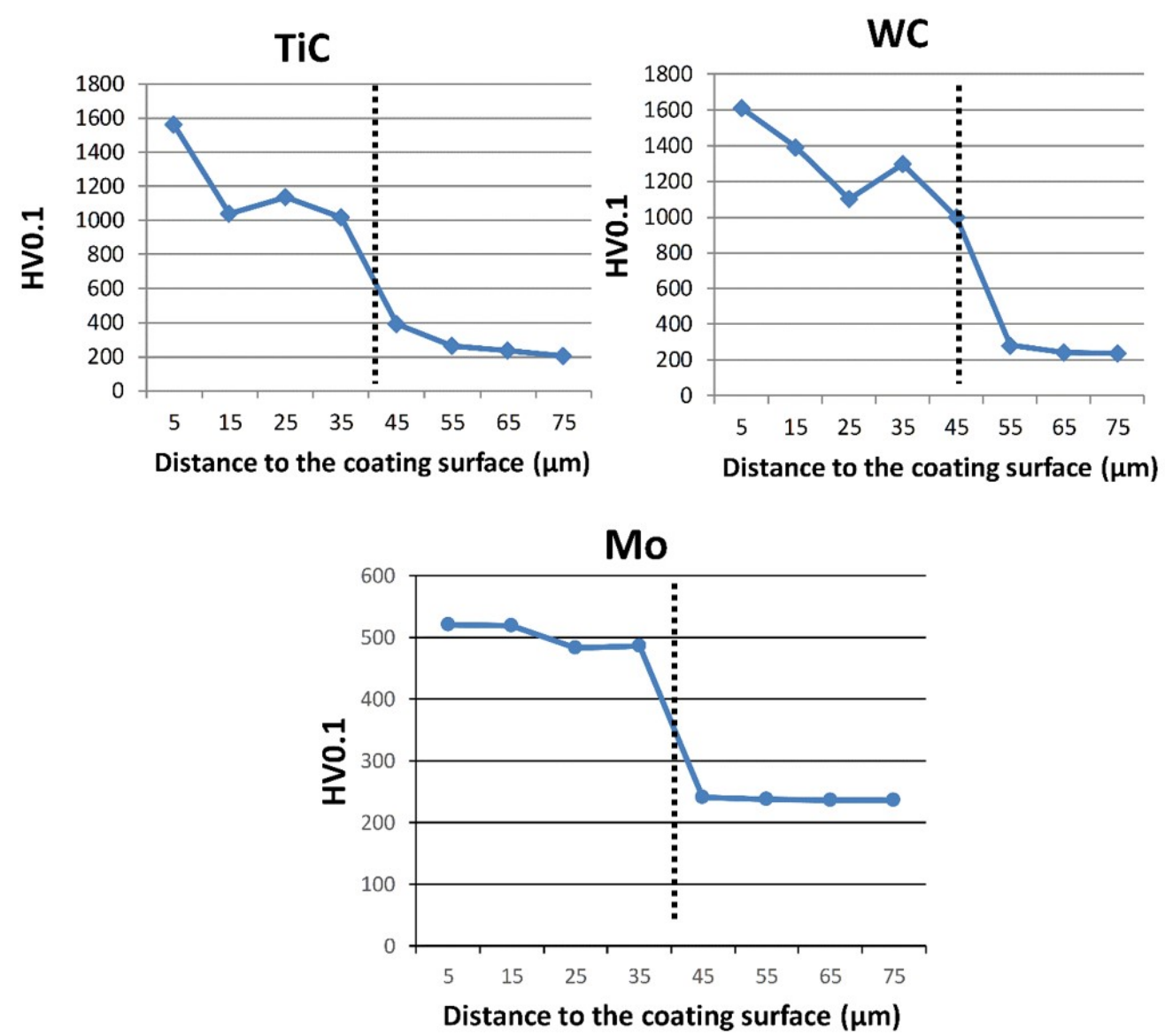

Figure 4-7 Micro-hardness results of coated stainless steel (dashed lines indicates the location of interface)

Table 4-2 Micro-hardness of different coatings

\begin{tabular}{|c|c|c|c|c|}
\hline HV0.1 & TiC & WC & Mo & SS \\
\hline Average & 1188.5 & 1279.8 & 502.0 & 237.5 \\
\hline $\begin{array}{c}\text { Increase over } \\
\text { base metal }\end{array}$ & $500 \%$ & $539 \%$ & $211 \%$ & - \\
\hline
\end{tabular}




\subsubsection{Wear Resistance}

Figure 4-8 shows wear resistance test results of TiC, WC and Mo coated stainless steel. In this study, wear resistance is evaluated by mass loss. The quantitative results are listed in Table 4-3. In these three coatings, WC exhibits the best wear resistance which is more than 5 times better than that of base metal. TiC and Mo coating is 2.5 times better than stainless steel.

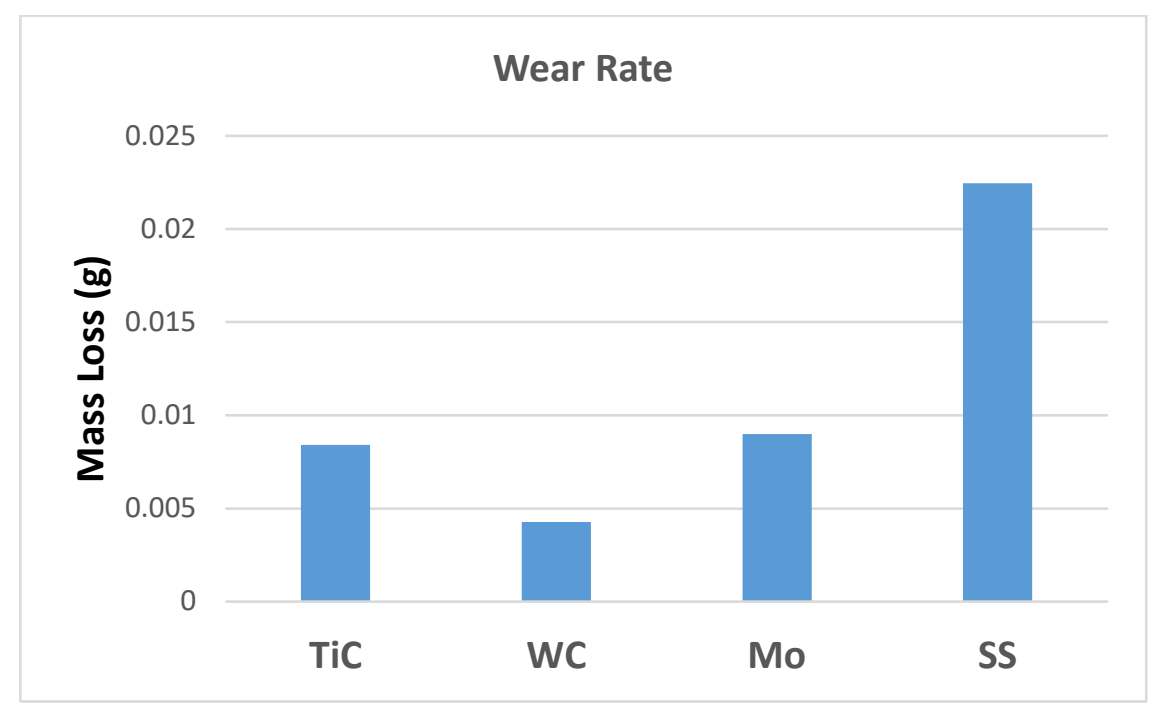

Figure 4-8 Wear resistance results of ESD coated stainless steel

Table 4-3 Mass loss of different ESD coated stainless steel

\begin{tabular}{|c|c|c|c|c|}
\hline Mass Loss (mg) & TiC & WC & Mo & SS \\
\hline Average & 8.41 & 4.27 & 9.00 & 22.45 \\
\hline Reduction in \\
wear rate
\end{tabular}




\subsection{Corrosion Resistance of Surface Modified 304 Stainless Steel}

\subsubsection{Tafel test}

Tafel test is a commonly used electro-chemical method to evaluate corrosion resistance. Figure 49 shows the Tafel plot of base metal 304 stainless steel in $5 \% \mathrm{NaCl}$ solution. Two dashed lines are the fitting tangents of the Tafel curve. The corrosion voltage and corrosion current can be derived for the intersection of the two tangents. The green line indicates the value of corrosion current. The calculated value of corrosion current and voltage are shown in Table 4-4.

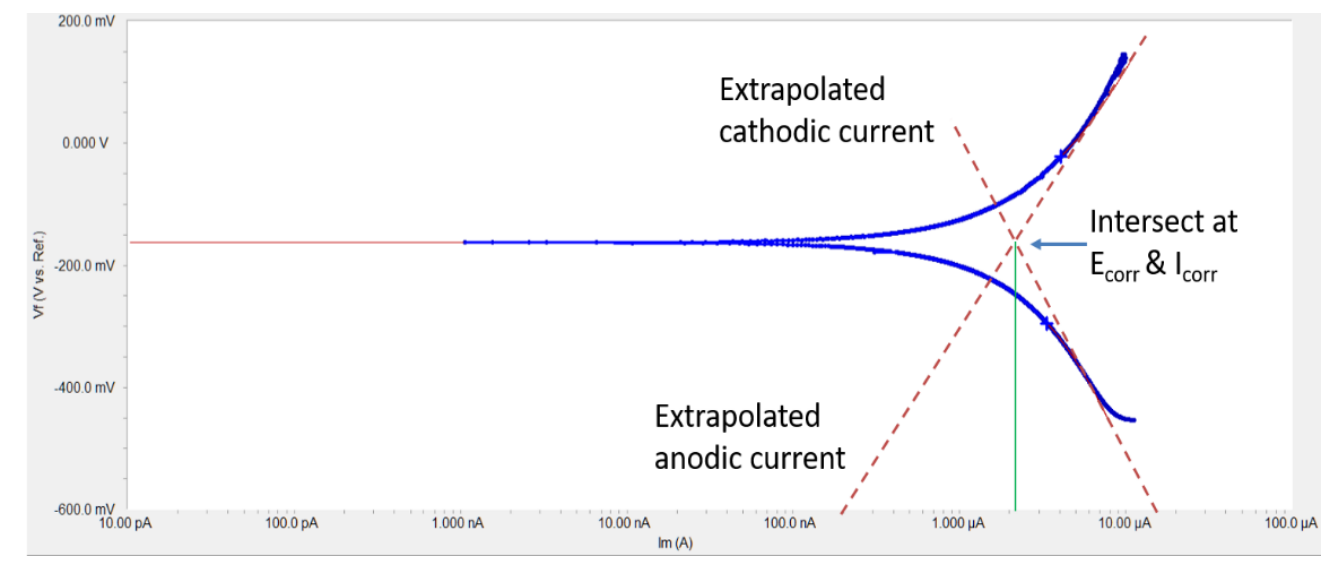

Figure 4-9 Tafel analysis of stainless steel in $5 \% \mathrm{NaCl}$ solution

Table 4-4 Tafel analysis of stainless steel in $5 \% \mathrm{NaCl}$ solution

\begin{tabular}{|c|c|c|}
\hline Tafel & Ecorr $_{\text {(mV) }}$ & I $_{\text {corr }}$ (A) \\
\hline Stainless Steel & -163 & $2.90 \times 10^{-6}$ \\
\hline
\end{tabular}

Tafel tests for TiC, WC and Mo coated samples in $5 \% \mathrm{NaCl}$ solution were also investigated using the same method. The Tafel plots are shown in Figure 4-10. As demonstrated above, the corrosion current and voltage are determined by fitting two tangents to the Tafel plot. Ideally, the sample 
with better corrosion resistance should have a Tafel curve on the top left. It can be seen from Figure 4-10 that Mo coated stainless steel has the best corrosion resistance.

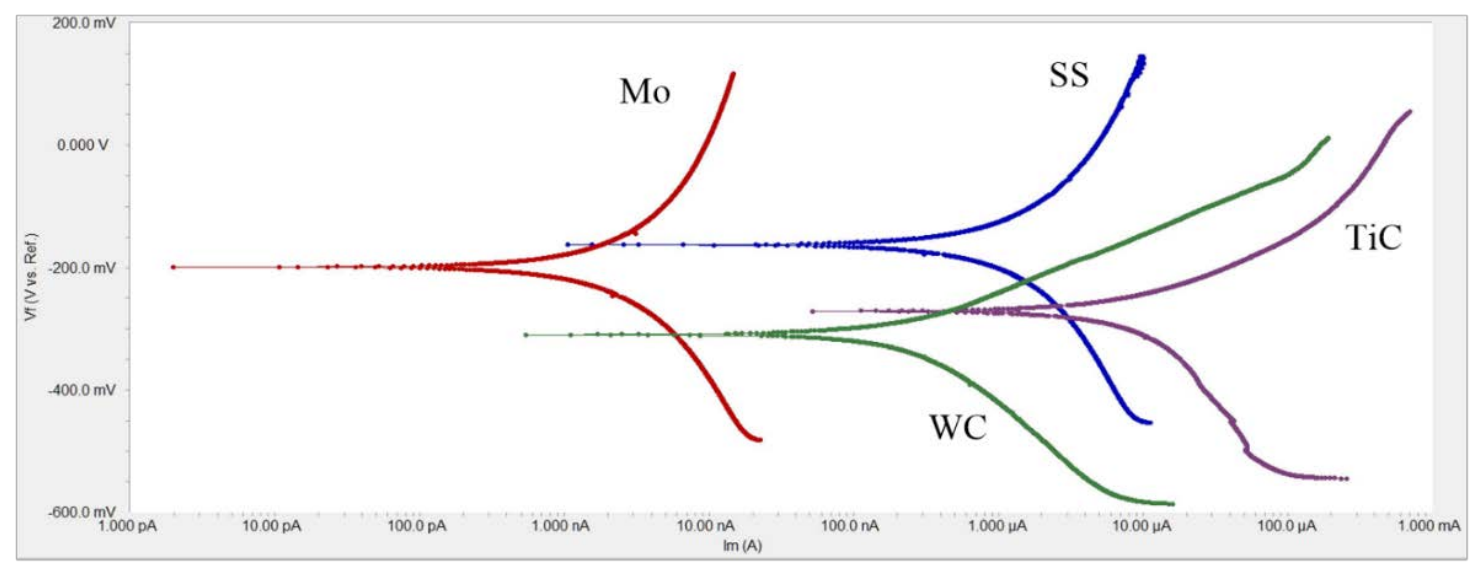

Figure 4-10 Tafel test results of ESD coated stainless steel in 5\% NaCl solution

The measured corrosion voltage, corrosion current and calculated corrosion rate are listed in Table 4-5. It should be noted that Mo coated sample has a much lower corrosion current, which makes it corrodes more than 350 times slower than that of base metal stainless steel. WC coating exhibits nearly 10 times better corrosion resistance than base metal. In comparison, the TiC coating does not show promising results on corrosion resistance.

Table 4-5 Tafel analysis of ESD coated stainless steel in $5 \% \mathrm{NaCl}$ solution

\begin{tabular}{|c|c|c|c|c|}
\hline Tafel & SS & Mo & TiC & WC \\
\hline $\mathbf{E}_{\text {corr }}(\mathbf{m V})$ & -163 & -199 & -272 & -309 \\
\hline $\mathbf{I}_{\text {corr }}(\mathbf{A})$ & $2.90 \times 10^{-6}$ & $8.18 \times 10^{-9}$ & $9.39 \times 10^{-6}$ & $2.93 \times 10^{-7}$ \\
\hline CR (mpy) & 14.89 & $4.20 \times 10^{-2}$ & 48.21 & 1.505 \\
\hline
\end{tabular}




\subsubsection{EIS analysis}

To investigate the corrosion behavior of coated stainless steel, EIS analysis was carried out. EIS analysis employs equivalent circuit to fit the measured curve. The equivalent circuit can be designed and modified based on specific material structures. Figure 4-11 shows a schematic image of the constant phase element (CPE) equivalent circuit. $\mathrm{R}_{\mathrm{s}}$ represents the resistance of solution and $\mathrm{R}_{\mathrm{p}}$ is the polarization resistance of the tested sample.

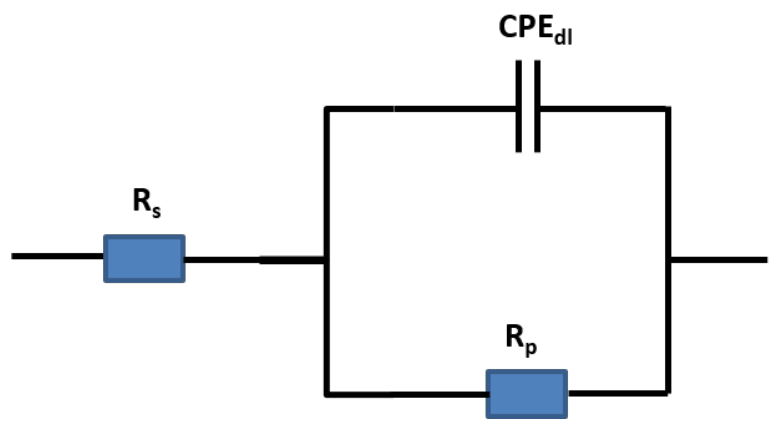

Figure 4-11 Schematic image of CPE equivalent circuit

The polarization resistance can be calculated by fitting the bode plot curve, as shown in Figure 412 and Figure 4-13. The calculated polarization resistance is listed in Table 4-6.

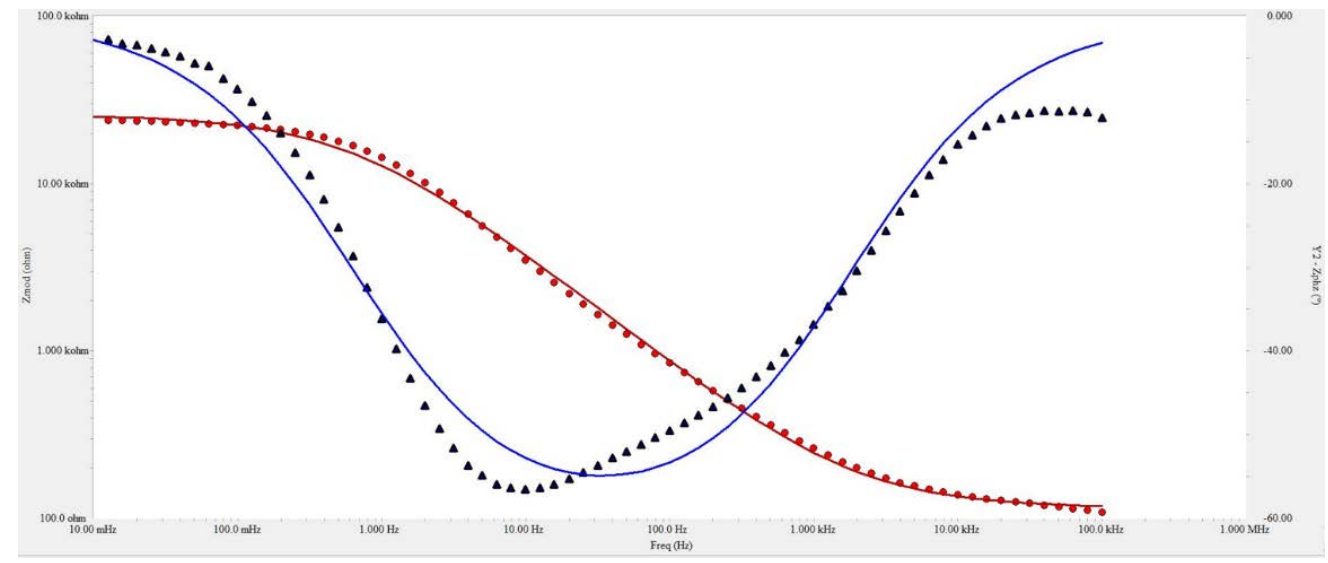

Figure 4-12 Bode plot of EIS spectra of 304 stainless steel 


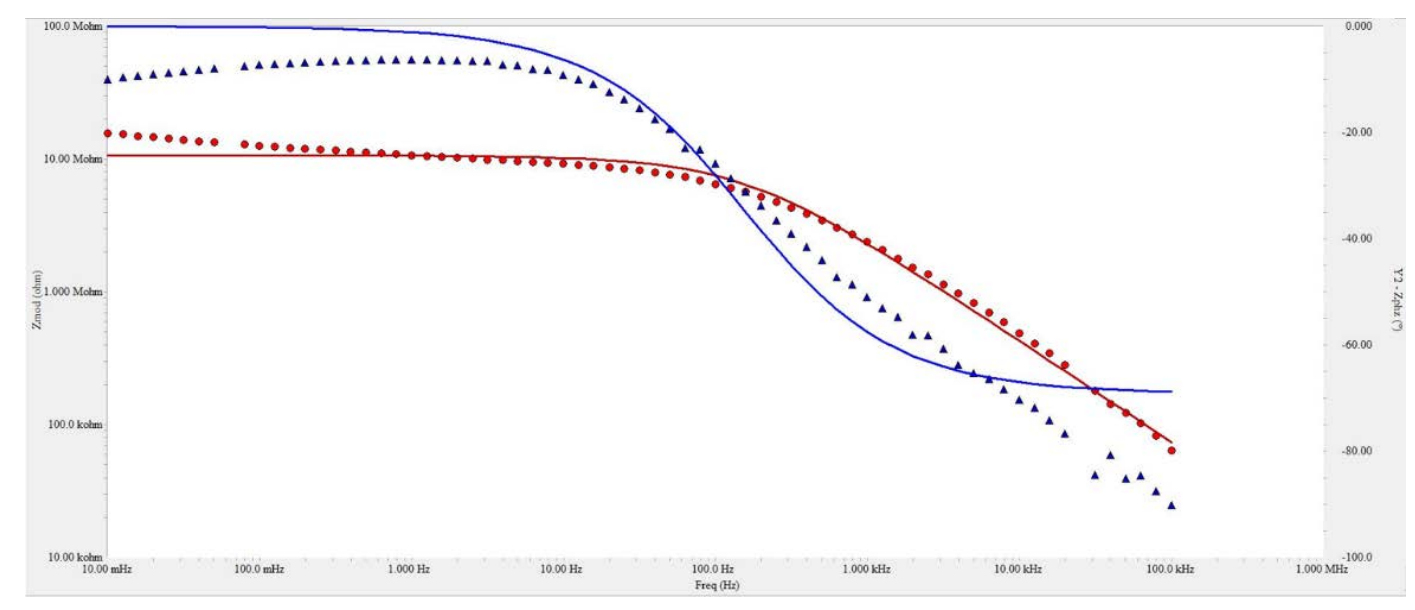

Figure 4-13 Bode plot of EIS spectra of Mo coated stainless steel

Table 4-6 EIS results with CPE equivalent circuit

\begin{tabular}{|c|c|c|c|c|}
\hline EIS & SS & Mo & TiC & WC \\
\hline Polarization & $2.579 \times 10^{4}$ & $1.070 \times 10^{7}$ & 215.7 & 437.0 \\
Resistance (omh) & & & & \\
\hline
\end{tabular}

From EIS results, it's clear that the polarization resistance of Mo coated sample is nearly 3 magnitudes larger than that of stainless steel. The high polarization resistance contributes to low corrosion rate and thus Mo coated sample has much better corrosion resistance.

\subsubsection{Detail tests for Molybdenum coated stainless steel}

XRD analysis were conducted to characterize the phase transformation after ESD of Mo. XRD pattern of base metal 304 stainless steel is shown in Figure 4-14. The XRD pattern displays that 304 stainless steel is mainly austenite structure ( $\gamma$ phase). Two $\alpha$ phase peaks indicate there is some ferrite structure in the base metal. 


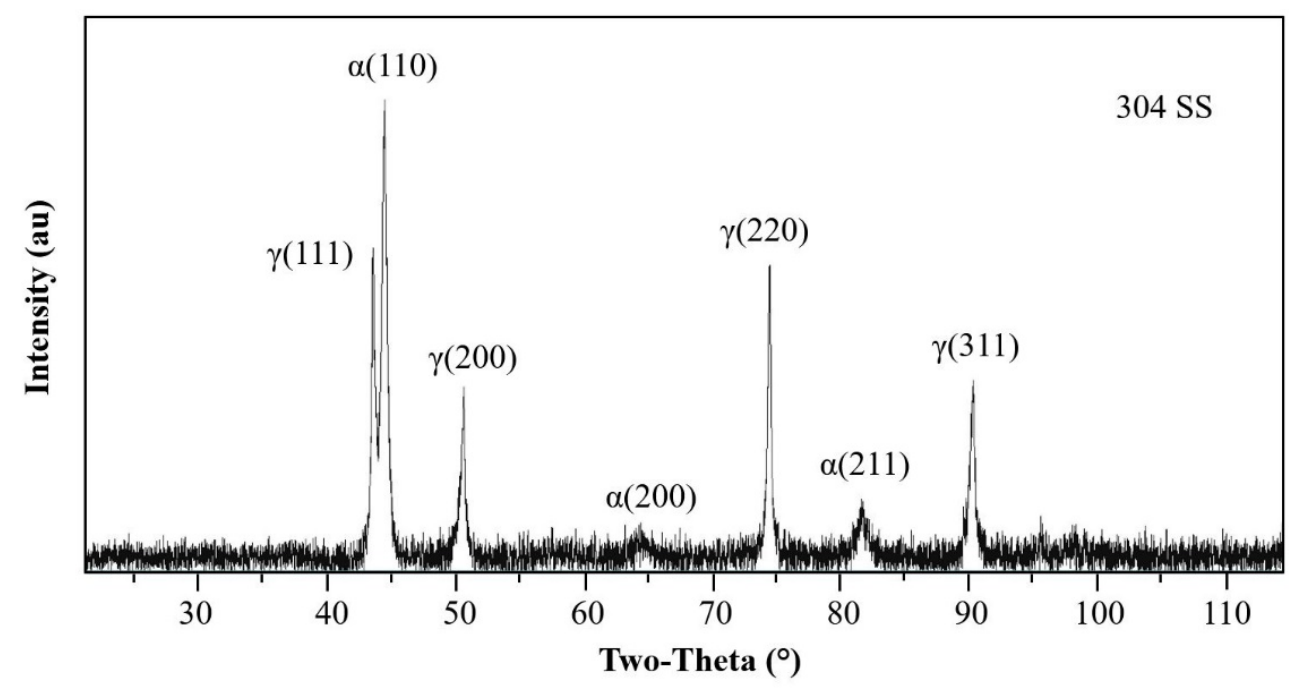

Figure 4-14 XRD pattern of 304 stainless steel

Figure 4-15 is the XRD pattern of Mo coated 304 stainless steel. The relative intensity of austenite structure ( $\gamma$ phase) peaks decrease, while ferrite structure ( $\alpha$ phase) peaks significantly increase. This data indicates that Mo is mainly alloyed with 304 stainless steel, instead of existing as pure Mo. The results indicate the phase transformation from austenite to ferrite after ESD of Mo.

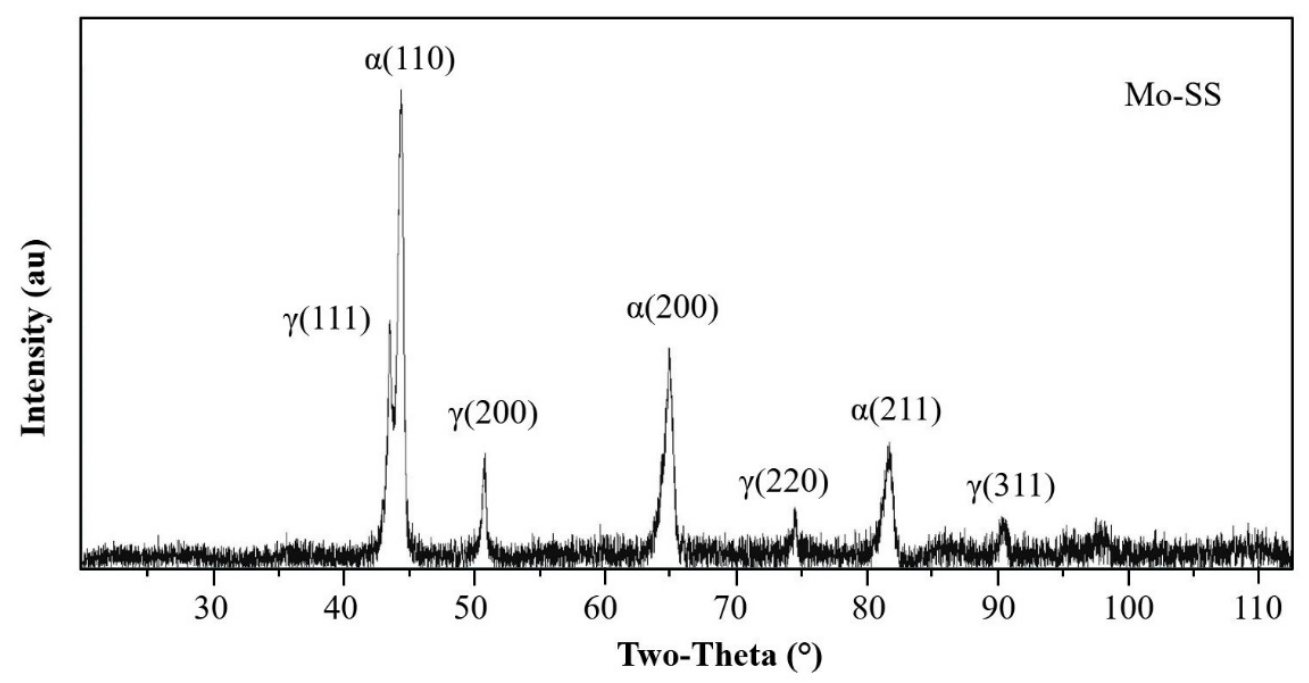

Figure 4-15 XRD pattern of Mo coated 304 stainless steel 
Surface roughness is an important factor that can affect corrosion behavior. A Mo coated sample got grinding on 1200 grit grinding paper for 30 second was tested to see the roughness influence on corrosion behavior. The Tafel test result is shown in Figure 4-16. It can be found that the sample after grinding has even better corrosion resistance than as deposited sample. After grinding over 2 mins, there are some uncovered areas which means some coating is gone during grinding process.

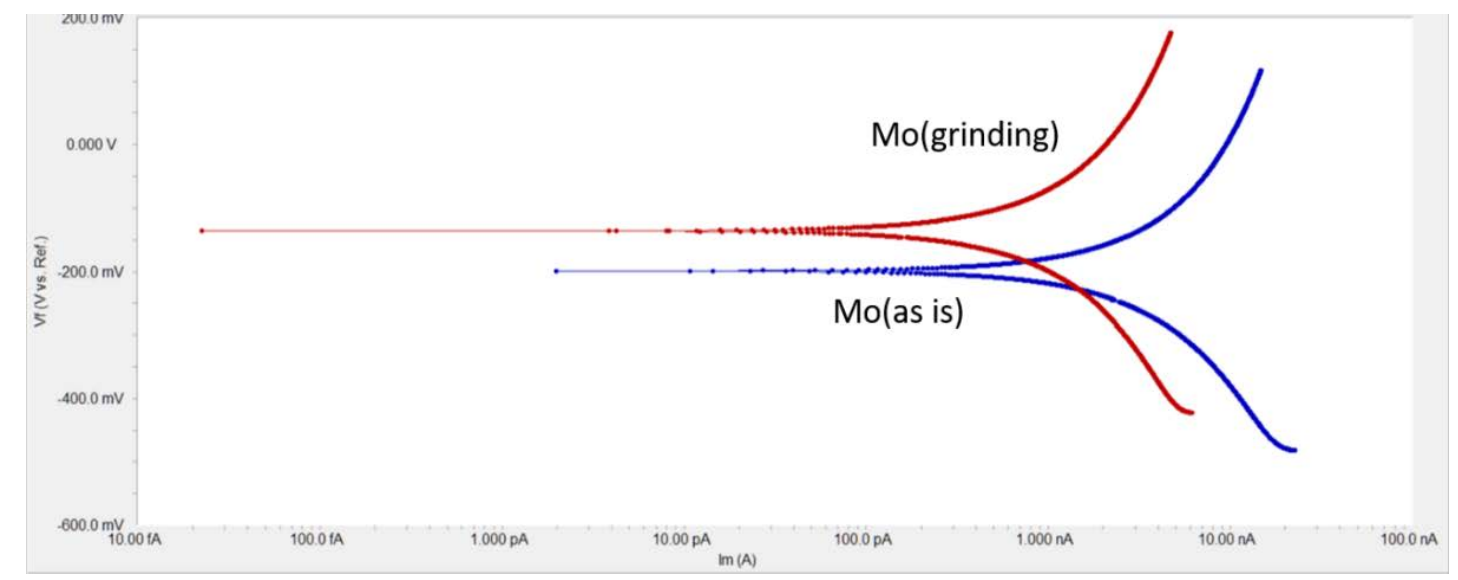

Figure 4-16 Effect of surface roughness on corrosion resistance of Mo coated stainless steel

The calculated corrosion rates are listed in Table 4-7. It can be seen that Mo coated sample after grinding corrodes nearly 2 times slower than as deposited sample. The surface of as-deposited sample was not flat, as shown in microstructure analysis. Grinding the sample surface could get rid of some residual debris and make the surface smoother than that of as deposited sample. The lower surface roughness could contribute to better corrosion resistance. The mechanical grinding has to be precisely performed due to the thin coating thickness. Over grinding would end up losing all the coated layers. 
Table 4-7 Effect of surface roughness on Tafel results of Mo coated stainless steel

\begin{tabular}{|c|c|c|}
\hline Tafel & Mo (as is) & Mo (grinding) \\
\hline $\mathbf{E}_{\text {corr }}(\mathbf{m V})$ & -199 & -136 \\
\hline $\mathbf{I}_{\text {corr }}$ (A) & $8.18 \times 10^{-9}$ & $4.12 \times 10^{-9}$ \\
\hline CR (mpy) & $4.20 \times 10^{-2}$ & $2.11 \times 10^{-2}$ \\
\hline
\end{tabular}

Duplex stainless steel 2205 is considered as a benchmark of commercial material for high corrosion resistance. In order to evaluate how good is the Mo coated stainless steel, Tafel test was also carried out for 2205 duplex stainless steel for comparison. The Tafel test result is shown in Figure 4-17.

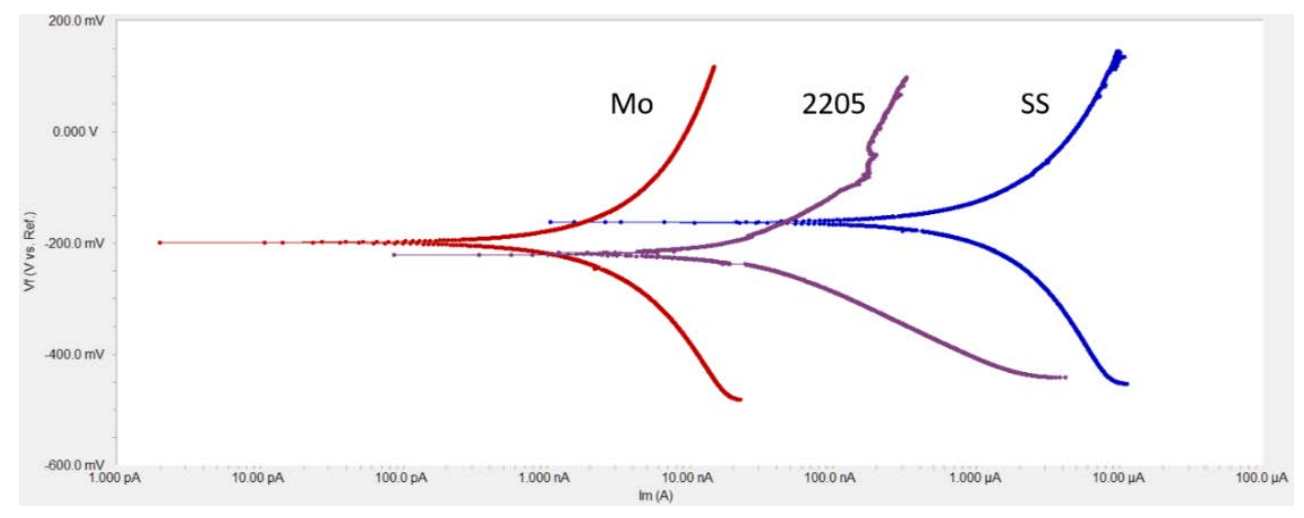

Figure 4-17 Tafel test of 2205 duplex stainless steel

It can be seen from the Tafel test results that Mo coated stainless steel exhibit better corrosion resistance compared to benchmark 2205 duplex stainless steel. The quantitative results are listed in Table 4-8. The result shows that the corrosion resistance of Mo coated stainless steel is nearly four times better than that of duplex 2205. 
Table 4-8 Tafel test results of 2205 duplex stainless steel

\begin{tabular}{|c|c|c|c|}
\hline Tafel & SS & Mo & $\mathbf{2 2 0 5}$ \\
\hline $\mathbf{E}_{\text {corr }}(\mathbf{m V})$ & -163 & -199 & -219 \\
\hline $\mathbf{I}_{\text {corr }}(\mathbf{A})$ & $2.90 \times 10^{-6}$ & $8.18 \times 10^{-9}$ & $3.20 \times 10^{-8}$ \\
\hline CR (mpy) & 14.89 & $4.20 \times 10^{-2}$ & 0.165 \\
\hline
\end{tabular}

Mo is considered as an effective alloy element to improve corrosion resistance. ESD of Mo on 304 stainless steel has exhibited significant improvement of corrosion resistance in $\mathrm{NaCl}$ solution. It's necessary to figure out if the ESD approach applies to other steels. A series of experiments were conducted to investigate the compatibility of Mo coated steel.

Figure 4-18 shows the Tafel tests of Mo coated DP980 steel. Corrosion resistance tests of DP980 and 304 stainless steel are also shown here for comparison. Mo coated DP980 did not show much improvement on corrosion resistance. The Tafel tests results are listed in Table 4-9.

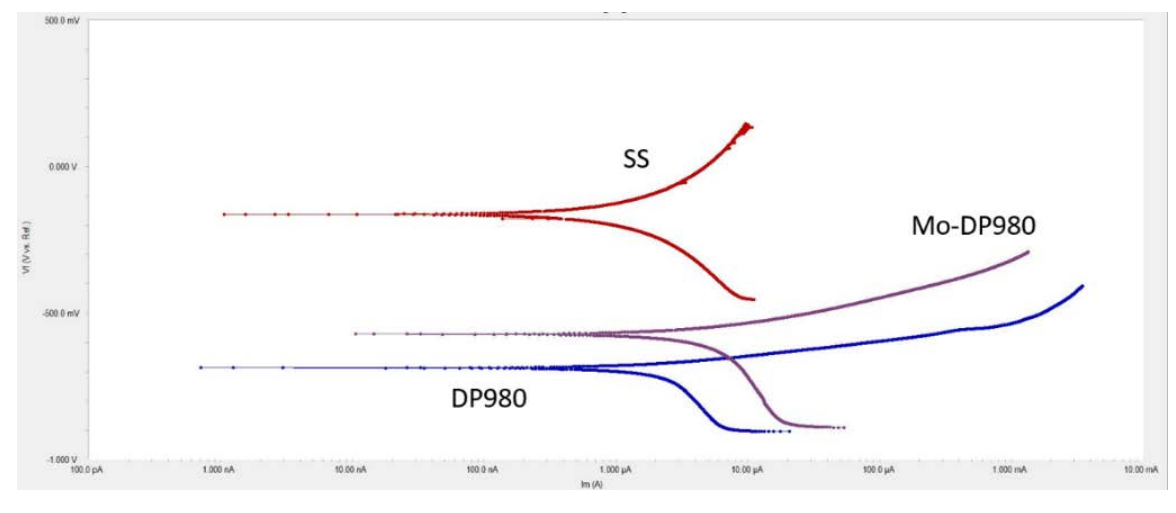

Figure 4-18 Tafel test of Molybdenum coated DP980 steel 
Table 4-9 Tafel test results of Molybdenum coated DP980 steel

\begin{tabular}{|c|c|c|c|}
\hline Tafel & SS & DP980 & Mo-DP980 \\
\hline $\mathbf{E}_{\text {corr }}(\mathbf{m V})$ & -163 & -687 & -572 \\
\hline $\mathbf{I}_{\text {corr }}(\mathbf{A})$ & $2.90 \times 10^{-6}$ & $3.34 \times 10^{-6}$ & $4.89 \times 10^{-6}$ \\
\hline CR (mpy) & 14.89 & 17.13 & 25.2 \\
\hline
\end{tabular}

DP980 exhibits much lower corrosion potential than 304 stainless steel, which means it has more tendency to dissolve in an electrolyte. Mo coated DP980 shows higher corrosion potential. However, the corrosion rate of Mo coated DP980 also increases, which may be attributed to the coating roughness and defects.

Corrosion resistance of Mo coated duplex stainless steel 2205 is also investigated, as shown in Figure 4-17. It is obvious that Mo coated sample has lower corrosion potential and higher corrosion current, which indicates the corrosion resistance of Mo coated sample is much worse than uncoated sample. The Tafel test results are listed in Table 4-10. The calculated corrosion rate of Mo coated 2205 is approximately 1000 time faster than that of base metal 2205.

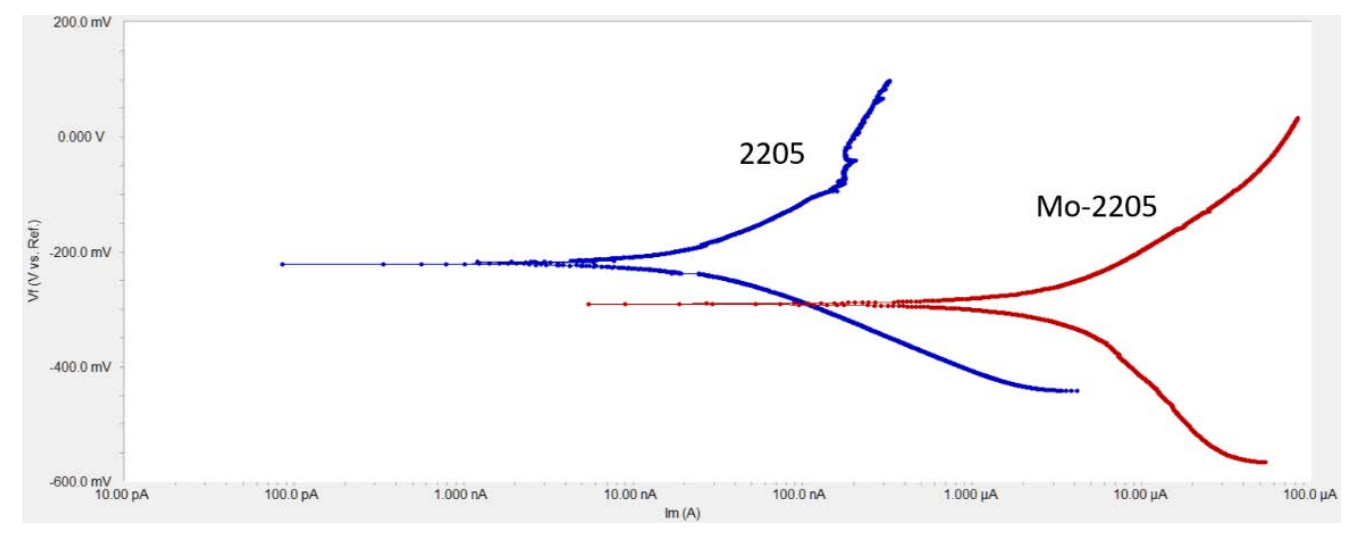

Figure 4-19 Tafel test of Molybdenum coated 2205 duplex stainless steel 
Table 4-10 Tafel test results of Molybdenum coated 2205 duplex stainless steel

\begin{tabular}{|c|c|c|}
\hline Tafel & $\mathbf{2 2 0 5}$ & Mo-2205 \\
\hline $\mathbf{E}_{\text {corr }}$ (mV) & -219 & -199 \\
\hline $\mathbf{I}_{\text {corr }}(\mathbf{A})$ & $3.20 \times 10^{-8}$ & $3.17 \times 10^{-5}$ \\
\hline CR (mpy) & 0.165 & 163.4 \\
\hline
\end{tabular}

Overall, surface alloying Mo into 304 stainless steel is an effective approach to dramatically increase the corrosion resistance of the base metal. However this method is not applicable for other steel like DP980 and duplex stainless steel 2205.

\subsection{Summary}

In this chapter, the processing window of stainless steel surface modification by ESD is presented. The microstructure and mechanical performance of TiC, WC and Mo coating on stainless steel are discussed. Coating quality, morphology and elemental analysis are investigated with SEM and EDX. TiC and WC coatings dramatically increase the micro-hardness of 304 stainless steel. WC coating improves the wear resistance of stainless steel by more than 5 times, while $\mathrm{TiC}$ and Mo coatings also improve it by 2.5 times. Mo coating exhibits significant improvement on corrosion resistance in $\mathrm{NaCl}$ solutions, which corrodes 350 times slower than stainless steel. TiC coating also increases the corrosion resistance with 10 times slower corrosion rate. WC coating does not show improvement on the corrosion resistance. It is suggested that WC is not well alloyed and saturated in the coating layer, which could decrease the corrosion resistance. EIS tests has shown the polarization resistance of Mo coated sample is much larger than that of base metal stainless 
steel. XRD analysis indicate the phase transformation from austenite to ferrite after ESD of Mo. Lower surface roughness can contribute to higher corrosion resistance. The surface alloying of Mo approach to increase corrosion resistance cannot apply to other steels like DP980 and duplex stainless steel 2205. 


\section{Chapter 5: Effects of Heat Treatment on Microstructure and}

\section{Corrosion Resistance}

The Molybdenum coated 304 stainless steel exhibits significant improvement on corrosion resistance in $\mathrm{NaCl}$ solution. The microstructure analysis indicates the surface layer contains more than $30 \%$ of Molybdenum, which may make it not in a stable status. Heat treatment of the Molybdenum coated sample is carried out to investigate the effect of heat treatment on microstructure and corrosion resistance. Heat treatment in different temperature under both air and Ar atmosphere are discussed. Some previous research showed a sensitizing temperature range, from $450^{\circ} \mathrm{C}$ to $850^{\circ} \mathrm{C}$, for Mo alloyed stainless steel. During this temperature range, carbide precipitation may be formed at the grain boundaries, which will be vulnerable to intergranular attack in corrosive environment. In this chapter, heat treatment of Mo coated stainless steel at $400^{\circ} \mathrm{C}, 650^{\circ} \mathrm{C}$ and $900^{\circ} \mathrm{C}$ for 1 hour respectively are discussed. EIS analysis results are presented to explain the corrosion behavior changes after heat treatment.

\subsection{Microstructure of Heat Treated Samples}

\subsubsection{EDX Analysis}

SEM and EDX analysis were carried out to characterize coating morphology and composition change after heat treatment. Figure 5-1 (a) shows SEM results of Mo coated stainless steel after heat treatment in air at $400^{\circ} \mathrm{C}$ for 1 hour. The points indicate the EDX test locations and the EDX results are shown in Figure 5-1 (b). Figure 4-6 indicates that the as-deposited Mo coating is approximately $40 \mu \mathrm{m}$. While after heat treatment at $400^{\circ} \mathrm{C}$ in air, no obvious change is found on the Mo coating thickness. EDX results show that Mo content is slightly higher than that of as- 
deposited sample in some areas. This may be attributed to the diffusion of alloy elements. Since ESD is a non-equilibrium process, more than $30 \%$ of Mo is alloy on the surface which makes it an unstable status. With heat treatment, atom redistribution may occur to lower the energy of the sample.

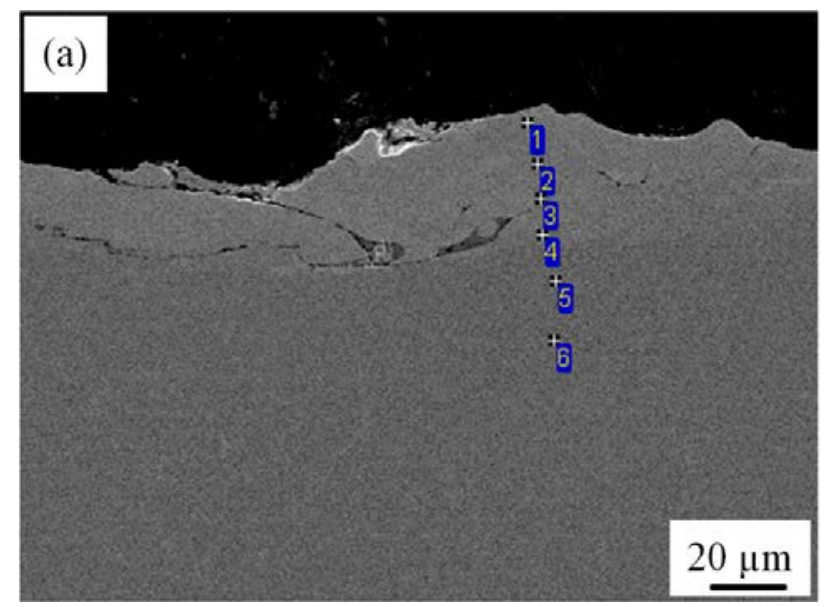

(b)

Figure 5-1 EDX results of Mo coated stainless steel after heat treatment in air at $400^{\circ} \mathrm{C}$

(a) The points indicate testing location (b) Corresponding composition data

Figure 5-2 shows the SEM and EDX results of Mo coated stainless steel after heat treatment in Ar at $400^{\circ} \mathrm{C}$ for 1 hour. Like the one heat treated in air, no obvious change on coating thickness is found. However, it should be noted that some areas have very high Mo content, up to 79\%. The different with heat treatment in air may be attributed to oxidation of the coating. 


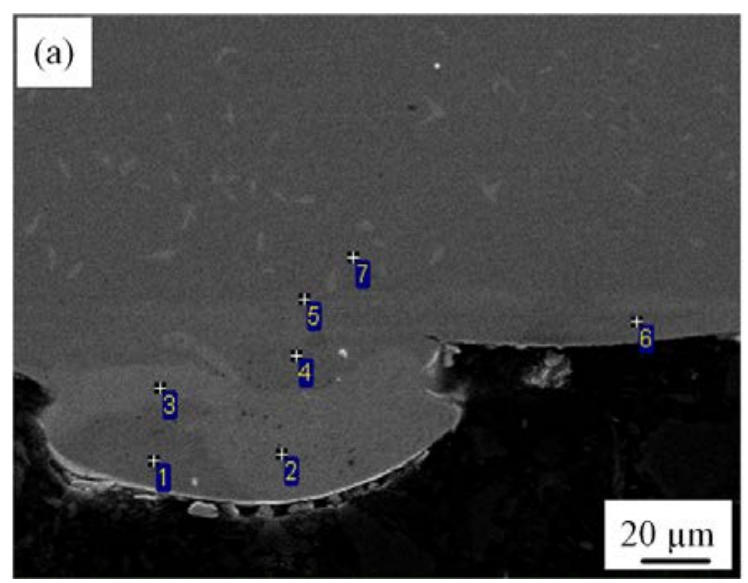

(b)

\begin{tabular}{|c|c|c|c|}
\hline Spectrum & Cr & Fe & Mo \\
\hline $\mathbf{1}$ & 17.33 & 60.56 & 22.10 \\
\hline $\mathbf{2}$ & 3.81 & 24.25 & 71.94 \\
\hline $\mathbf{3}$ & 3.15 & 21.92 & 74.93 \\
\hline $\mathbf{4}$ & 17.05 & 69.01 & 13.95 \\
\hline $\mathbf{5}$ & 15.35 & 65.58 & 19.07 \\
\hline $\mathbf{6}$ & 15.11 & 62.05 & 22.84 \\
\hline $\mathbf{7}$ & 21.38 & 77.34 & 1.28 \\
\hline
\end{tabular}

Figure 5-2 EDX results of Mo coated stainless steel after heat treatment in Ar at $400^{\circ} \mathrm{C}$

(a) The points indicate testing location (b) Corresponding composition data

Figure 5-3 shows the SEM and EDX results of Mo coated sample after heat treatment in air at $650^{\circ} \mathrm{C}$ for 1 hour. The coating thickness decrease a lot to approximately $10 \mu \mathrm{m}$. In addition, some coating debris can be found on the coating surface, which indicates some coating surface may break during the heat treatment process. Localized higher content Mo is also found in the heattreated sample. The decreased coating thickness maybe attributed to two factors. First is the break of coating surface may loss some coating materials. Second is the re-distribution of Mo atoms that more Mo diffuses towards the coating surface.

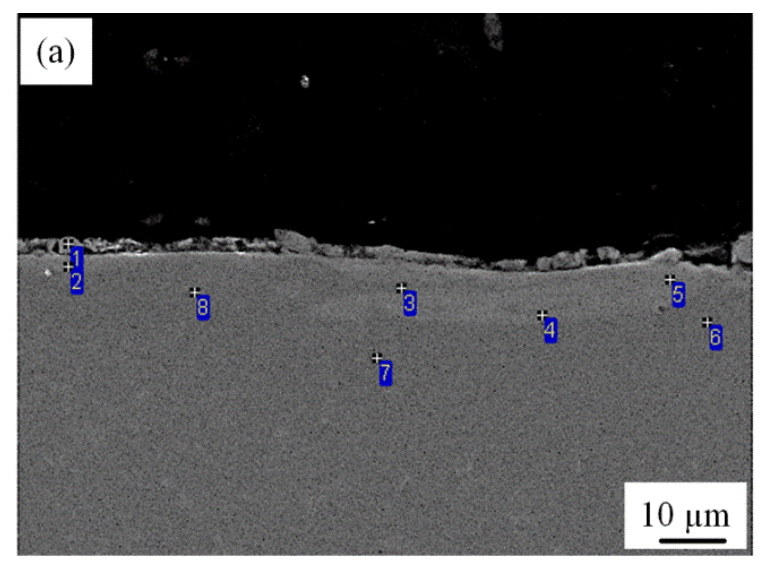

(b)

\begin{tabular}{|c|c|c|c|}
\hline Spectrum & $\mathbf{C r}$ & $\mathbf{F e}$ & Mo \\
\hline $\mathbf{1}$ & 7.88 & 42.47 & 49.65 \\
\hline $\mathbf{2}$ & 9.15 & 46.27 & 44.58 \\
\hline $\mathbf{3}$ & 19.37 & 67.82 & 12.81 \\
\hline $\mathbf{4}$ & 11.34 & 63.90 & 24.76 \\
\hline $\mathbf{5}$ & 11.98 & 56.31 & 31.71 \\
\hline $\mathbf{6}$ & 21.48 & 78.52 & \\
\hline $\mathbf{7}$ & 21.71 & 78.29 & \\
\hline $\mathbf{8}$ & 17.11 & 71.94 & 10.95 \\
\hline
\end{tabular}

Figure 5-3 EDX results of Mo coated stainless steel after heat treatment in air at $650^{\circ} \mathrm{C}$

(a) The points indicate testing location (b) Corresponding composition data 
Figure 5-4 shows the SEM and EDX results of Mo coated sample after heat treatment in Ar at $650^{\circ} \mathrm{C}$ for 1 hour. The coating thickness also decreases to approximately $10 \mu \mathrm{m}$, and some coating debris are found on the coating surface.

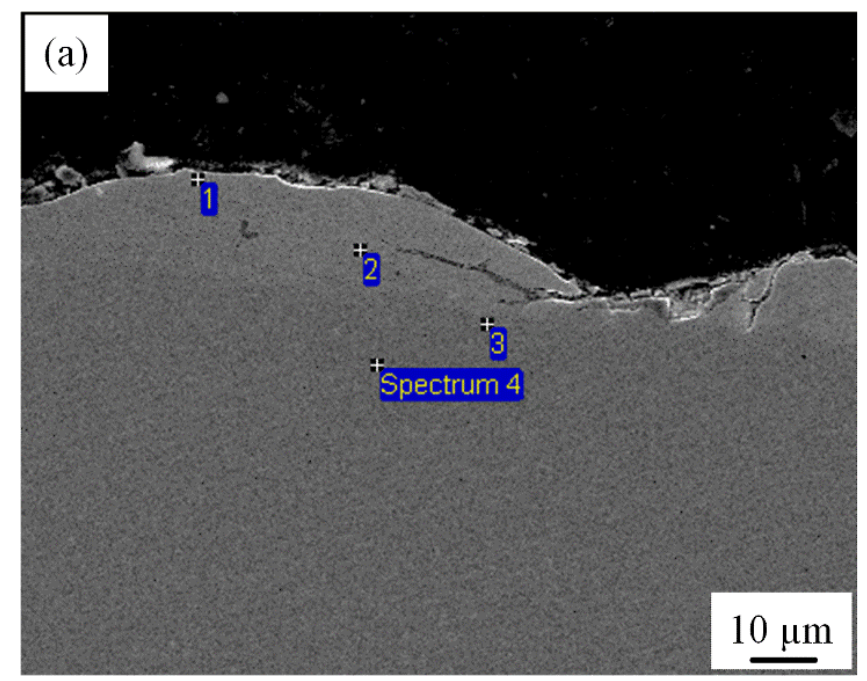

(b)

\begin{tabular}{|c|c|c|c|}
\hline Spectrum & $\mathbf{C r}$ & $\mathbf{F e}$ & Mo \\
\hline $\mathbf{1}$ & 12.27 & 57.49 & 30.24 \\
\hline $\mathbf{2}$ & 9.71 & 47.04 & 43.25 \\
\hline $\mathbf{3}$ & 17.64 & 82.12 & 0.24 \\
\hline Spectrum 4 & 20.54 & 77.70 & 1.76 \\
\hline
\end{tabular}

Figure 5-4 EDX results of Mo coated stainless steel after heat treatment in Ar at $650^{\circ} \mathrm{C}$

(a) The points indicate testing location (b) Corresponding composition data

Figure 5-5 shows the SEM and EDX results of Mo coated sample after heat treatment in air at $900^{\circ} \mathrm{C}$ for 1 hour. The coating morphology indicates more defects, while not many coating debris are found on the coating surface. The EDX result displays that the coating thickness further decreases to less than $5 \mu \mathrm{m}$. However, the Mo content does not increase a lot in the coating area, which means the coating surface may broke and be removed from the sample. Also, it should be noted that Cr content significantly increases in the surface area. This may be caused by oxidation of $\mathrm{Cr}$ and the $\mathrm{Cr}$ atoms localized on the surface area and react with oxygen. 


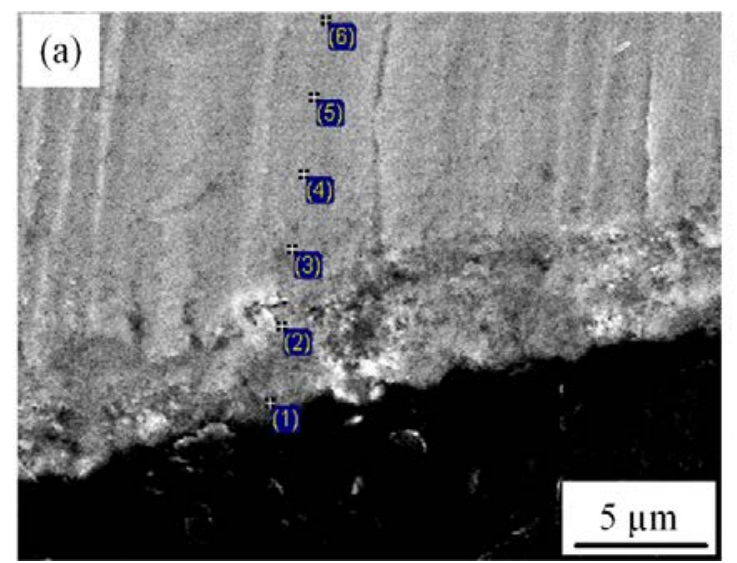

(b)

\begin{tabular}{|c|c|c|c|c|}
\hline Spectrum & $\mathbf{C r}$ & $\mathbf{F e}$ & $\mathbf{N i}$ & $\mathbf{M o}$ \\
\hline $\mathbf{( 1 )}$ & 45.53 & 11.03 & 1.72 & 41.71 \\
\hline $\mathbf{( 2 )}$ & 32.31 & 28.59 & 5.89 & 33.21 \\
\hline $\mathbf{( 3 )}$ & 20.49 & 71.95 & 6.93 & 0.64 \\
\hline $\mathbf{( 4 )}$ & 19.38 & 71.75 & 8.86 & \\
\hline $\mathbf{( 5 )}$ & 19.36 & 70.43 & 10.21 & \\
\hline $\mathbf{( 6 )}$ & 20.06 & 71.46 & 8.47 & \\
\hline
\end{tabular}

Figure 5-5 EDX results of Mo coated stainless steel after heat treatment in air at $900^{\circ} \mathrm{C}$

(a) The points indicate testing location (b) Corresponding composition data

Figure 5-6 shows the SEM and EDX results of Mo coated sample after heat treatment in Ar at $900^{\circ} \mathrm{C}$ for 1 hour. The coating condition is better than that in air. No debris and major defects are found in the coating area. The coating thickness also decreases to less than $5 \mu \mathrm{m}$. EDX result indicates that Mo content is only $14.2 \%$ on the coating surface. It is suggested that most Mo coating has been removed during the heat treatment process. Cr content is relatively consistent compared to the sample heat-treated in air, which indicates oxidation may cause localization of $\mathrm{Cr}$ atoms in the coating surface.

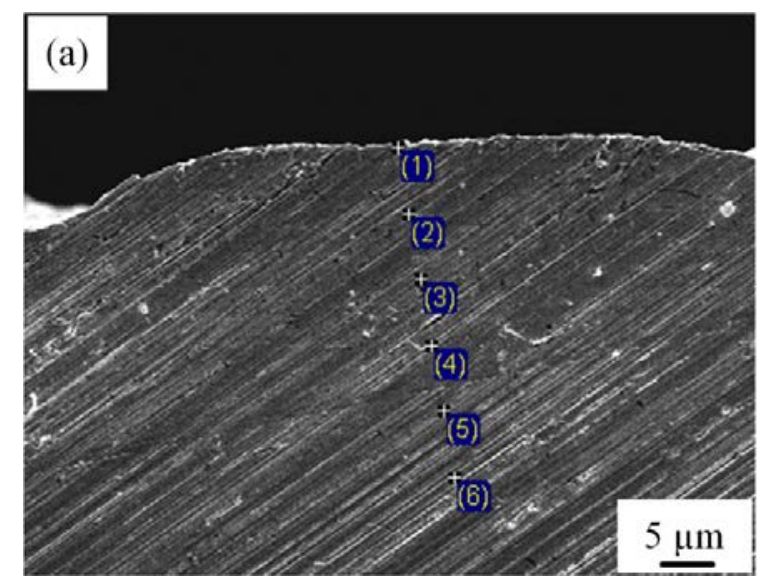

(b)

\begin{tabular}{|c|c|c|c|c|}
\hline Spectrum & $\mathbf{C r}$ & $\mathbf{F e}$ & $\mathbf{N i}$ & Mo \\
\hline $\mathbf{( 1 )}$ & 14.12 & 63.99 & 7.69 & 14.20 \\
\hline $\mathbf{( 2 )}$ & 19.31 & 71.36 & 8.84 & 0.48 \\
\hline $\mathbf{( 3 )}$ & 19.07 & 73.79 & 7.15 & \\
\hline $\mathbf{( 4 )}$ & 17.79 & 74.54 & 7.68 & \\
\hline $\mathbf{( 5 )}$ & 18.71 & 70.55 & 10.74 & \\
\hline $\mathbf{( 6 )}$ & 19.05 & 70.46 & 10.49 & \\
\hline
\end{tabular}

Figure 5-6 EDX results of Mo coated stainless steel after heat treatment in $\mathrm{Ar}$ at $900^{\circ} \mathrm{C}$

(a) The points indicate testing location (b) Corresponding composition data 


\subsubsection{XRD Analysis}

XRD analysis were employed to characterize the phase transformation, oxidation and intermetallic formation during heat treatment process. Figure 5-7 (a) is the XRD pattern of Mo coated stainless steel after heat treatment in air at $400^{\circ} \mathrm{C}$ for 1 hour. Compared with the XRD pattern of asdeposited sample in Figure 4-15, austenite peaks $\gamma(220)$ and $\gamma(311)$ disappear and the relative intensity of $\gamma(200)$ decreases. This indicates a further phase transformation from austenite to ferrite. In addition, two peaks of $\mathrm{Cr}$ oxide are found in the heat-treated sample.

Figure 5-7 (b) shows the XRD pattern of heat-treated sample in Ar at $400^{\circ} \mathrm{C}$ for 1 hour. Phase transformation from austenite to ferrite is also observed. Mo is a ferrite former, which could facilitate this phase transformation when heat up to $400^{\circ} \mathrm{C}$. The $\mathrm{Cr}$ oxidation peaks are relatively much lower than that in air, which may imply that the Cr oxide is only on the coating surface.
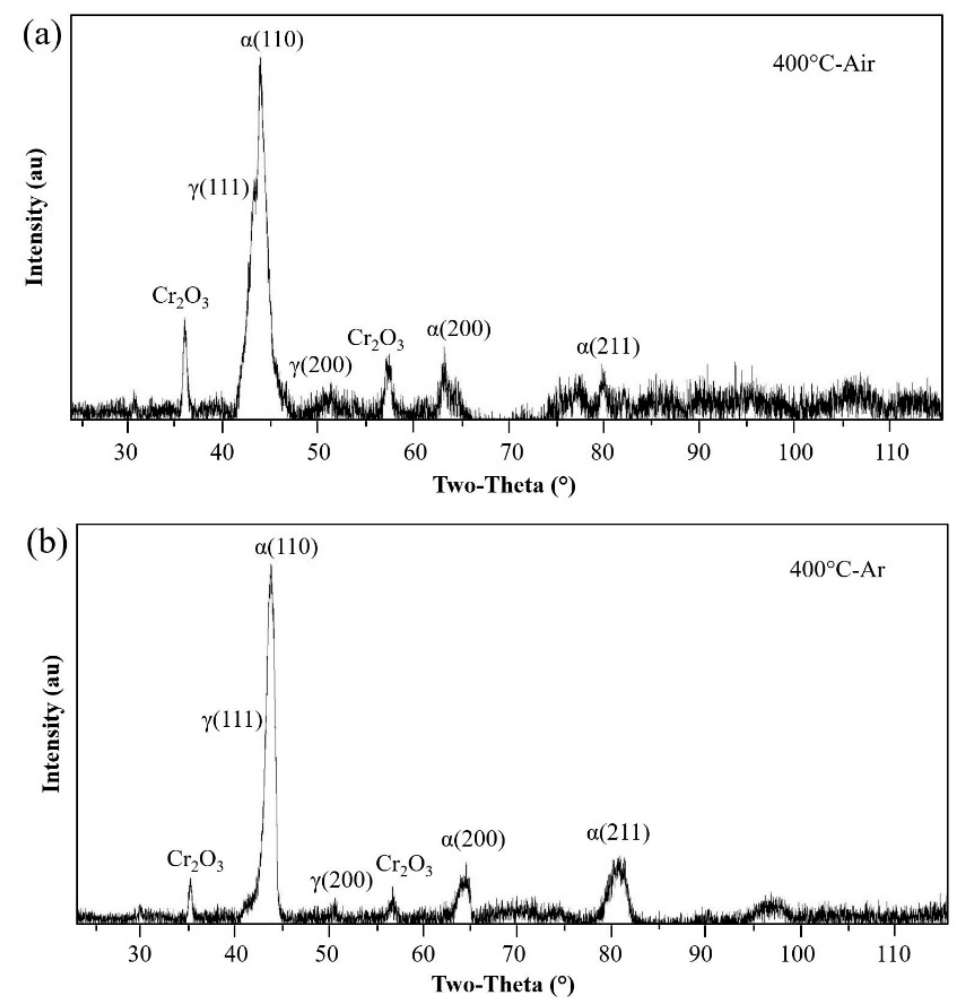

Figure 5-7 XRD patterns of heat treated samples after $400^{\circ} \mathrm{C}$ (a) air (b) $\mathrm{Ar}$ 
The XRD pattern of Mo coated stainless steel after heat treatment in Air at $650^{\circ} \mathrm{C}$ for 1 hour is shown in Figure 5-8 (a). $650^{\circ} \mathrm{C}$ is within sensitizing temperature range of Mo alloy stainless steel. Some $\mathrm{Cr}$ rich and Mo rich phase as well as some carbide may be formed under this temperature range. The results display that more austenite is formed than that in heat-treated sample at $400^{\circ} \mathrm{C}$. The XRD pattern shows several peaks of Mo oxide and Cr oxide, some of which have very high intensity. The results imply $650^{\circ} \mathrm{C}$ is already above Mo and $\mathrm{Cr}$ oxidation temperature. It should be noted that some metallic phase of Mo is found in XRD pattern. This may be attributed to the formation of Mo rich intermetallic under this specific temperature.

Figure 5-8 (b) shows the XRD pattern of heat-treated sample at $650^{\circ} \mathrm{C}$ in $\mathrm{Ar}$ for 1 hour.
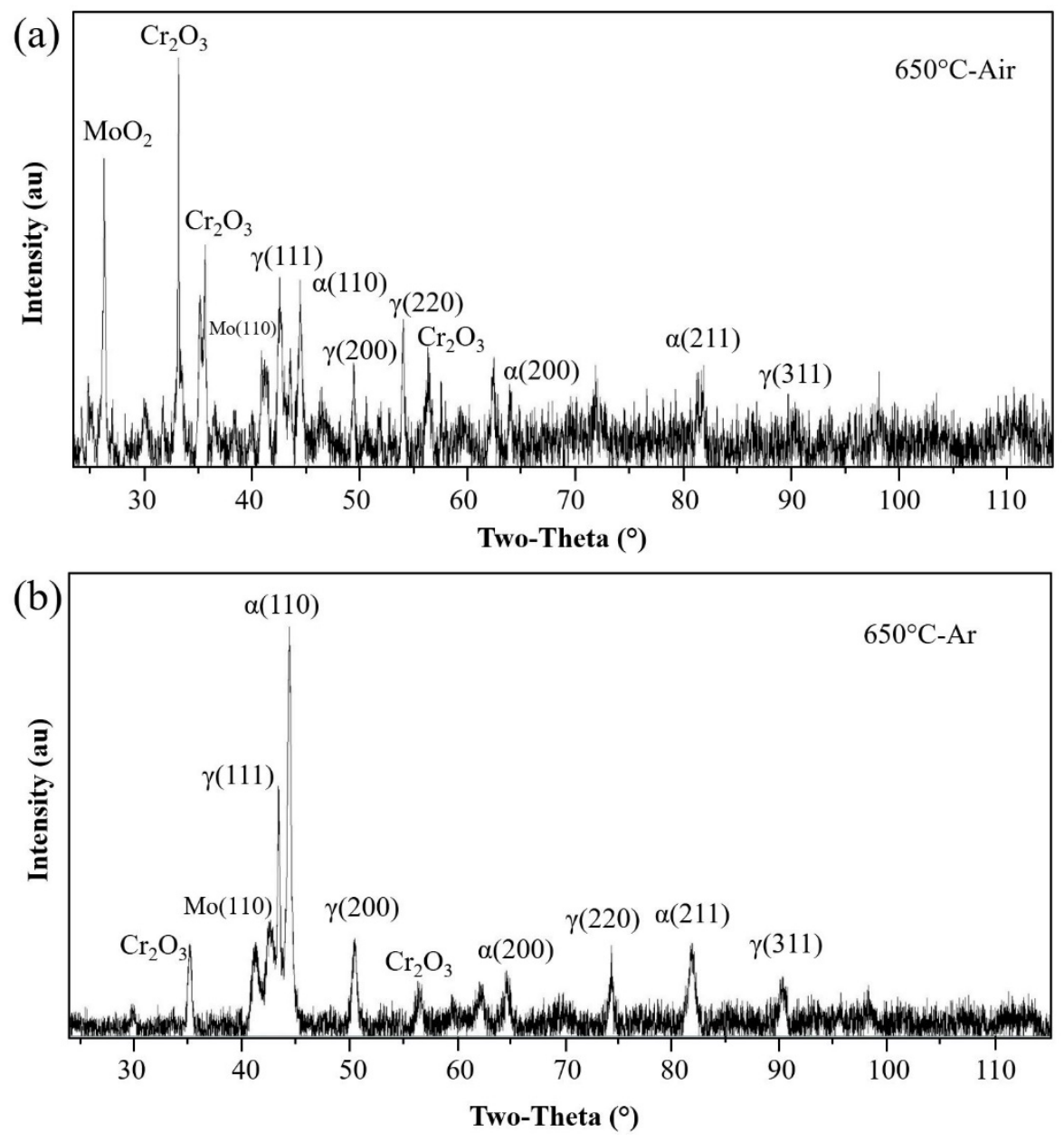

Figure 5-8 XRD patterns of heat treated samples after $650^{\circ} \mathrm{C}$ (a) air (b) Ar 
The results display no Mo oxide was detected in the sample. Some Cr oxide peaks are very similar to that in heat-treated sample at $400^{\circ} \mathrm{C}$, which indicates $\mathrm{Cr}$ oxide may be found just on the coating surface. Metallic phase of Mo peak is also found in the sample, which suggests that Mo rich intermetallic phase is form depend on the specific temperature range.

Figure 5-9 (a) and (b) show the XRD results of Mo coated stainless steel after heat treatment at $900^{\circ} \mathrm{C}$ in air and $\mathrm{Ar}$ respectively.
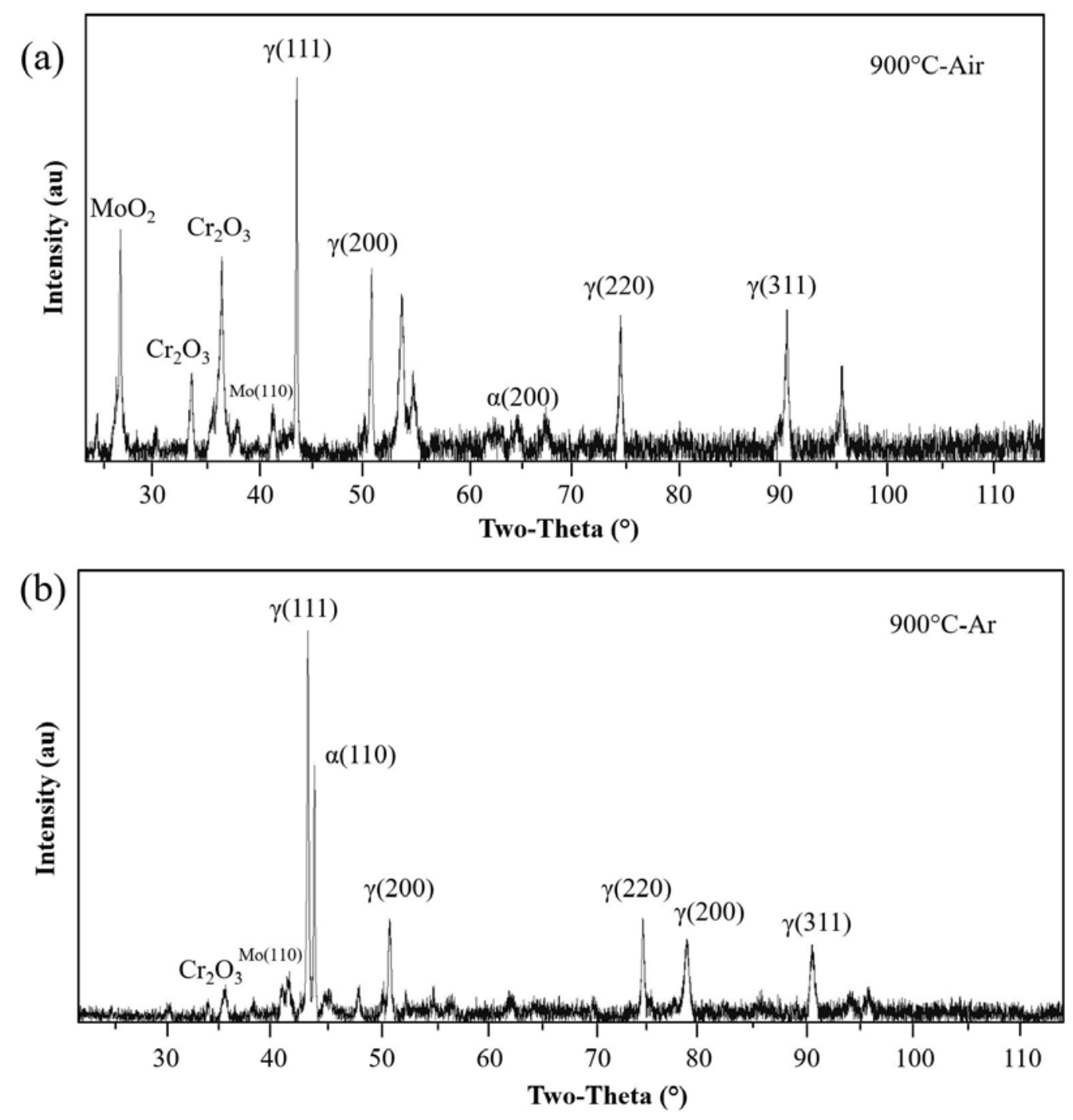

Figure 5-9 XRD patterns of heat treated samples after $900^{\circ} \mathrm{C}$ (a) air (b) $\mathrm{Ar}$ 
From the results, it is obvious that ferrite structure $\alpha$ phases peaks decrease or disappear, which indicates the phase transformation from ferrite to austenite at this temperature. Mo oxide and $\mathrm{Cr}$ oxide are also found in this sample while the relative intensity are lower than that at $650^{\circ} \mathrm{C}$. The EDX results show the coating thickness of Mo coated sample at $900^{\circ} \mathrm{C}$ is less than $5 \mu \mathrm{m}$, while the coating at $650^{\circ} \mathrm{C}$ is around $10 \mu \mathrm{m}$. This explains why the relative peak intensity of Mo and Cr oxide is lower than that at $650^{\circ} \mathrm{C}$. No Mo oxide are found in the sample. Phase transformation from ferrite to austenite are displayed in the XRD pattern.

\subsubsection{XPS Analysis}

XPS analysis was carried out to investigate the surface chemical state of heat-treated samples. Firstly, it will provide valuable information of the coating surface. Secondly, it can help validate $\mathrm{XRD}$ results to better understand the coating microstructure change after heat treatment.

Figure 5-10 shows the XPS results for $\mathrm{Cr} 2 \mathrm{p}$ in heat-treated samples in air at different temperatures.

(a)

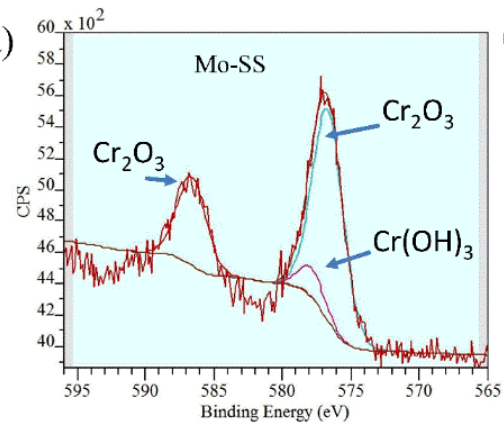

(c)

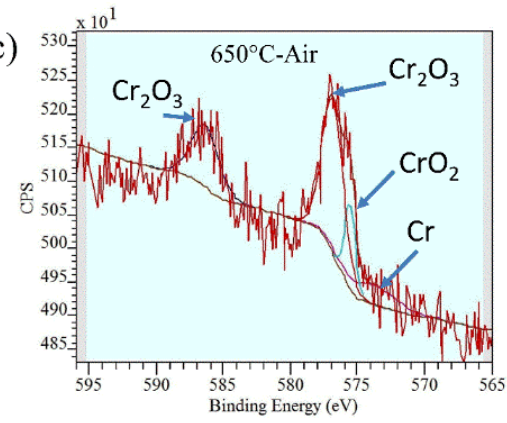

(b)

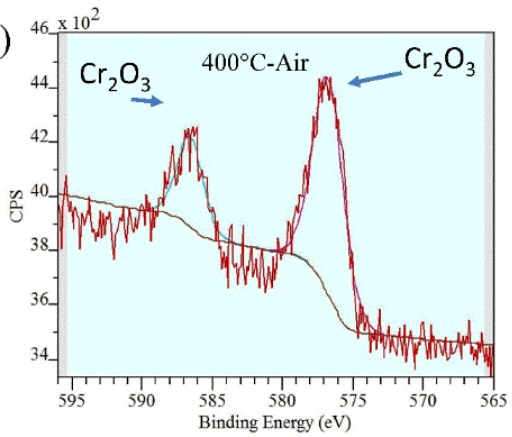

(d)

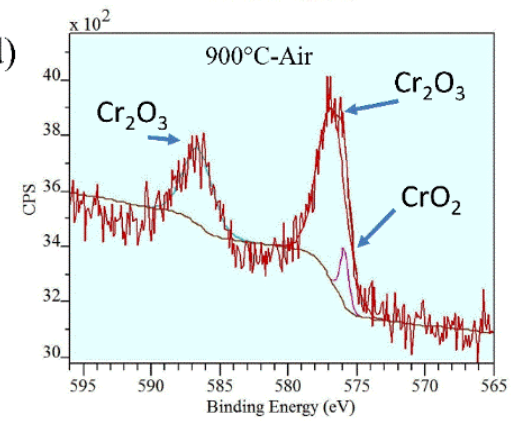

Figure 5-10 XPS analysis results for $\mathrm{Cr} 2 \mathrm{p}$ in heat treated samples in air

(a) Mo coated stainless steel (b) $400^{\circ} \mathrm{C}$ in air (c) $650^{\circ} \mathrm{C}$ in air (d) $900^{\circ} \mathrm{C}$ in air 
It can be seen that $\mathrm{Cr}$ mainly exists as $\mathrm{Cr}$ oxide at the coating surface. It should be noted that some metallic phase of $\mathrm{Cr}$ is detected in the $650^{\circ} \mathrm{C}$ samples, which may be some $\mathrm{Cr}$ rich intermetallic formed at the temperature.

Figure 5-11 shows the XPS results for Mo 3d in in heat-treated samples in air at different temperatures. As-deposited Mo coated stainless steel displays 3 peaks for Mo 3d, one of which is the metallic Mo state. However, after heat-treatment all Mo on the surface is oxidized. The metallic Mo peak disappears from $400^{\circ} \mathrm{C}$ to $900^{\circ} \mathrm{C}$. In XRD results, no Mo oxide is found at $400^{\circ} \mathrm{C}$ while in XPS result the metallic Mo peak disappears at $400^{\circ} \mathrm{C}$. This may imply that Mo get oxidized only at the coating surface when heat-treated to $400^{\circ} \mathrm{C}$.

(a)

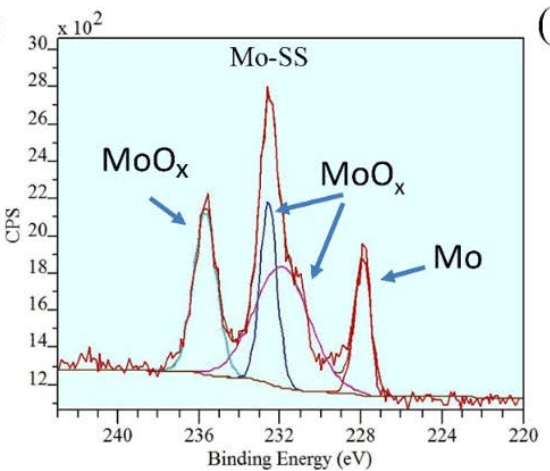

(c)

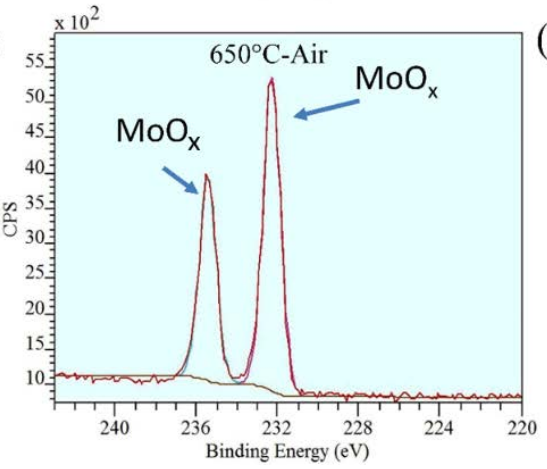

(b)

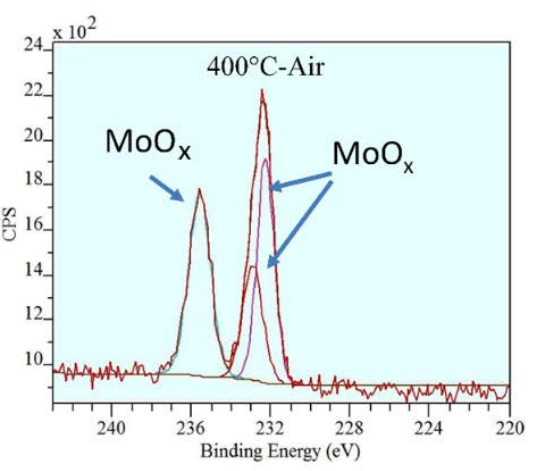

(d)

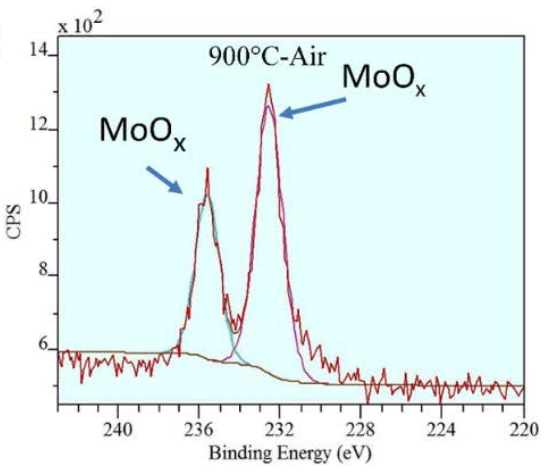

Figure 5-11 XPS analysis results for Mo 3d in heat treated samples in air

(a) Mo coated stainless steel (b) $400^{\circ} \mathrm{C}$ in air (c) $650^{\circ} \mathrm{C}$ in air (d) $900^{\circ} \mathrm{C}$ in air 
Figure 5-12 shows the XPS results for Cr 2p in heat-treated samples in Ar at different temperatures. The heat-treated samples show no difference compared to as-deposited sample. All $\mathrm{Cr}$ exists as $\mathrm{Cr}$ oxide on the coating surface.

(a)

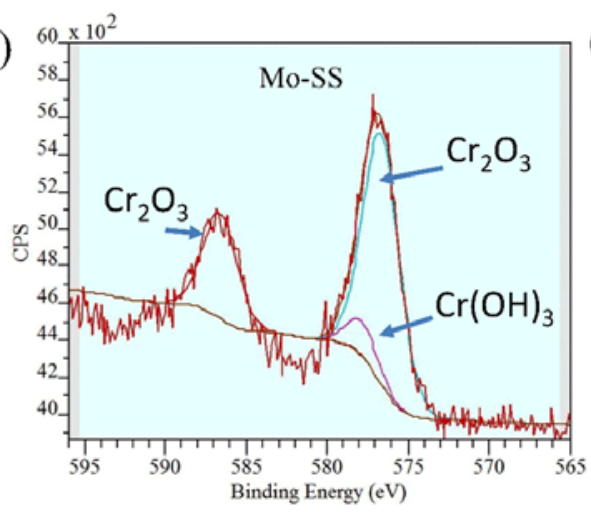

(c)

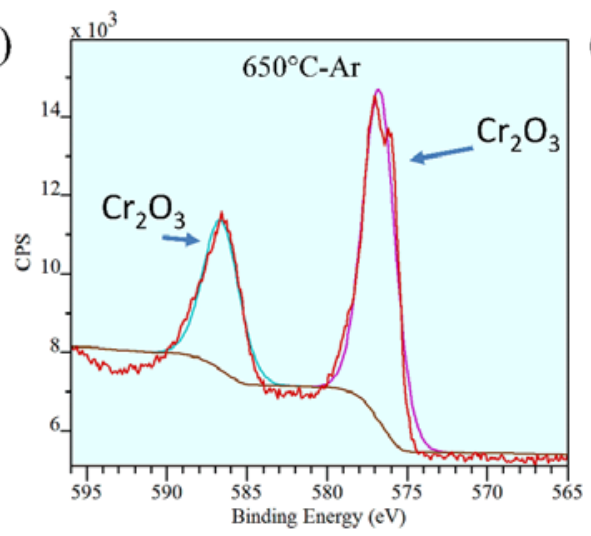

(b)

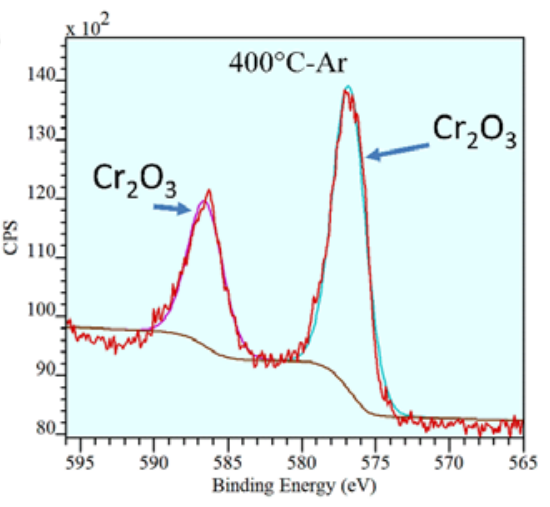

(d)

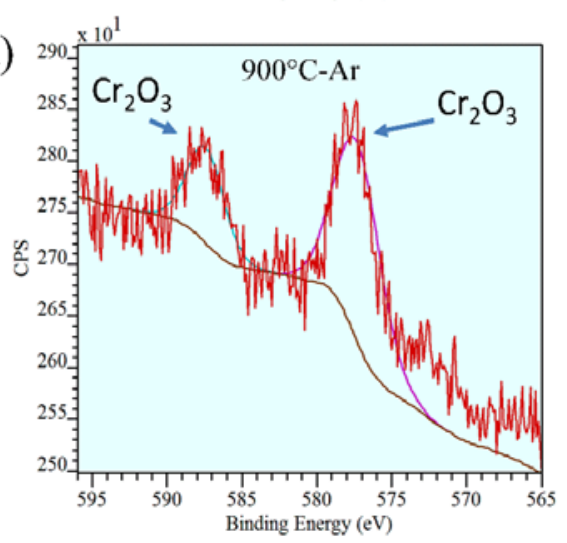

Figure 5-12 XPS analysis results for $\mathrm{Cr} 2 \mathrm{p}$ in heat treated samples in $\mathrm{Ar}$

(a) Mo coated stainless steel (b) $400^{\circ} \mathrm{C}$ in air (c) $650^{\circ} \mathrm{C}$ in air (d) $900^{\circ} \mathrm{C}$ in air

Figure 5-13 shows the XPS results for Mo 3d in in heat-treated samples in Ar at different temperatures. At $400^{\circ} \mathrm{C}$, both Mo oxide and metallic Mo state can be found at the coating surface. However, the metallic Mo state peak disappears at $650^{\circ} \mathrm{C}$. By comparing XPS results with XRD results, it is suggested that metallic Mo forms Mo rich intermetallic at this specific temperature. This is in good agreement with XRD results that some Mo phase is detected at $650^{\circ} \mathrm{C}$. At $900^{\circ} \mathrm{C}$, the metallic state of Mo is also detected, while the peak intensity is relatively low. This is also in 
agreement with Figure 5-9 that some Mo forms Mo intermetallic and oxide. The rest of Mo keeps in metallic state.

(a)

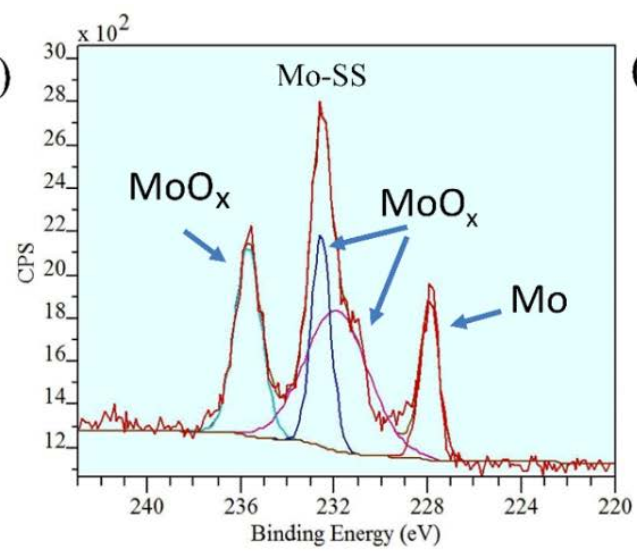

(c)

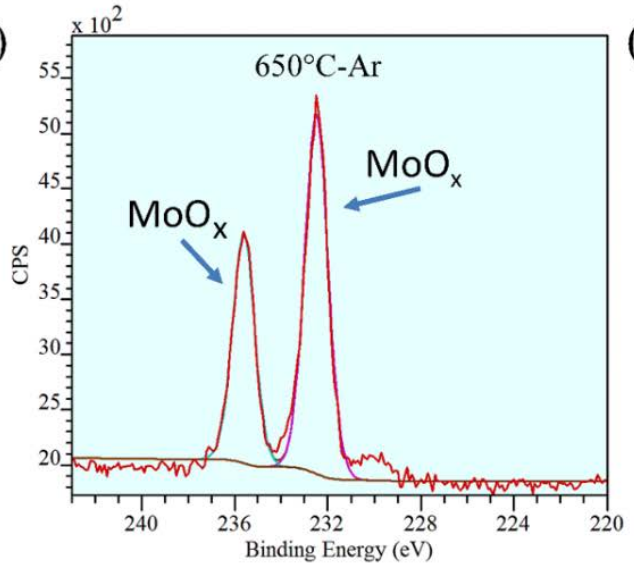

(b)

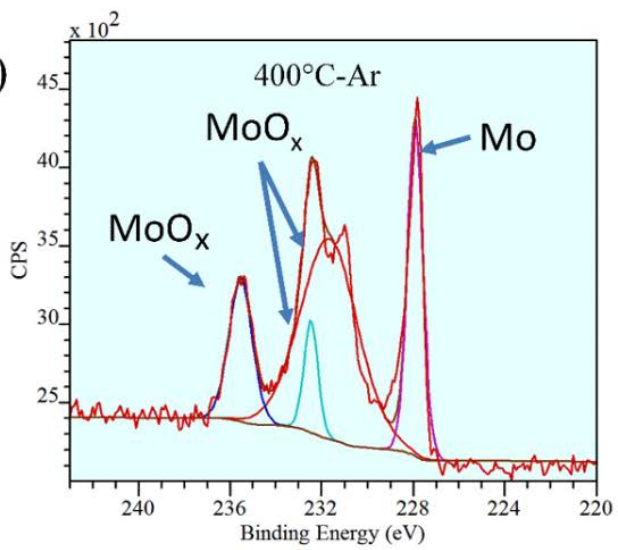

(d)

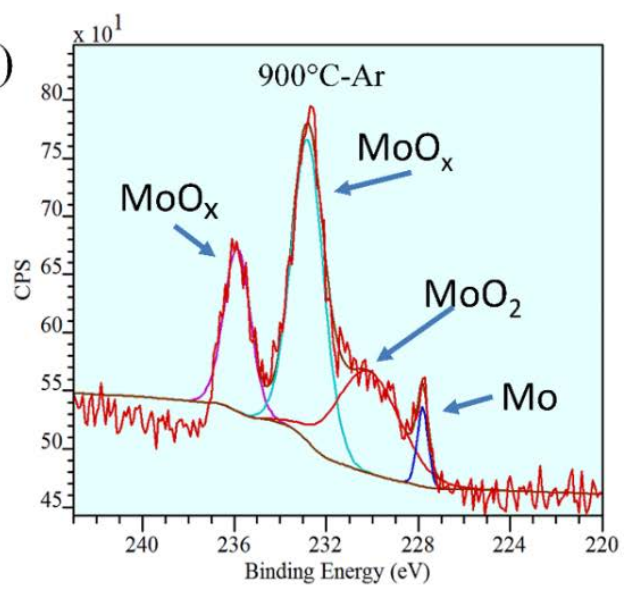

Figure 5-13 XPS analysis results for Mo 3d in heat treated samples in Ar

(a) Mo coated stainless steel (b) $400^{\circ} \mathrm{C}$ in air (c) $650^{\circ} \mathrm{C}$ in air (d) $900^{\circ} \mathrm{C}$ in air

\subsection{Corrosion Resistance of Heat Treated Samples}

Corrosion resistance tests were conducted to evaluate the effects of heat treatment on corrosion behaviors. Figure 5-14 shows the Tafel test results of Mo coated stainless steel after heat treatment in air at different temperatures. As-deposited Mo coated 304 stainless steel is included in the plot 
for comparison. It can be seen that none of the heat-treated samples in air has better corrosion resistance of the as-deposited sample. The Tafel test results are listed in Table 5-1.

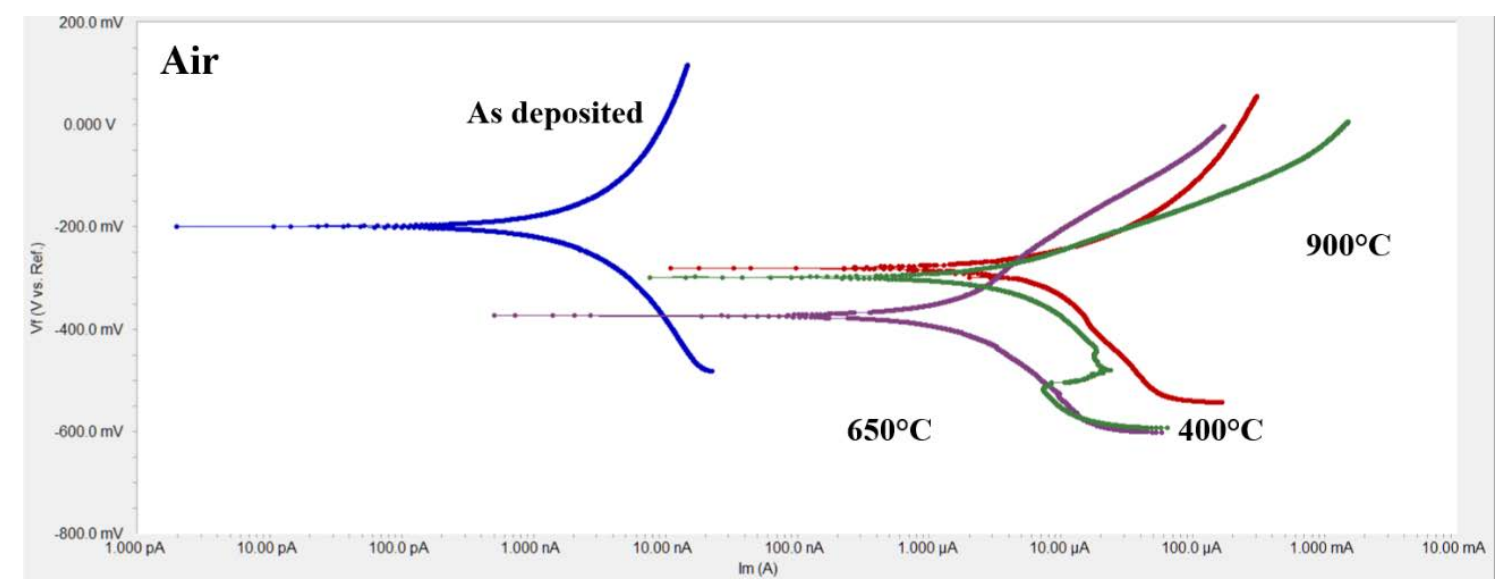

Figure 5-14 Tafel test of heat treated samples in air

Table 5-1 Tafel test results of Mo coated stainless steel after heat treatment in air

\begin{tabular}{|c|c|c|c|c|}
\hline Air-1h & $\begin{array}{c}\text { As } \\
\text { deposited }\end{array}$ & $\mathbf{4 0 0}^{\circ} \mathbf{C}$ & $\mathbf{6 5 0}^{\circ} \mathbf{C}$ & $\mathbf{9 0 0}^{\circ} \mathbf{C}$ \\
\hline $\mathbf{E}_{\text {corr }}(\mathbf{m V})$ & -199 & -281 & -374 & -299 \\
\hline $\mathbf{I}_{\text {corr }}(\mathbf{A})$ & $8.18 \times 10^{-9}$ & $6.98 \times 10^{-6}$ & $3.70 \times 10^{-6}$ & $4.73 \times 10^{-6}$ \\
\hline $\mathbf{C R}$ (mpy) & $4.20 \times 10^{-2}$ & 35.96 & 19.05 & 24.36 \\
\hline
\end{tabular}

The Tafel test results indicate the heat-treated sample at $650^{\circ} \mathrm{C}$ has the lowest corrosion potential. It can be attributed to the formation of Mo rich intermetallic, which could be vulnerable in corrosive environment. That is why the sample at $650^{\circ} \mathrm{C}$ has lowest corrosion potential and more likely to react with the electrolyte. In addition, previous research showed the ratio of austenite and 
ferrite at a certain range will contribute to corrosion resistance. However, the sample heat-treated at $400^{\circ} \mathrm{C}$ exhibit much less austenite that other samples, which may increase the corrosion rate.

Figure 5-15 shows the Tafel test results of Mo coated stainless steel after heat treatment in $\mathrm{Ar}$ at different temperatures. None of the heat-treated samples exhibit better corrosion resistance than the as-deposited sample. The Tafel test results are listed in Table 5-2.

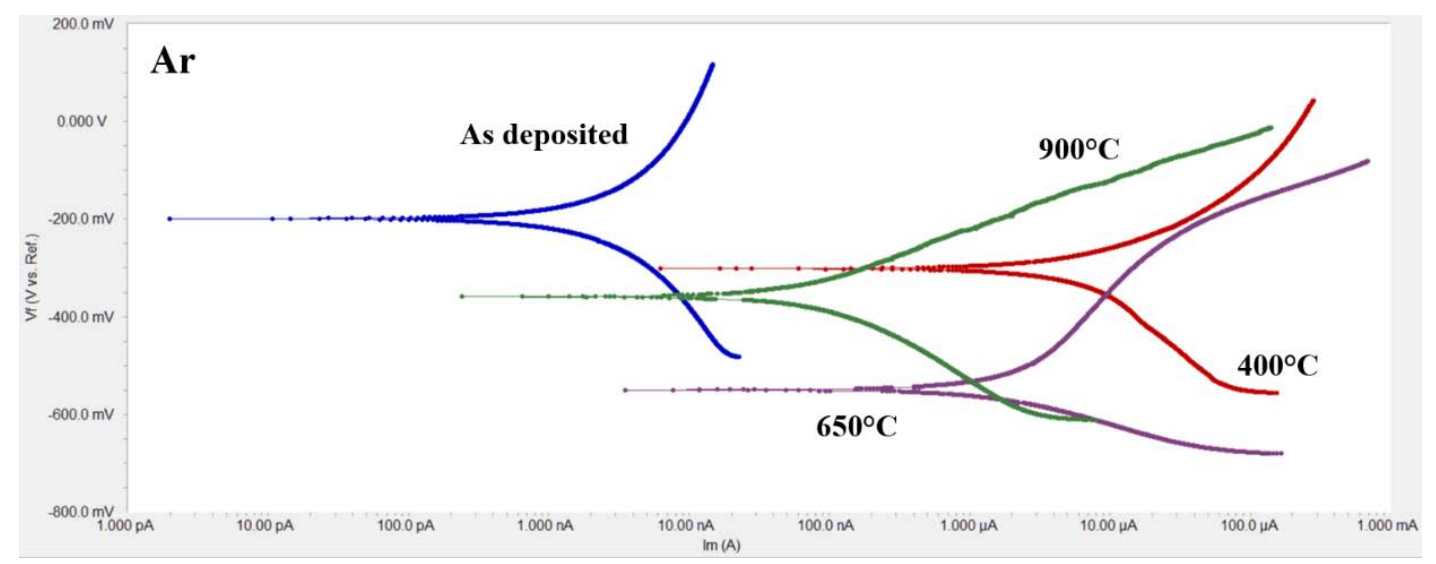

Figure 5-15 Tafel test of heat treated samples in Ar

Table 5-2 Tafel test results of Mo coated stainless steel after heat treatment in Ar

\begin{tabular}{|c|c|c|c|c|}
\hline Ar-1h & $\begin{array}{c}\text { As } \\
\text { deposited }\end{array}$ & $\mathbf{4 0 0}^{\circ} \mathbf{C}$ & $\mathbf{6 5 0}^{\circ} \mathbf{C}$ & $\mathbf{9 0 0}^{\circ} \mathbf{C}$ \\
\hline $\mathbf{E}_{\text {corr }}$ (mV) & -199 & -301 & -550 & -358 \\
\hline $\mathbf{I}_{\text {corr }}(\mathbf{A})$ & $8.18 \times 10^{-9}$ & $8.88 \times 10^{-6}$ & $2.10 \times 10^{-6}$ & $9.6 \times 10^{-8}$ \\
\hline $\mathbf{C R}$ (mpy) & $4.20 \times 10^{-2}$ & 45.73 & 10.80 & 0.466 \\
\hline
\end{tabular}

Table 5-2 shows that the sample at $650^{\circ} \mathrm{C}$ also has the lowest corrosion potential. As discussed above, this may be attributed to the formation of Mo rich intermetallic. Cr oxidation and Mo 
oxidation formed at $650^{\circ} \mathrm{C}$ and $900^{\circ} \mathrm{C}$ in air may result in lower corrosion resistance. The heattreated samples at $650^{\circ} \mathrm{C}$ and $900^{\circ} \mathrm{C}$ in $\mathrm{Ar}$ can potentially has less defect no oxidation was formed in the coating.

\subsection{EIS Analysis of Heat Treated Samples}

EIS analysis was carried out to further evaluate the effects of microstructure on the corrosion behaviors. The structure of coated samples is much more complicated than bulk materials, which requires modified equivalent circuit to better fit the EIS analysis. Figure 5-16 (a) shows the schematic image of the coated sample structure. In this study, electrolyte is $5 \% \mathrm{NaCl}$ solution, coating is Mo alloy surface coating and metal substrate is 304 stainless steel. The equivalent circuit diagram is shown in Figure 5-17 (b).
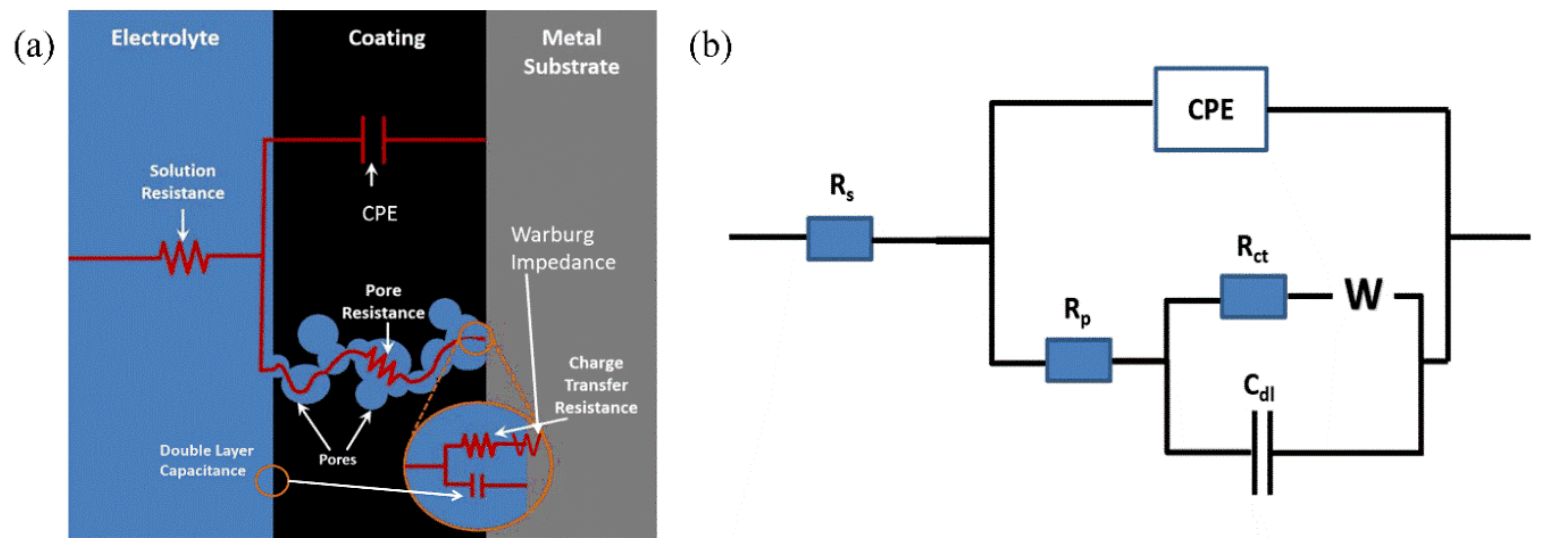

Figure 5-16 Schematic image of modified equivalent circuit

(a) sample analysis (b) equivalent circuit diagram

In this equivalent circuit, Rs is the solution resistance. Rp is the coating resistance, which is related to coating thickness, surface roughness and porosities in the coating. Rct represents charge transfer resistance, which is determined by electron transfer. CPE is Constant Phase Element, which is used to describe how uniform the surface is. $\mathrm{C}_{\mathrm{dl}}$ represents double layer capacitance, which is 
formed at the electrode/electrolyte interface. $\mathrm{W}$ is the Warburg impedance which describe the ion diffusion or mass transfer.

EIS spectra of Mo coated stainless steel with modified equivalent circuit is shown in Figure 5-17. Compared to simple CPE model, as shown in Figure 4-13, the modified model can fit the EIS curve more accurately. Figure 5- 17 shows an example of the fitting curve and the spectra for other samples are shown in Appendix. The EIS test results of heat-treated samples in air with modified equivalent circuit are shown in Table 5-3.

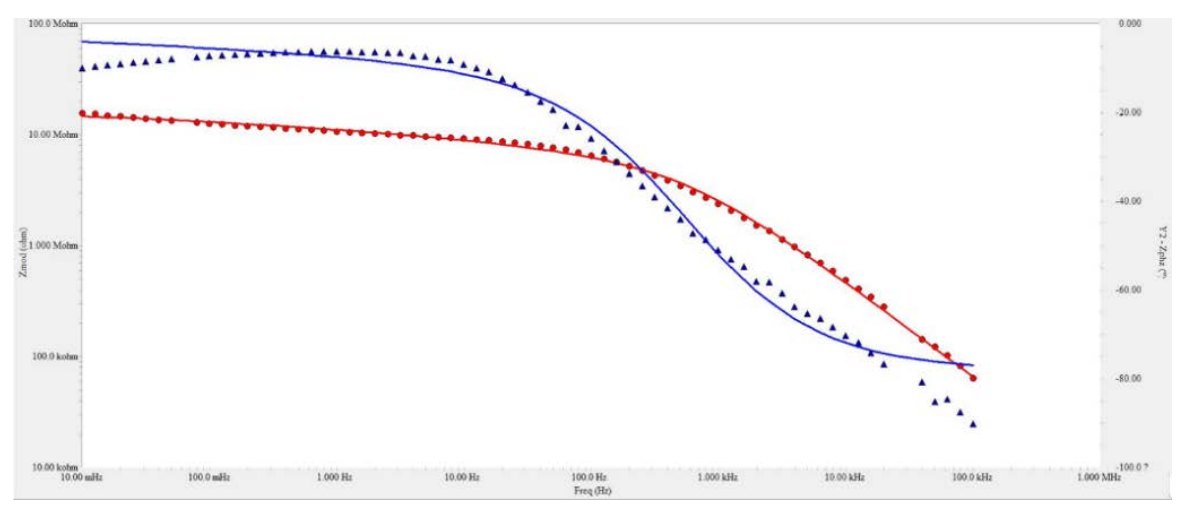

Figure 5-17 Bode plot of EIS spectra with modified equivalent circuit

Table 5-3 EIS test results Mo coated stainless steel after heat treatment in air

\begin{tabular}{|c|c|c|c|c|c|c|c|}
\hline Air & Rs(ohm) & Rct(ohm) & Rp(ohm) & $C_{d l}(F)$ & Ссре (F) & W & Goodness \\
\hline $\begin{array}{c}\text { As } \\
\text { deposited }\end{array}$ & $1.5 \times 10^{-5}$ & $1.05 \times 10^{8}$ & $5.42 \times 10^{3}$ & $1.79 \times 10^{-10}$ & $1.05 \times 10^{-14}$ & $7.97 \times 10^{9}$ & $8.4 \times 10^{-4}$ \\
\hline $400^{\circ} \mathrm{C}$ & 47.39 & $5.1 \times 10^{7}$ & 760.7 & $4.66 \times 10^{15}$ & $1.41 \times 10^{-4}$ & 234.9 & $2.5 \times 10^{-3}$ \\
\hline $650^{\circ} \mathrm{C}$ & 571.3 & $2.15 \times 10^{7}$ & 374.9 & $1.95 \times 10^{15}$ & $9.35 \times 10^{-5}$ & 76.99 & $6.0 \times 10^{-3}$ \\
\hline $900^{\circ} \mathrm{C}$ & 47.35 & $4.62 \times 10^{6}$ & 113.4 & $1.02 \times 10^{15}$ & $8.51 \times 10^{-4}$ & 0.778 & $8.9 \times 10^{-3}$ \\
\hline
\end{tabular}


The data in Table 5-3 indicates that the coating resistance Rp decreased significantly after heattreatment. In heat-treated samples, the coating resistance further decreases with the increase of heat treatment temperature. The coating resistance $\mathrm{Rp}$ is inversely proportional to the area of surface defects, which implying more defects, such as porosities and cracks, were generated in the heat-treated sample surface. This may be attributed to the oxidation of the coating in high temperature. On the other hand, the coating thickness also changed after heat treatment. The Mo coating thickness decreases with the increase of heat-treatment temperature. Charge transfer resistance Rct describes a single reaction at equilibrium state. For example, the metal substrate is in contact with an electrolyte and the metal can dissolve into the electrolyte, where the charge is transferred. The Rct results indicate the as-deposited sample has higher charge transfer resistance and the heat-treated sample at higher temperature has lower charge transfer resistance. It is suggested that heat treated sample is easier to react with the electrolyte. The CPE describes the uniformity of surface and lower capacitance indicates higher impedance. The CPE results display that the capacitance dramatically increased after heat-treatment, which implies the coating surface of heat treated samples are not as uniform as untreated sample. It is suggested that the heat-treated coating surface has higher roughness due to oxidation in high temperature. In addition, XRD and EDX results indicate the redistribution of alloy elements, forming some localized Mo rich areas. This will also decrease the uniformity of heat-treated samples. Warburg impedance is the diffusional impedance for the diffusion layer, which describes the ion diffusion or mass transfer effect. At high frequencies, the Warburg impedance is small since diffusing reactants do not have to move very far. At low frequencies, the reactants have to diffuse farther, increasing the Warburgimpedance. The Warburg impedance of the as-deposited sample is significantly higher than that of heat-treated samples, which indicates there were much more mass transfer or ion diffusion 
occurs in heat-treated samples. Thus, the heat-treated samples will be easier to react with the solutions, which displays lower corrosion resistance. An electrical double layer exists on the interface between an electrode and its surrounding electrolyte. This double layer is formed as ions from the electrolyte adsorb onto the electrode surface. The charged electrode is separated from the charged ions by an insulating space, so the material immersed in the solution will form a capacitor. The double layer capacitance depends on various factors, such as corrosion potential, ionic concentrations, types of ions, oxide layers, electrode roughness, etc. EIS results indicate that the double layer capacitance of heat treated samples are significantly higher than that of as-deposited samples, which means the heat-treated samples has much lower impedance. It can be attributed to the higher roughness of heat-treated samples, since there is more surface area in heat-treated samples.

The electrochemical analysis software Echem Analyst provides fitting goodness and the corresponding data deviation is listed in Table 5-4. The goodness of data calculated from the modified equivalent circuit was between $10^{-2}$ to $10^{-4}$, indicating the data accuracy was fair with less than $10 \%$ deviation.

Table 5-4 Fitting goodness for electrochemical analysis

\begin{tabular}{|c|c|c|}
\hline Goodness & Evaluation & Deviation \\
\hline$\sim \mathbf{1 0}^{-\mathbf{4}}$ & Good & $\sim 1 \%$ \\
\hline$\sim \mathbf{1 0}^{-\mathbf{2}}$ & Fair & $\sim 10 \%$ \\
\hline$\sim \mathbf{1 0}^{\mathbf{- 1}}$ & Poor & $>30 \%$ \\
\hline
\end{tabular}


EIS analysis of heat-treated samples in Ar were also carried out to compare the effects of shielding gas in heat treatment process. The EIS test results with modified equivalent circuit are shown in Table 5-5.

Table 5-5 EIS test results of Mo coated stainless steel after heat treatment in Ar

\begin{tabular}{|c|c|c|c|c|c|c|c|}
\hline Ar & Rs(ohm) & Rct(ohm) & $\mathbf{R p ( o h m )}$ & $\mathbf{C}_{\text {dl }}(\mathbf{F})$ & Ccpe (F) & W & Goodness \\
\hline As & $1.5 \times 10^{-5}$ & $1.05 \times 10^{8}$ & $5.42 \times 10^{3}$ & $1.79 \times 10^{-10}$ & $1.05 \times 10^{-14}$ & $7.97 \times 10^{9}$ & $8.4 \times 10^{-4}$ \\
\hline $\mathbf{4 0 0}^{\circ} \mathbf{C}$ & 74.72 & $3.93 \times 10^{7}$ & 749.7 & $1.61 \times 10^{16}$ & $3.92 \times 10^{-5}$ & 498.8 & $3.4 \times 10^{-4}$ \\
\hline $\mathbf{6 5 0}^{\circ} \mathbf{C}$ & 55.30 & $9.33 \times 10^{3}$ & 27.83 & $3.35 \times 10^{16}$ & $2.37 \times 10^{-4}$ & $2.57 \times 10^{3}$ & $5.6 \times 10^{-3}$ \\
\hline $\mathbf{9 0 0}^{\circ} \mathbf{C}$ & 176.2 & $2.17 \times 10^{5}$ & 276.7 & $9.29 \times 10^{14}$ & $2.87 \times 10^{-5}$ & 0.563 & $9.9 \times 10^{-3}$ \\
\hline
\end{tabular}

The EIS data in Table 5-5 also shows fitting goodness between $10^{-2}$ to $10^{-4}$ with less than $10 \%$ deviation. Comparing the data of heat-treated samples with as-deposited sample, the trend is similar to that of hear-treated samples in air. The heat treaded samples in Ar has much lower coating resistance Rp, indicating more porosities or cracks in the coating layer. They also have lower charge transfer resistance which means higher susceptibility to the electrolyte. Significantly higher double layer capacitance and CPE capacitance suggests the heat-treated samples have rougher and more uniform surface than that of as-deposited sample. Much lower impedance also indicates the heat-treated coatings facilitate the reaction with the electrolyte. However, when comparing the data within heat-treated samples, the sample heat-treated at $650^{\circ} \mathrm{C}$ has different trend. Microstructure analysis results showed the structure of the sample is different mainly due to the formation of intermetallic at the specific temperature range. XPS and XRD results indicate that 
Mo rich phase was formed by consume metallic state Mo in the coating area. The intermetallic caused the huge decrease of charge transfer resistance, which means it's much easier to initiate the reaction with the electrolyte. This explains why the sample at $650^{\circ} \mathrm{C}$ in $\mathrm{Ar}$ has a much lower corrosion potential, as shown in Figure 5- 15. In the meanwhile, the Warburg-impedance of the sample is much higher than that of other heat-treated samples, indicating the mass transfer or ion diffusion is less than others. This means although the intermetallic is easier to react, the reaction rate is much lower. That is why the sample has low corrosion potential but the corrosion rate is not high, compared to other heat-treated samples.

The heat-treated samples at $400^{\circ} \mathrm{C}$ shows the highest corrosion rate for both under air and $\mathrm{Ar}$ circumstances. XRD results indicate that the main difference of the samples treated at $400^{\circ} \mathrm{C}$ is the phase transformation from austenite to ferrite. Mo is a ferrite stabilizer which can facilitate the transformation at $400^{\circ} \mathrm{C}$. The ratio of austenite to ferrite is much lower than that of other samples, which may contribute to the increase of corrosion rate.

\subsection{Summary}

In this chapter, comprehensive metallurgy analysis of Mo coated 304 stainless steel after heat treatment at $400^{\circ} \mathrm{C}, 650^{\circ} \mathrm{C}$ and $900^{\circ} \mathrm{C}$ are conducted. The effects of heat treatment atmosphere are investigated by comparing the sample treated in air and Ar gas. SEM and EDX results show the coating thickness decreases with the increase of heat treatment temperature. Mo content is higher in the coating area than that of as-deposited sample. Localized Mo rich area is found in heat-treated samples. More cracks, porosities and rougher surface conditions are observed in heat-treated samples. XRD analysis display phase transformation from austenite to ferrite at $400^{\circ} \mathrm{C}$. Mo rich intermetallic is detected at $650^{\circ} \mathrm{C}$ under $\mathrm{Ar}$ gas. Mo and $\mathrm{Cr}$ oxides are found in heat-treated samples 
above $650^{\circ} \mathrm{C}$ in air. XPS results show metallic state Mo disappears after heat treatment in air, while metallic state Mo only disappears at $650^{\circ} \mathrm{C}$ in Ar gas. It is suggested that Mo rich intermetallic is formed at specific temperature range around $650^{\circ} \mathrm{C}$. Electrochemical test indicates heat-treated samples have lower corrosion resistance than as-deposited sample. EIS analysis with modified equivalent circuit is conducted to further investigate the electrochemical behavior. It is suggested that the heat-treated sample has lower corrosion resistance due to the rougher coating surface and more porosities and cracks in the coating layer. In addition, heat-treated samples introduce more nonuniform coating layers because of oxidation and diffusion of alloy elements. Metallic state Mo and a certain ratio of austenite and ferrite can contribute to better corrosion resistance. Mo rich intermetallic phase decreases the corrosion potential of the heat-treated sample at $650^{\circ} \mathrm{C}$ in $\mathrm{Ar}$, while also decreases the corrosion rate of the sample. 


\section{Chapter 6: Conclusions and Recommendations}

In this chapter, major observations, results and conclusions from the study are summarized. The recommendations for future work are also presented.

\subsection{Conclusions}

\subsubsection{Characterization of Surface Modified Stainless Steel by Electro-Spark Deposition}

In this chapter, TiC, WC and Mo coatings are applied to 304 stainless steel surface by ESD. Some key conclusions include:

1) The processing window of stainless steel surface modification by ESD is presented. ESD in Ar exhibits fine spray coating morphology while in air the deposition displays that it was formed from molten droplets.

2) The microstructure and composition of TiC, WC and Mo coating on stainless steel are discussed. Coating quality, morphology and elemental analysis are investigated with SEM and EDX.

3) The mechanical properties of coated 304 stainless steel are evaluated. TiC and WC coatings dramatically increase the micro-hardness of 304 stainless steel. WC coating improves the wear resistance of stainless steel by more than 5 times, while $\mathrm{TiC}$ and Mo coatings also improve it by 2.5 times.

4) Mo coating exhibits significant improvement on corrosion resistance in $5 \% \mathrm{NaCl}$ solutions, which corrodes 350 times slower than stainless steel. TiC coating also increases the corrosion resistance with 10 times slower corrosion rate. WC coating does not show improvement on the corrosion resistance. 
5) EIS tests has shown the polarization resistance of Mo coated sample is much larger than that of base metal stainless steel. XRD analysis indicate the phase transformation from austenite to ferrite after ESD of Mo.

6) Lower surface roughness can contribute to higher corrosion resistance for Mo coated stainless steel. The surface alloying of Mo approach to increase corrosion resistance cannot apply to other steels like DP980 and duplex stainless steel 2205.

\subsubsection{Effects of Heat Treatment on Microstructure and Corrosion Resistance}

In this chapter, comprehensive metallurgy analysis of Mo coated 304 stainless steel after heat treatment at $400^{\circ} \mathrm{C}, 650^{\circ} \mathrm{C}$ and $900^{\circ} \mathrm{C}$ are conducted. The effects of heat treatment atmosphere are investigated by comparing the sample treated in air and Ar gas. Some key conclusions include:

1) SEM and EDX results show the coating thickness decreases with the increase of heat treatment temperature. Mo content is higher in the coating area than that of as-deposited sample. Localized Mo rich area is found in heat-treated samples. More cracks, porosities and rougher surface conditions are observed in heat-treated samples.

2) $\mathrm{XRD}$ analysis indicates phase transformation from austenite to ferrite at $400^{\circ} \mathrm{C}$. Mo rich intermetallic is detected at $650^{\circ} \mathrm{C}$ under $\mathrm{Ar}$ gas. Mo and $\mathrm{Cr}$ oxides are found in heat-treated samples above $650^{\circ} \mathrm{C}$ in air.

3) XPS results show metallic state Mo disappears after heat treatment in air, while metallic state Mo only disappears at $650^{\circ} \mathrm{C}$ in Ar gas. It is suggested that Mo rich intermetallic is formed at specific temperature range around $650^{\circ} \mathrm{C}$. 
4) Electrochemical test indicates heat-treated samples, either in Ar or in air atmosphere, have lower corrosion resistance than as-deposited sample. Metallic state Mo and a certain ratio of austenite and ferrite can contribute to better corrosion resistance.

5) EIS analysis with modified equivalent circuit is conducted to further investigate the electrochemical behavior. It is suggested that the heat-treated sample has lower corrosion resistance due to the rougher coating surface and more porosities and cracks in the coating layer. In addition, heat-treated samples introduce more nonuniform coating layers because of oxidation and diffusion of alloy elements. Mo rich intermetallic phase decreases the corrosion potential of the heat-treated sample at $650^{\circ} \mathrm{C}$ in $\mathrm{Ar}$, while also decreases the corrosion rate of the sample.

\subsection{Recommendations}

In this study, WC coating on 304 stainless steel exhibits good improvement on wear resistance. Optimization of ESD process for WC is necessary to obtain better wear resistance. The test carried out in this study was dry-sand abrasion wear test, following ASTM G65-04 standard. Pin-on-disk wear test would also be interesting depend on specific applications.

Mo coating on 304 stainless steel shows excellent corrosion resistance in $\mathrm{NaCl}$ solutions. EIS analysis indicates that the coating quality has great effect on the electrochemical behaviors. Detailed studies about optimizing Mo coating quality, controlling coating thickness and composition are necessary. Heat-treatment investigation in this study cannot cover all the conditions. Further studies of heat-treatment effects will be very interesting to improve the corrosion resistance. Particularly, heat treatment of Mo coated sample can have effects on phase transformation of austenite to ferrite, which has great influence on corrosion behavior. 
Furthermore, electrochemical analysis under different temperature, solution and gas environment are necessary depend on specific applications. 


\section{References}

[1] Chen, Z. and Y. Zhou, Surface modification of resistance welding electrode by electrospark deposited composite coatings: Part I. Coating characterization. Surface \& Coatings Technology, 2006. 201(3-4): 1503-1510.

[2] Johnson, R. N., Electrospark deposition: principles and applications. 45th Annual Technical Conference of Society of Vacuum Coaters. 2002, Albuquerque, NM: Society of Vacuum Coaters.

[3] B.D. Sartwell, K.O. Legg, N. Price, D. Aylor, V. Champagne, T. Pollard, Electrospark deposition for depot- and field-level component repair and replacement of hard chromium plating. USA DOD Environmental Security Technology Certification Program (ESTCP), Project WP-0202, 2006.

[4] Johnson, R. N. and G. L. Sheldon, Advances in the Electrospark Deposition Coating Process. Journal of Vacuum Science \& Technology a-Vacuum Surfaces and Films, 1986. 4(6): 2740-2746.

[5] Frangini, S., A. Masci, and A. Di Bartolomeo, Cr7C3-based cermet coating deposited on stainless steel by electrospark process: structural characteristics and corrosion behavior. Surface and Coatings Technology, 2002. 149(2-3): 279-286.

[6] Society, American Welding, Classifications of Stainless Steel. https://app.aws.org/wj/1998/11/kotecki/.

[7] Bae, S. H., et al., A Study on the Mechanical Properties of Duplex Stainless Steel Weldment According to Mo Contents. Korean Journal of Metals and Materials, 2012. 50(9): 645-651.

[8] Wang, W. F., et al., Microstructure and cavitation erosion characteristics of Al-Si alloy coating prepared by electrospark deposition. Surface \& Coatings Technology, 2008. 202(21): 5116-5121.

[9] Tang, Siu Kei, Master's thesis: The Process Fundamentals and Parameters of ElectroSpark Deposition. University of Waterloo, 2009.

[10] Galinov, I. V. and R. B. Luban, Mass transfer trends during electrospark alloying. Surface \& Coatings Technology, 1996. 79(1-3): 9-18. 
[11] Liu, Jun, Ruijun Wang, and Yiyu Qian, The formation of a single-pulse electrospark deposition spot. Surface and Coatings Technology, 2005. 200(7): 2433-2437.

[12] Raju, K. R. C. S., et al., Electro-spark coatings for enhanced performance of twist drills. Surface \& Coatings Technology, 2008. 202(9): 1636-1644.

[13] Kolomeichenko, A. V. and I. S. Kuznetsov, Tribotechnical properties of electrospark coatings of amorphous and nanocrystalline iron alloys. Journal of Friction and Wear, 2014. 35(6): 501-504.

[14] Luo, C., X. A. Xiong, and S. J. Dong, TiB2/Ni coatings on surface of copper alloy electrode prepared by electrospark deposition. Transactions of Nonferrous Metals Society of China, 2011. 21(2): 317-321.

[15] Frangini, S., A. Masci, and A. Di Bartolomeo, Cr7C3-based cermet coating deposited on stainless steel by electrospark process: structural characteristics and corrosion behavior. Surface \& Coatings Technology, 2002. 149(2-3): 279-286.

[16] Ribalko, A. V., O. Sahin, and K. Korkmaz, A modified electrospark alloying method for low surface roughness. Surface \& Coatings Technology, 2009. 203(23): 3509-3515.

[17] Victor Champagne, Marc Pepi, and Brian Edwards Electrospark Deposition for the Repair of Army Main Battle Tank Components. Army Research Laboratory, 2006.

[18] Tusek, J., et al., Electrospark Deposition for Die Repair. Metalurgija, 2012. 51(1): 17-20.

[19] Liou, Horng-Yih, et al., Effects of alloying elements on the mechanical properties and corrosion behaviors of 2205 duplex stainless steels. Journal of Materials Engineering and Performance, 2001. 10(2): 231-241.

[20] Gunn, R, Duplex stainless steels: microstructure, properties and applications. 1997: Elsevier.

[21] Sathiya, P., et al., Effect of shielding gases on mechanical and metallurgical properties of duplex stainless-steel welds. Journal of Materials Science, 2009. 44(1): 114-121.

[22] Tan, Hua, et al., Effect of annealing temperature on the pitting corrosion resistance of super duplex stainless steel UNS S32750. Materials Characterization, 2009. 60(9): 10491054. 
[23] Deng, Bo, et al., Effect of thermal cycles on the corrosion and mechanical properties of UNS S31803 duplex stainless steel. Corrosion Science, 2009. 51(12): 2969-2975.

[24] Hänninen, H., et al., Effects of processing and manufacturing of high nitrogen-containing stainless steels on their mechanical, corrosion and wear properties. Journal of Materials Processing Technology, 2001. 117(3): 424-430.

[25] Lothongkum, G., et al., Effect of nitrogen on corrosion behavior of 28Cr-7Ni duplex and microduplex stainless steels in air-saturated 3.5 wt\% NaCl solution. Corrosion Science, 2006. 48(1): 137-153.

[26] Huang, Chi-Shang and Chia-Chang Shih, Effects of nitrogen and high temperature aging on $\sigma$ phase precipitation of duplex stainless steel. Materials Science and Engineering: A, 2005. 402(1-2): 66-75.

[27] Toor, Ihsan-ul-Haq, Park Jung Hyun, and Hyuk Sang Kwon, Development of high Mn-N duplex stainless steel for automobile structural components. Corrosion Science, 2008. 50(2): 404-410.

[28] Krawiec, H., et al., Influence of the dissolution of MnS inclusions under free corrosion and potentiostatic conditions on the composition of passive films and the electrochemical behaviour of stainless steels. Electrochimica Acta, 2006. 51(16): 3235-3243.

[29] Banas, Jacek and Andrzej Mazurkiewicz, The effect of copper on passivity and corrosion behaviour of ferritic and ferritic-austenitic stainless steels. Materials Science and Engineering: A, 2000. 277(1-2): 183-191.

[30] Hwang, H. and Y. Park, Effects of Heat Treatment on the Phase Ratio and Corrosion Resistance of Duplex Stainless Steel. Materials Transactions, 2009. 50(6): 1548-1552.

[31] Jithin M, Anees Abdul Hameed, Ben Jose, Anush Jacob, Influence of Heat Treatment on Duplex Stainless Steel to Study the Material Properties. International Journal of Scientific \& Technology Research, 2015. 4(2): 291-293.

[32] Paulraj, P. and R. Garg, Effect of Intermetallic Phases on Corrosion Behavior and Mechanical Properties of Duplex Stainless Steel and Super-Duplex Stainless Steel. Advances in Science and Technology-Research Journal, 2015. 9(27): 87-105. 
[33] L., Karlsson, Intermetallic phase precipitation in duplex stainless steels and weld metals: Metallurgy, influence on properties. 1999.

[34] Hsieh, Chih-Chun and Weite Wu, Overview of Intermetallic Sigma Phase Precipitation in Stainless Steels. ISRN Metallurgy, 2012. 2012: 16.

[35] Sieurin, Henrik and Rolf Sandström, Sigma phase precipitation in duplex stainless steel 2205. Materials Science and Engineering: A, 2007. 444(1-2): 271-276.

[36] Magnabosco, Rodrigo, Kinetics of sigma phase formation in a Duplex Stainless Steel. Materials Research, 2009. 12: 321-327.

[37] Pohl, Michael, Oliver Storz, and Thomas Glogowski, Effect of intermetallic precipitations on the properties of duplex stainless steel. Materials Characterization, 2007. 58(1): 65-71.

[38] Martins, Marcelo and Luiz Carlos Casteletti, Sigma phase morphologies in cast and aged super duplex stainless steel. Materials Characterization, 2009. 60(8): 792-795.

[39] Chen, T. H. and J. R. Yang, Effects of solution treatment and continuous cooling on $\sigma$ phase precipitation in a 2205 duplex stainless steel. Materials Science and Engineering: A, 2001. 311(1-2): 28-41.

[40] Martins, Marcelo and Luiz Carlos Casteletti, Microstructural characteristics and corrosion behavior of a super duplex stainless steel casting. Materials Characterization, 2009. 60(2): 150-155.

[41] Sieurin, Henrik and Rolf Sandström, Austenite reformation in the heat-affected zone of duplex stainless steel 2205. Materials Science and Engineering: A, 2006. 418(1-2): 250256.

[42] Escriba, D. M., et al., Chi-phase precipitation in a duplex stainless steel. Materials Characterization, 2009. 60(11): 1214-1219.

[43] Kobayashi, Darlene Yuko and Stephan Wolynec Evaluation of the Low Corrosion Resistant Phase Formed During the Sigma Phase Precipitation in Duplex Stainless Steels. Materials Research, 1999. 2(4): 239-247. 
[44] Ramirez, A. J., J. C. Lippold, and S. D. Brandi, The relationship between chromium nitride and secondary austenite precipitation in duplex stainless steels. Metallurgical and Materials Transactions A, 2003. 34(8): 1575-1597.

[45] Cui, Jie, et al., Degradation of Impact Toughness due to Formation of R Phase in High Nitrogen 25Cr-7Ni-Mo Duplex Stainless Steels. ISIJ International, 2001. 41(2): 192-195.

[46] Hwang, T. H., et al., Effect of R-phase on impact toughness of 25Cr-7Ni-4Mo super duplex stainless steel. Metals and Materials International, 2014. 20(1): 13-17.

[47] Lo, K. H., C. H. Shek, and J. K. L. Lai, Recent developments in stainless steels. Materials Science and Engineering: R: Reports, 2009. 65(4-6): 39-104.

[48] Sahu, J. K., et al., Effect of $475{ }^{\circ} \mathrm{C}$ embrittlement on the mechanical properties of duplex stainless steel. Materials Science and Engineering: A, 2009. 508(1-2): 1-14.

[49] Zucato, Igor, et al., Microstructural Characterization and the Effect of Phase Transformations on Toughness of the UNS S31803 Duplex Stainless Steel Aged Treated at $850^{\circ} \mathrm{C}$. Materials Research, 2002. 5: 385-389.

[50] Instruments, Gamry. Review of the Electrochemical Basis of Corrosion. 2016; Available from:http://www.gamry.com/application-notes/corrosion-coatings/basics-ofelectrochemical-corrosion-measurements/.

[51] Instruments, Gamry. Basics of Electrochemical Impedance Spectroscopy. 2016; Available from:http://www.gamry.com/application-notes/EIS/basics-of-electrochemicalimpedance-spectroscopy/. 


\section{Appendix: EIS analysis data}

The EIS analysis data of heat-treated samples are presented in this section. Heat-treated samples at $400^{\circ} \mathrm{C}, 650^{\circ} \mathrm{C}, 900^{\circ} \mathrm{C}$ in both air and $\mathrm{Ar}$ atmosphere are analyzed. The test parameters are listed in Table 3-6. The modified equivalent circuit was shown in Figure 5-16. The bode plots of EIS spectra are shown as follows:

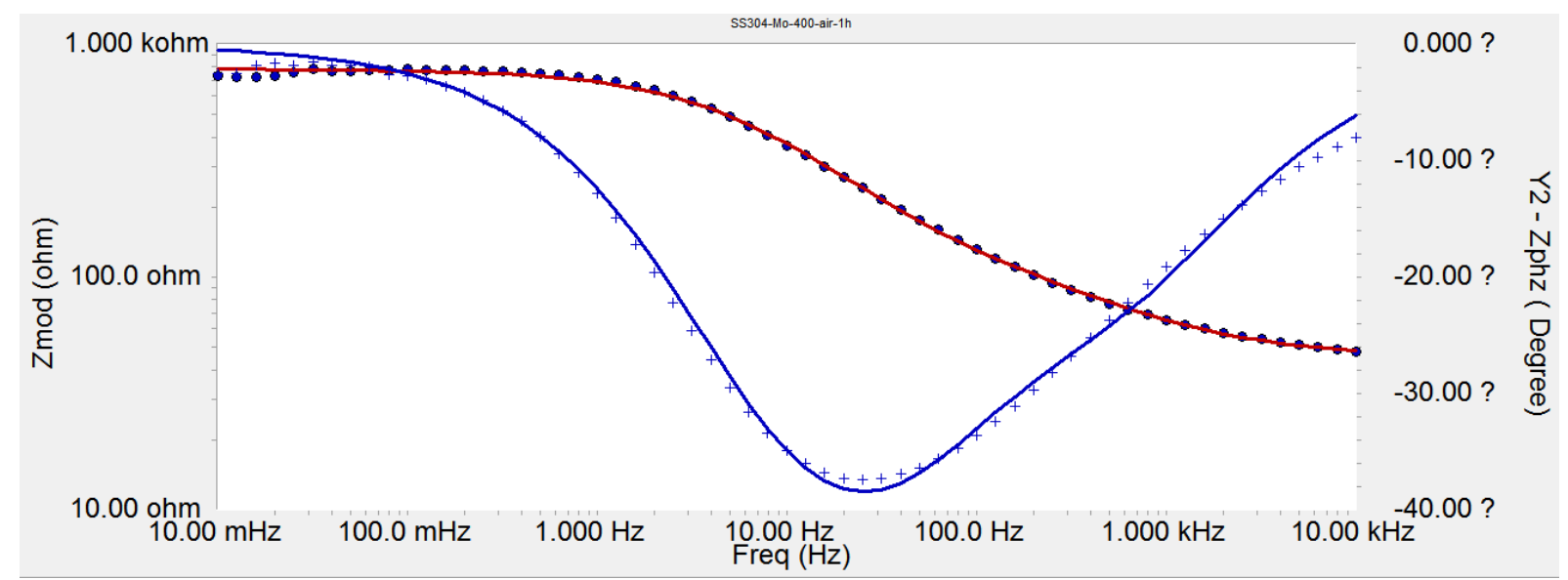

Figure A-1 Bode plot of EIS spectra of heat-treated sample at $400^{\circ} \mathrm{C}$ in air

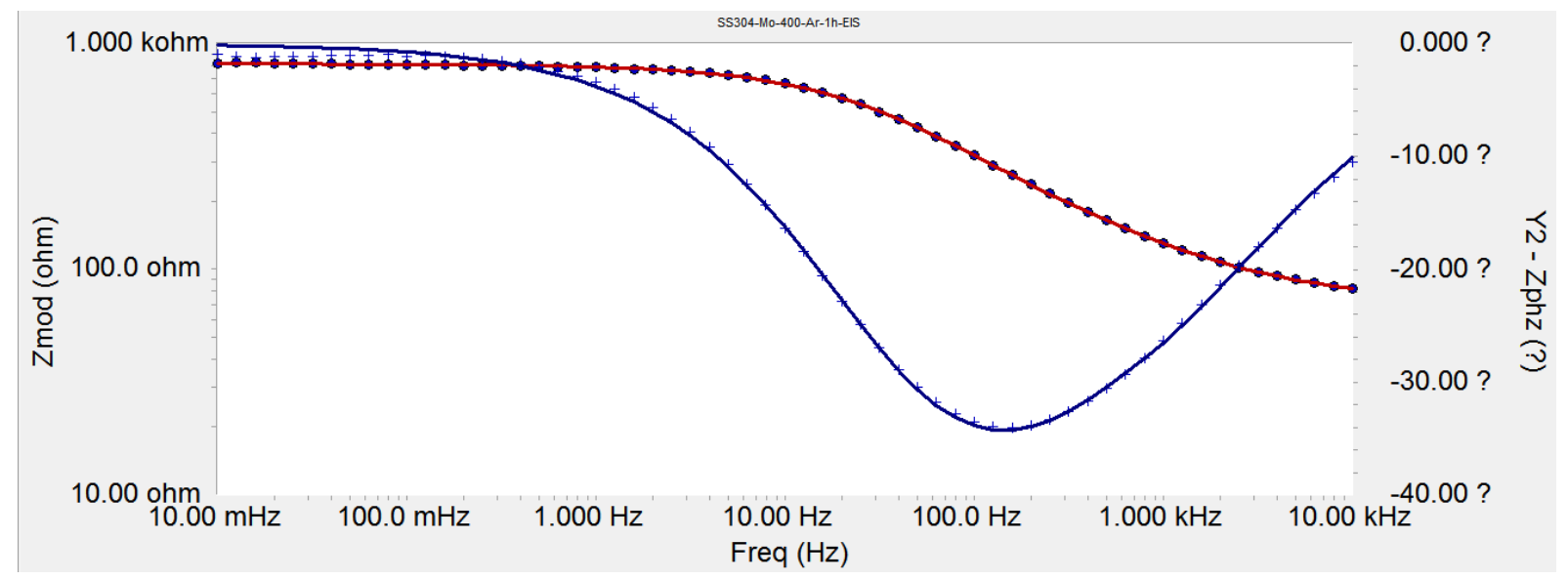

Figure A-2 Bode plot of EIS spectra of heat-treated sample at $400^{\circ} \mathrm{C}$ in $\mathrm{Ar}$ 


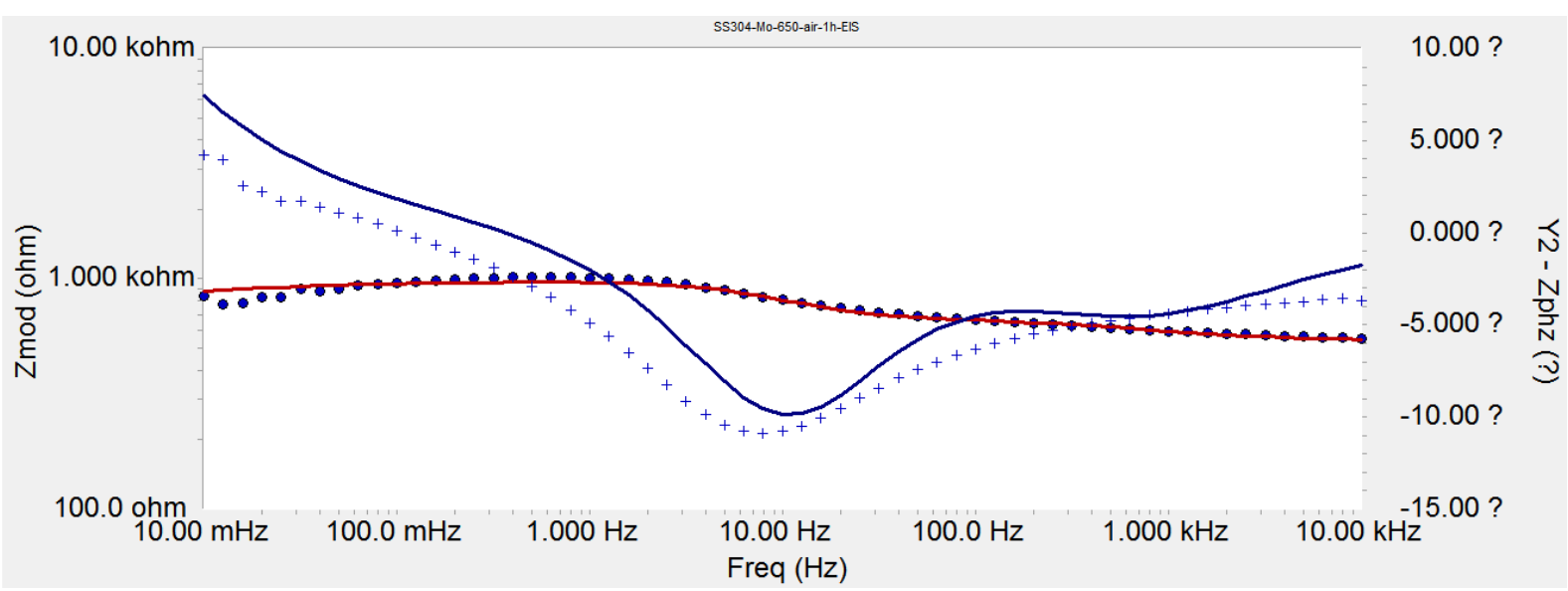

Figure A-3 Bode plot of EIS spectra of heat-treated sample at $650^{\circ} \mathrm{C}$ in air

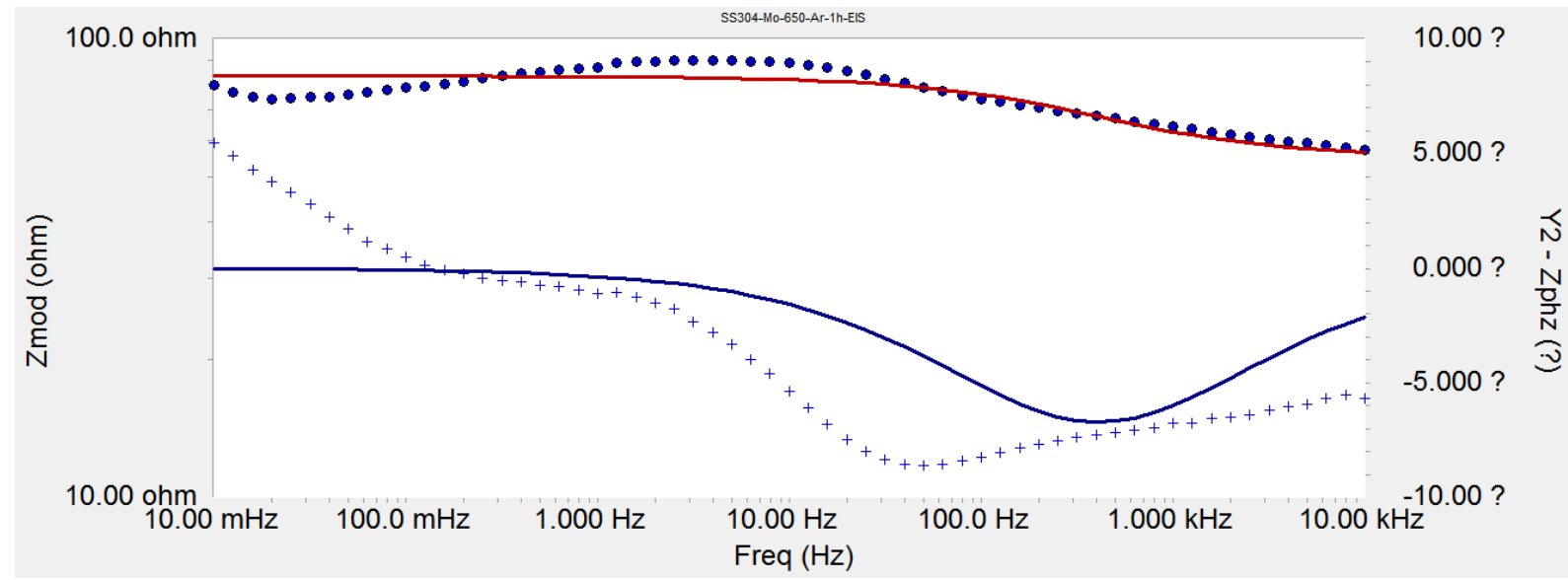

Figure A-4 Bode plot of EIS spectra of heat-treated sample at $650^{\circ} \mathrm{C}$ in $\mathrm{Ar}$

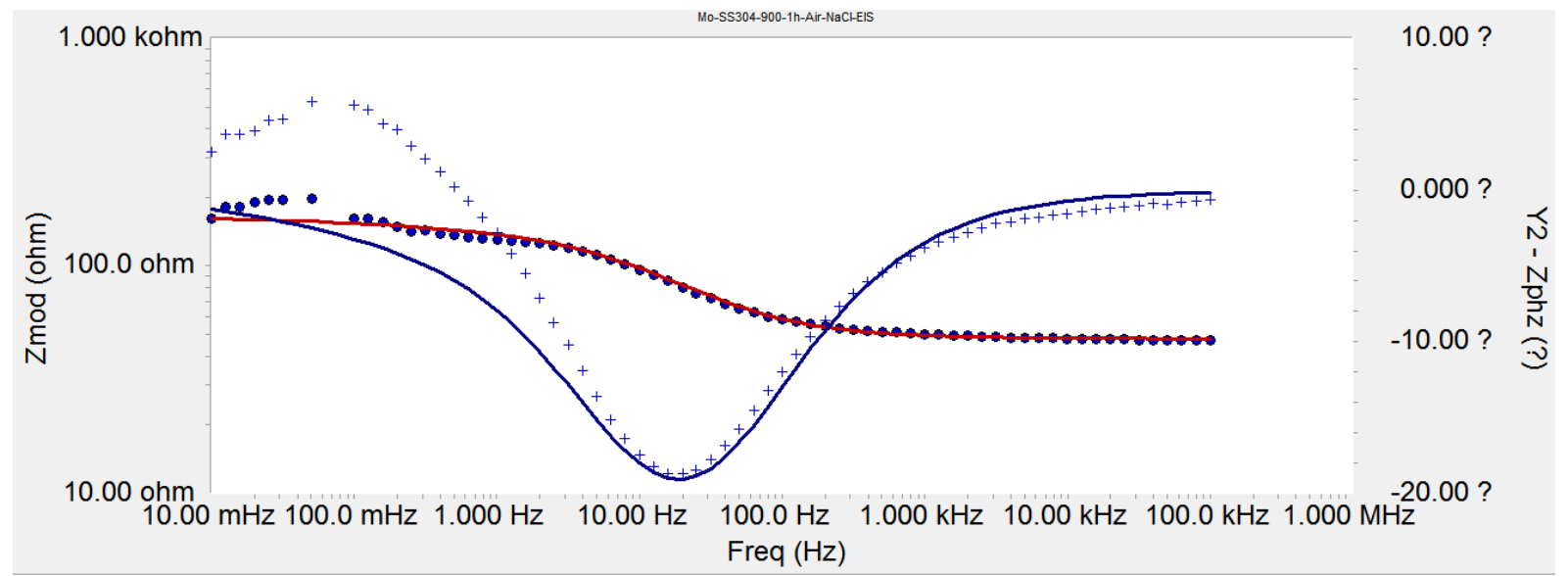

Figure A-5 Bode plot of EIS spectra of heat-treated sample at $900^{\circ} \mathrm{C}$ in air 


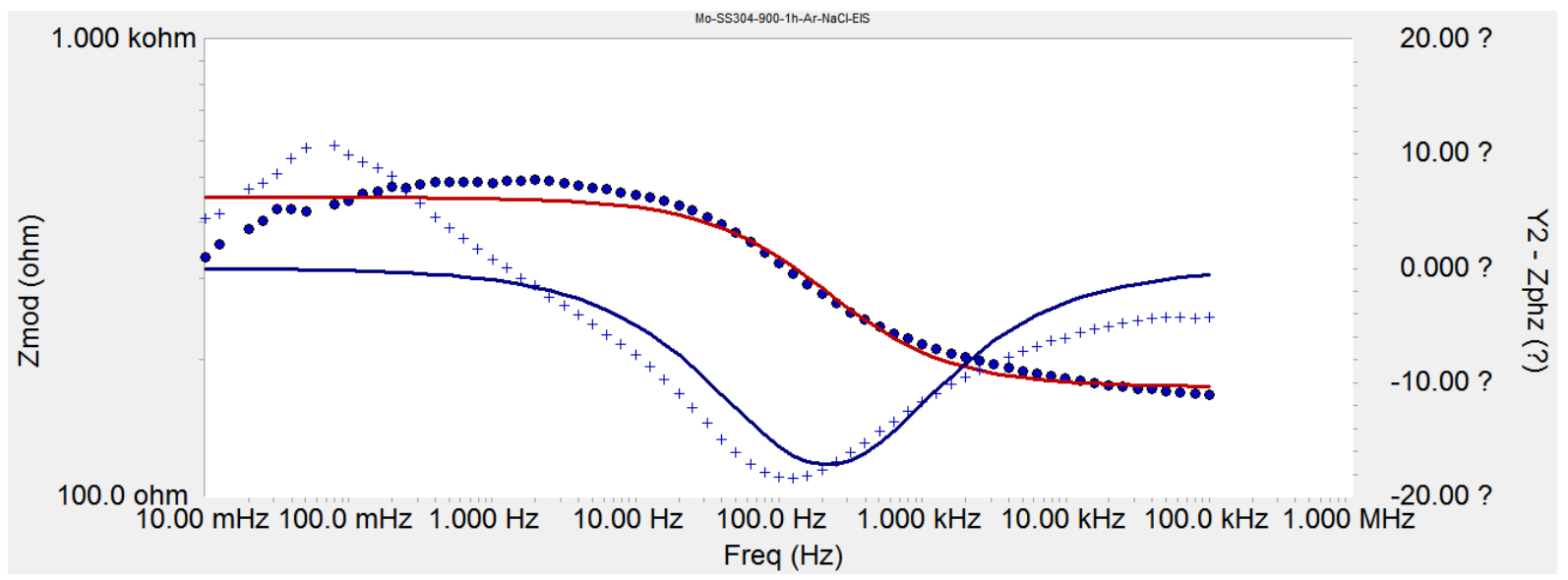

Figure A-6 Bode plot of EIS spectra of heat-treated sample at $900^{\circ} \mathrm{C}$ in $\mathrm{Ar}$ 